University of South Florida

DIGITAL COMMONS

@ UNIVERSITY OF SOUTH FLORIDA
Digital Commons @ University of

South Florida

6-1-2012

\title{
Best Practices in Bus Dispatch
}

CUTR

Follow this and additional works at: https://digitalcommons.usf.edu/cutr_nctr

\section{Recommended Citation}

"Best Practices in Bus Dispatch," National Center for Transit Research (NCTR) Report No. CUTR-NCTRRR-2011-03, Center for Urban Transportation Research, University of South Florida, 2012.

DOI: https://doi.org/10.5038/CUTR-NCTR-RR-2011-03

Available at: https://scholarcommons.usf.edu/cutr_nctr/120

This Technical Report is brought to you for free and open access by the National Center for Transit Research (NCTR) Archive (2000-2020) at Digital Commons @ University of South Florida. It has been accepted for inclusion in Research Reports by an authorized administrator of Digital Commons @ University of South Florida. For more information, please contact digitalcommons@usf.edu. 
Prepared by

National Center

for Transit Research

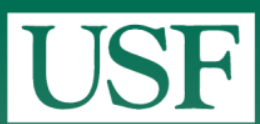

UNIVERSITY OF

SOUTH FLORIDA

\section{Best Practices in Bus Dispatch}

Final Report

June 2012

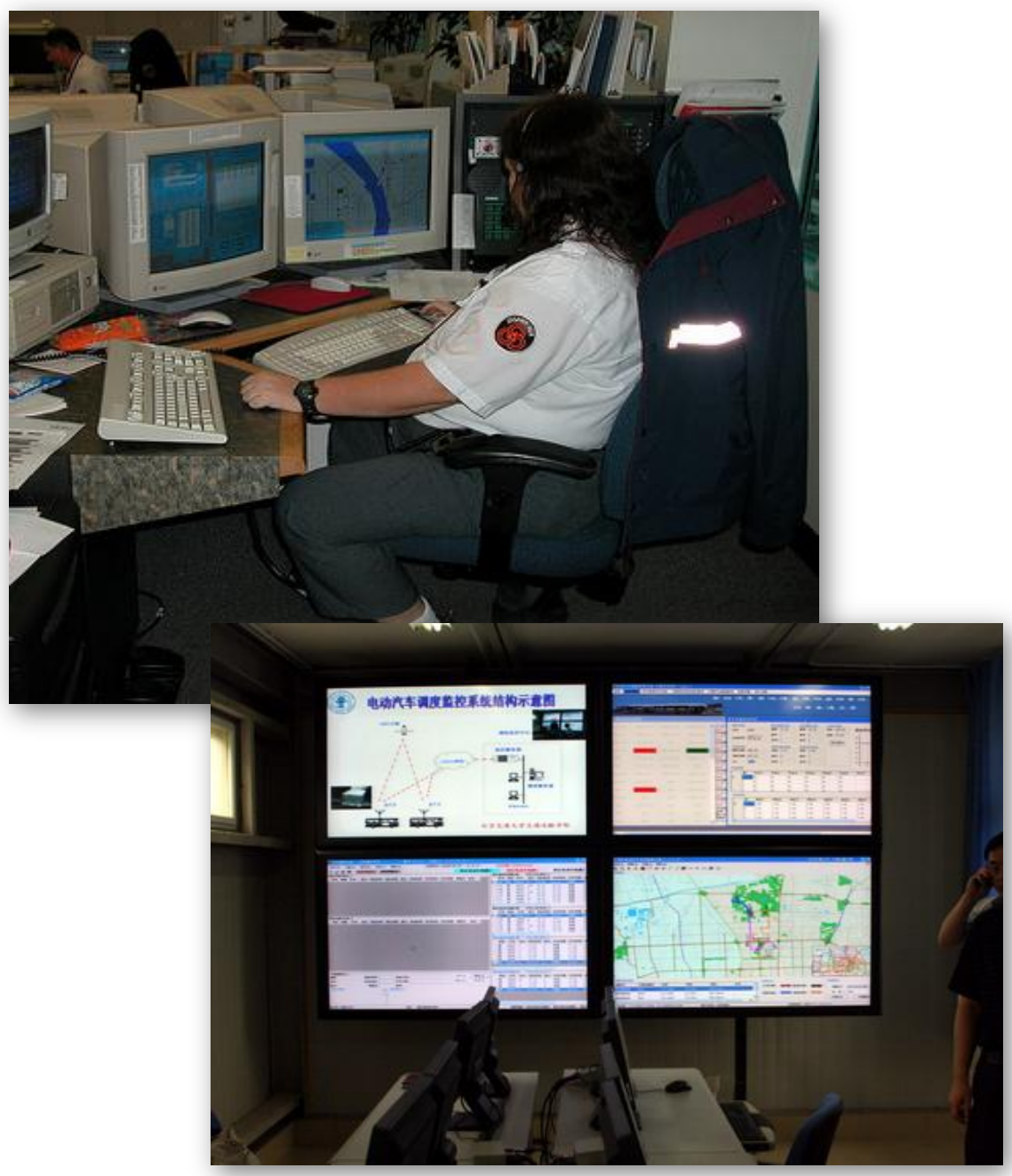

BDK85 977-25 


\section{Best Practices in Bus Dispatch}

\section{Final Report}

Prepared for

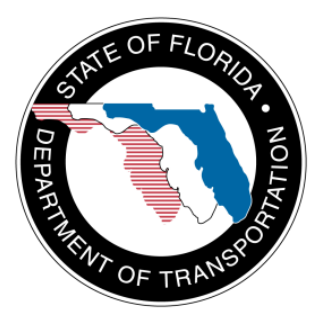

State of Florida Department of Transportation

Public Transit Office

605 Suwannee Street, MS 30

Tallahassee, Florida 32399-0450

FDOT Project Manager: Victor B. Wiley

\section{Prepared by}

Christopher DeAnnuntis and William Morris, NCTR Project Managers

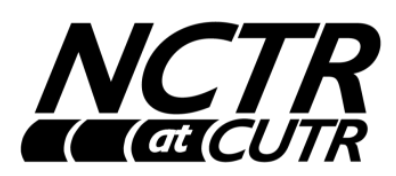

National Center for Transit Research

Center for Urban Transportation Research (CUTR)

University of South Florida

4202 East Fowler Avenue, CUT100

Tampa, Florida 33620-5375

June 2012 


\section{DISCLAIMER}

of this report reflect the views of the authors, who are responsible for the facts and the accuracy ation presented herein. This document is disseminated under the sponsorship of the Department of n University Transportation Centers Program and the Florida Department of Transportation, in the rrmation exchange. The U.S. Government and the Florida Department of Transportation assume the contents or use thereof. 


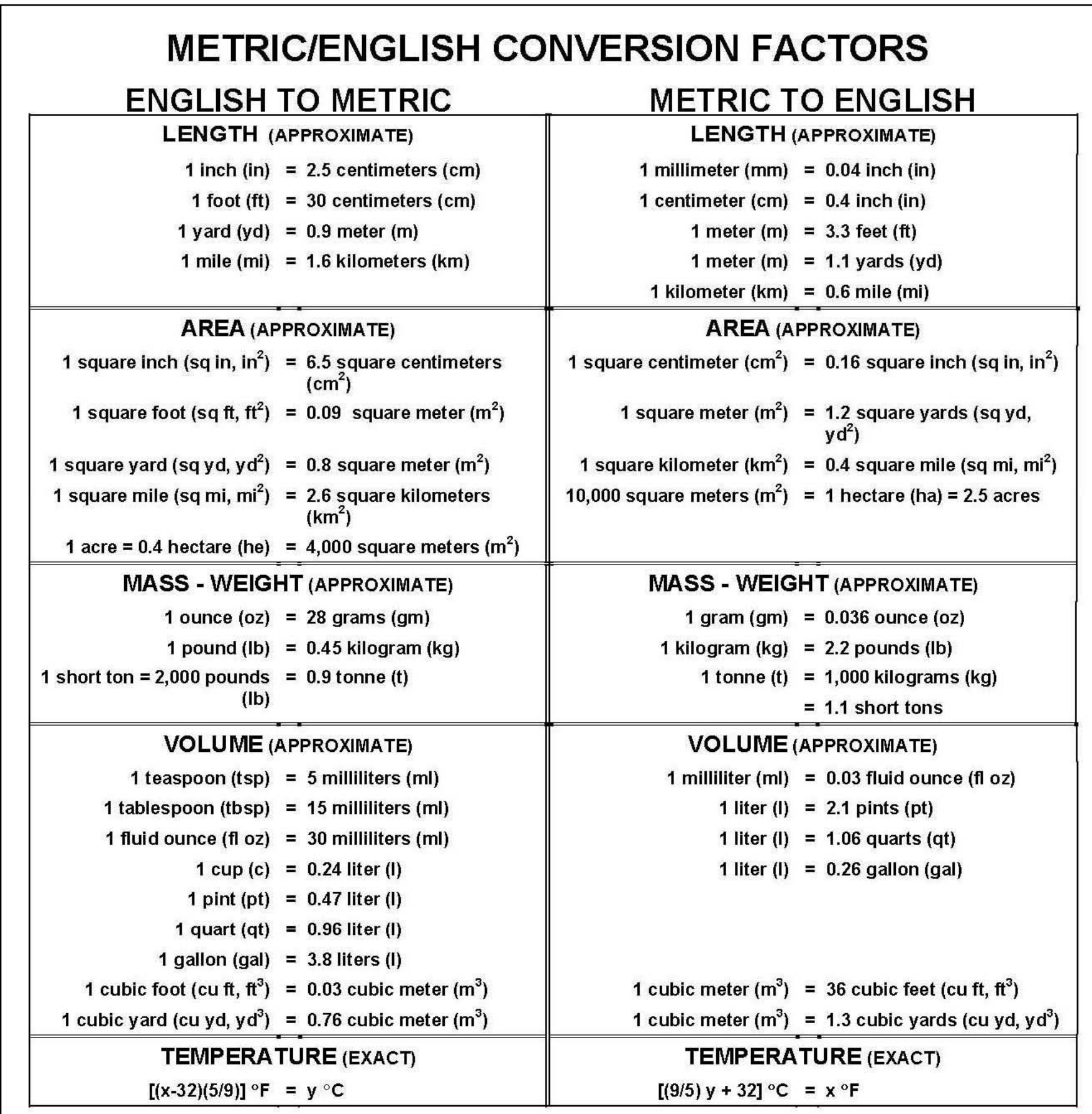

\section{QUICK INCH - CENTIMETER LENGTH CONVERSION}

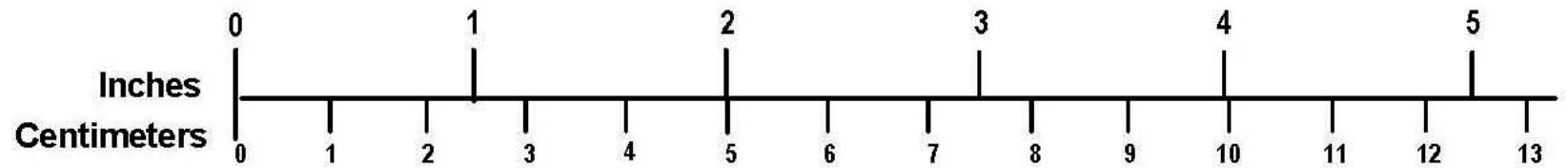

\section{QUICK FAHRENHEIT - CELSIUS TEMPERATURE CONVERSION}

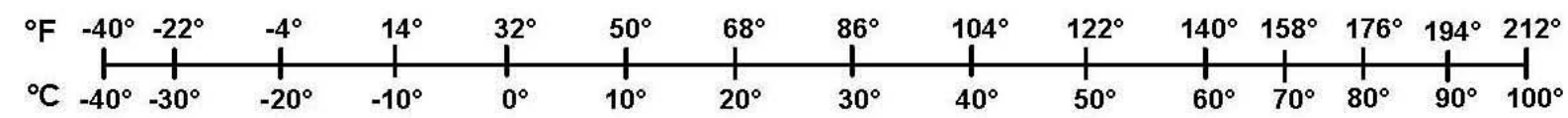

For more exact and or other conversion factors, see NIST Miscellaneous Publication 286. Units of Weights and Measures. 


\begin{tabular}{|c|c|c|c|c|}
\hline 1. Report No. & \multicolumn{2}{|c|}{ 2. Government Accession No. } & \multicolumn{2}{|c|}{ 3. Recipient's Catalog No. } \\
\hline \multirow{2}{*}{\multicolumn{2}{|c|}{$\begin{array}{l}\text { 4. Title and Subtitle } \\
\text { Best Practices in Bus Dispatch }\end{array}$}} & & \multicolumn{2}{|l|}{$\begin{array}{l}\text { 5. Report Date } \\
\text { June } 2012\end{array}$} \\
\hline & & & \multicolumn{2}{|c|}{ 6. Performing Organization Code } \\
\hline \multicolumn{3}{|c|}{$\begin{array}{l}\text { 7. Author(s) } \\
\text { Christopher DeAnnuntis and William P. Morris }\end{array}$} & \multicolumn{2}{|c|}{$\begin{array}{l}\text { 8. Performing Organization Report No. } \\
\text { NCTR 77930/FDOT BDK85 977-25 }\end{array}$} \\
\hline \multirow{2}{*}{\multicolumn{3}{|c|}{$\begin{array}{l}\text { 9. Performing Organization Name and Address } \\
\text { National Center for Transit Research, } \\
\text { Center for Urban Transportation Research } \\
\text { University of South Florida } \\
4202 \text { East Fowler Avenue, CUT100, Tampa, FL 33620-5375 }\end{array}$}} & \multicolumn{2}{|c|}{ 10. Work Unit No. (TRAIS) } \\
\hline & & & \multicolumn{2}{|c|}{$\begin{array}{l}\text { 11. Contract or Grant No. } \\
\text { FDOT BDK85 977-25/U.S.DOT } \\
\text { DTRS98-G-0032 }\end{array}$} \\
\hline \multirow{3}{*}{\multicolumn{3}{|c|}{$\begin{array}{l}\text { 12. Sponsoring Agency Name and Address } \\
\text { Research and Innovative Technology Administration } \\
\text { U.S. Department of Transportation } \\
\text { Mail Code RDT-30 } \\
1200 \text { New Jersey Ave, SE, Room E33, Washington, D.C. 20590-0001 } \\
\text { Florida Department of Transportation, Research Center } \\
605 \text { Suwannee Street, MS 30, Tallahassee, FL 32399-0450 }\end{array}$}} & \multirow{2}{*}{\multicolumn{2}{|c|}{$\begin{array}{l}\text { 13. Type of Report and Period Covered } \\
\text { Final Report } 12 / 15 / 2010-7 / 16 / 2012\end{array}$}} \\
\hline & & & & \\
\hline & & & \multicolumn{2}{|c|}{ 14. Sponsoring Agency Code } \\
\hline \multicolumn{5}{|l|}{ 15. Supplementary Notes } \\
\hline \multicolumn{5}{|c|}{$\begin{array}{l}\text { Supported by a grant from the Florida Department of Transportation and the U.S. Department of } \\
\text { Transportation }\end{array}$} \\
\hline \multicolumn{5}{|c|}{$\begin{array}{l}\text { 16. Abstract - } \\
\text { In 2007, the National Center for Transit Research (NCTR) sponsored a study to examine best practices in } \\
\text { extraboard operator management. In most transit agencies, extraboard manpower is managed by the } \\
\text { dispatch function, but extraboard management is only one of the many aspects of operating a transit system } \\
\text { managed by Dispatch. The study for extraboard management revealed a need to have a greater } \\
\text { understanding of operational functions within transit systems and to share optimal practices among transit } \\
\text { operations personnel. While the similarities of dispatch functions across all transit agencies are well known, } \\
\text { the differences in operating policies, procedures, and functions of dispatch have not been well researched or } \\
\text { documented. Very little is known about the differences between transit agencies in terms of the manner in } \\
\text { which dispatch is structured, the operational practices and procedures that dispatchers follow, and a } \\
\text { catalogue of all of the functions of dispatch. }\end{array}$} \\
\hline \multirow{2}{*}{\multicolumn{2}{|c|}{$\begin{array}{l}\text { 17. Key Word } \\
\text { Bus dispatch, bus operations, incident } \\
\text { management, labor management, } \\
\text { equipment management }\end{array}$}} & \multirow{2}{*}{\multicolumn{3}{|c|}{$\begin{array}{l}\text { 18. Distribution Statement } \\
\text { Available to the public through the National Technical } \\
\text { Information service (NTIS), } 5285 \text { Port Royal Road, Springfield, } \\
\text { VA 22161, (703) 487-46500, http://www.ntis.gov, and through } \\
\text { the NCTR website at http://www.nctr.usf.edu/ }\end{array}$}} \\
\hline & & & & \\
\hline $\begin{array}{l}\text { 19. Security Classif. (of this report) } \\
\text { Unclassified }\end{array}$ & & $\begin{array}{l}\text { ity Classif. (of this page) } \\
\text { sified }\end{array}$ & $\begin{array}{l}\text { 21. No. of Pages } \\
121\end{array}$ & 22. Price \\
\hline
\end{tabular}




\section{EXECUTIVE SUMMARY}

\section{BACKGROUND}

In 2007, the National Center for Transit Research (NCTR) sponsored a study to examine best practices in extraboard operator management. In most transit agencies, extraboard manpower is managed by the dispatch function, but extraboard management is only one of the many aspects of operating a transit system managed by Dispatch. The study for extraboard management revealed a need to have a greater understanding of operational functions within transit systems and to share optimal practices among transit operations personnel. While the similarities of dispatch functions across all transit agencies are well known, the differences in operating policies, procedures, and functions of dispatch have not been well researched or documented. Very little is known about the differences between transit agencies in terms of the manner in which dispatch is structured, the operational practices and procedures that dispatchers follow, and a catalogue of all of the functions of dispatch.

\section{OBJECTIVES}

The purpose of this study is to investigate best practices, standard operating procedures, and uses of technology in dispatch for small, medium, and large transit agencies. Specifically, a survey of all Florida transit agencies was conducted to achieve, at a minimum, the following:

- Catalogue the functions of dispatch

- Investigate interface of dispatch with other organizational functions

- Summarize standard operating policies, procedures, and responsibilities of dispatch

- Identify best practices, including processes and technology

- Assess impacts of new technologies on dispatch efficiency and management

- Identify essential job skills and examine the future of the profession.

\section{FINDINGS AND CONCLUSIONS}

The results of this research were synthesized from the literature review, the survey of transit agencies, and two case studies conducted at VOTRAN, Volusia County's public transit system in Daytona Beach, FL, and Pinellas Suncoast Transit Authority (PSTA) in Clearwater/St. Petersburg, FL. 


\section{Catalogue the Functions of Dispatch}

Clearly, there are three primary functions of dispatch as defined for window and radio functions are as follows:

- Incident management

- Labor management

- Equipment management

\section{Incident Management}

When operators in the field experience any kind of difficulty impacting the timely provision of service, radio dispatchers are the primary point of contact.

\section{Managing Labor}

Dispatchers play a role in managing the entire operator work force in conjunction with field supervisors. Managing labor includes checking operator uniform appearance, operator absences, assigning coaches to the operators, schedule adherence, and managing overall operator availability to perform scheduled service.

\section{Managing Equipment}

Equipment management has two components: internal and external. Internal equipment management entails the process used by Operations and Maintenance to ensure the availability of coaches for the service day. The external component of managing equipment responds to incidents, such as malfunctioning of mirrors, destination signs, fareboxes, and the malfunctioning of the coach itself.

In addition, the synthesis and conclusions include the following topical areas:

- Interface of dispatch with other organizational functions

- Best practices, including processes and technology

- Assess impacts of new technologies on dispatch efficiency and management

- Pace and Multitasking

- Extraboard Management

- Customer Service

- Generalized Job Duties versus Specialization

- Training

- Implications for Operations Managers

\section{BENEFITS}

The research team was unable to identify any effort similar to this one in the course of this study. The hope is that this study will offer new insights into the inner workings of dispatch. Previous research emphasizes how improved service efficiencies were achieved or how service was better for the customer through 
dispatch improvements. As this may be ground-breaking research that introduces new knowledge, there also emerged a need for future research that could explore a similar effort with other modes, such as rail and paratransit. In the area of training, future research could focus on development of more curriculum-based training and even standardized training for new trainees at the agency level. Also, there is a need to invest in professional development of dispatchers, with the possibility of creating certifications similar to maintenance technicians.

This research project was conducted by Christopher P. DeAnnuntis and William P. Morris, of the Center for Urban Transportation Research. For more information, contact Christopher P. DeAnnuntis, Principal Investigator, at (813) 974-8942, deannuntis@cutr.usf.edu. 


\section{Table of Contents}

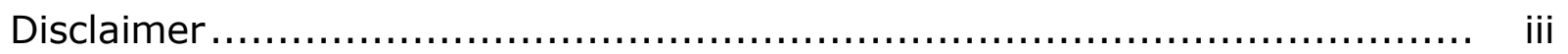

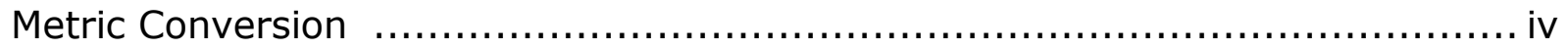

Technical Report Documentation Page .......................................... v

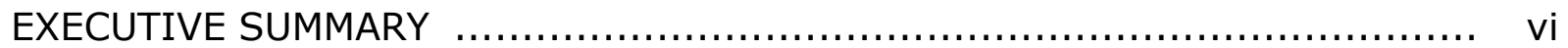

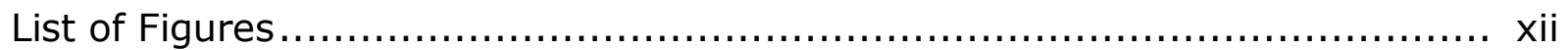

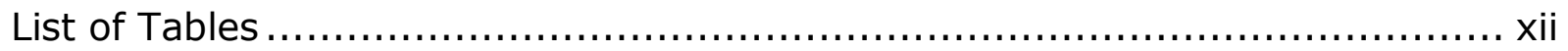

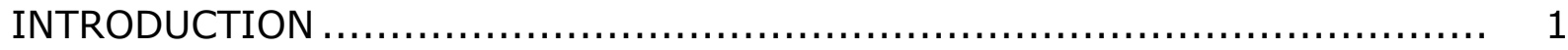

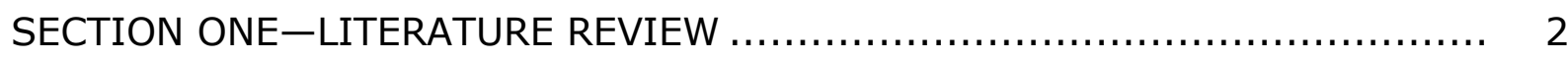

Computer-Aided Dispatch ..................................................... 2

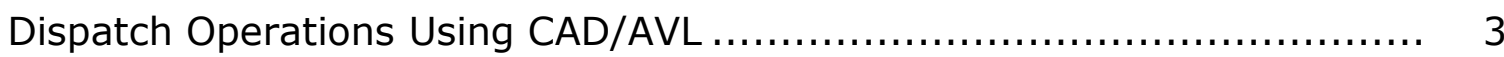

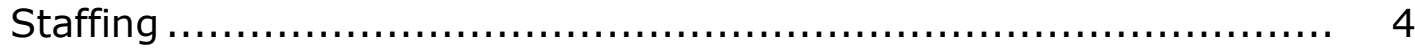

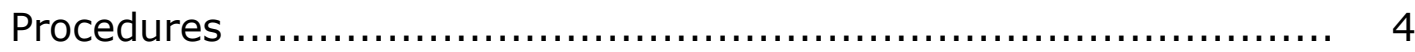

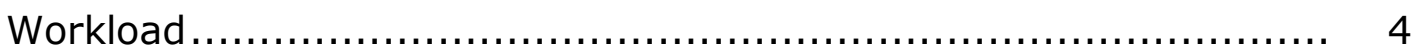

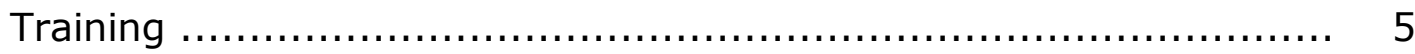

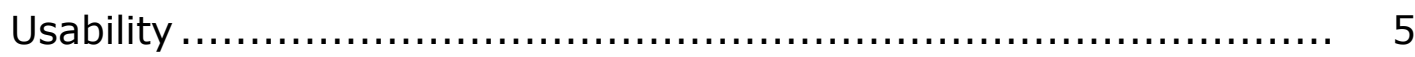

Miami-Dade TOS Manual ...................................................... 5

Evaluation and Management of Manpower ............................. 7

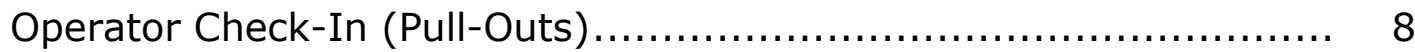

Extra List................................................................... 8

Management of the Extra List.......................................... 8

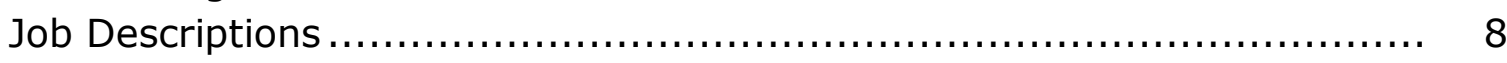

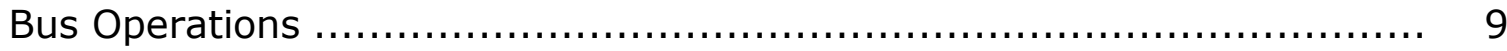

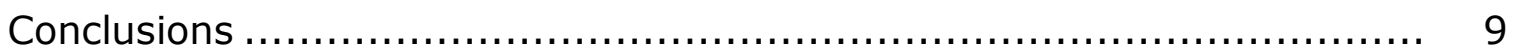

SECTION TWO-DISPATCH SURVEY OF TRANSIT AGENCIES ................... 11

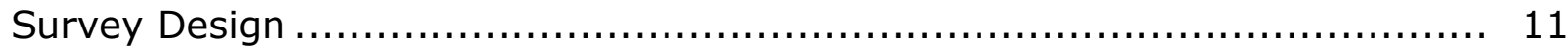

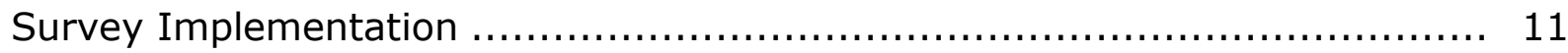

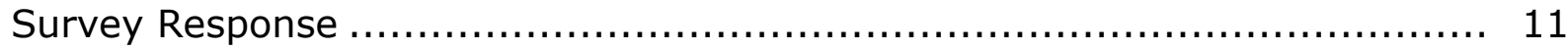

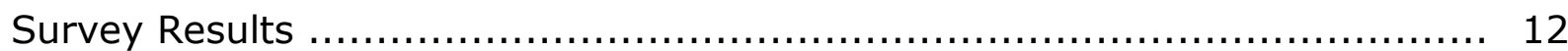

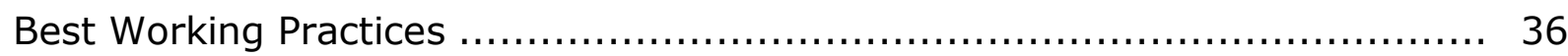

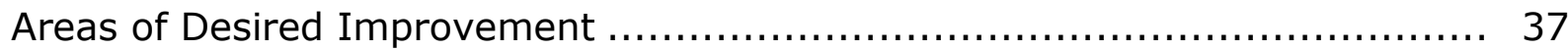

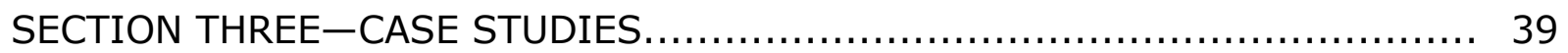

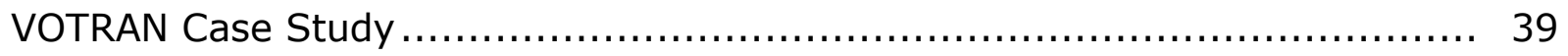

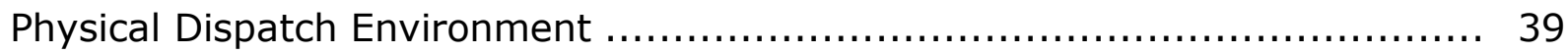

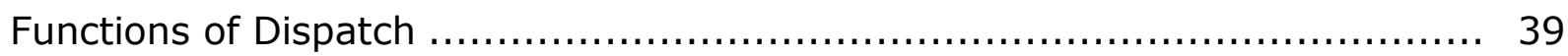

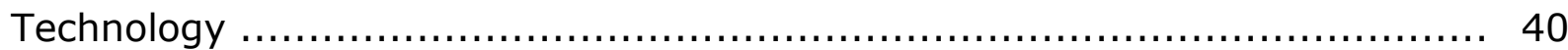

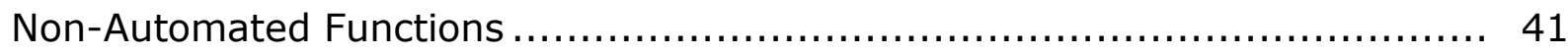




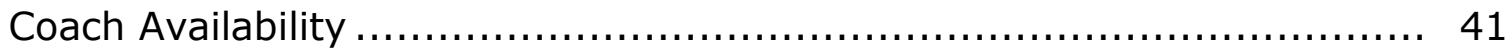

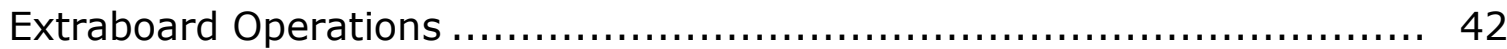

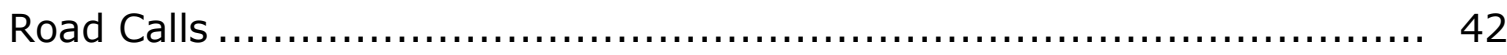

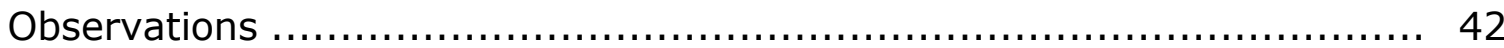

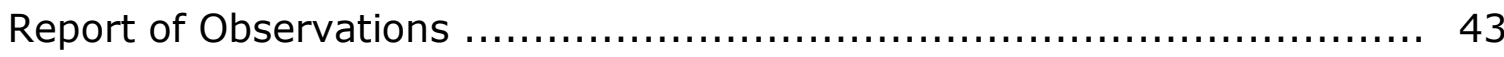

Pinellas Suncoast Transit Authority (PSTA) Case Study ..................... 45

Physical Dispatch Environment................................................ 45

Functions of Dispatch.......................................................... 45

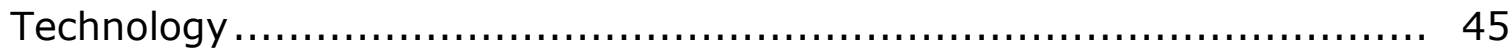

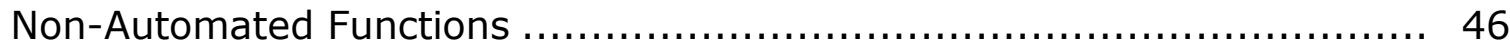

Dispatch: Operator Check-in and Coach Assignment ....................... 46

Dispatch: Absentee and Extraboard Management ......................... 47

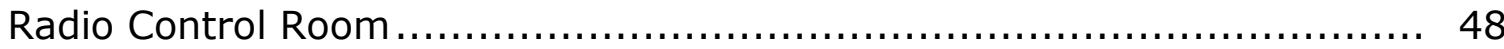

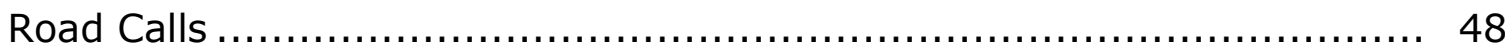

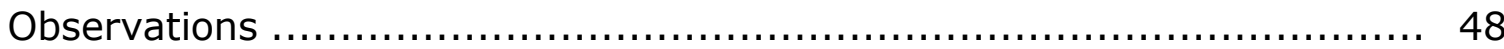

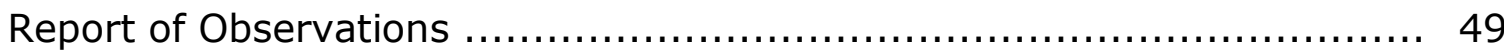

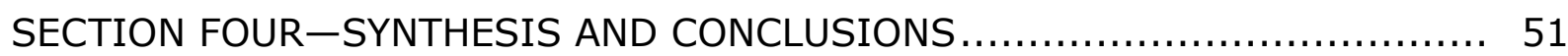

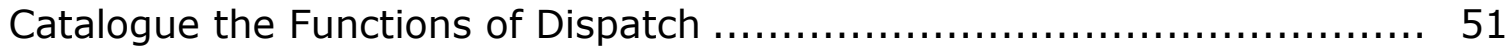

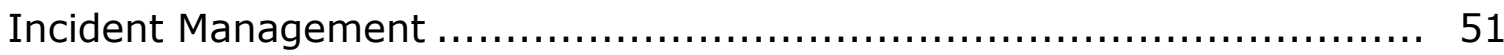

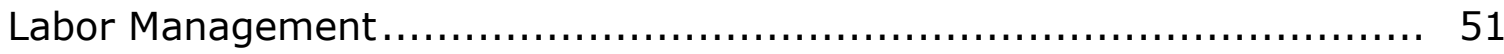

Equipment Management .................................................. 52

Interface of Dispatch with Other Organizational Functions ................. 52

Standard Operating Policies and Procedures ................................. 52

Best Practices Including Processes and Technology ......................... 52

Assess Impacts of New Technologies on Dispatch Efficiency and

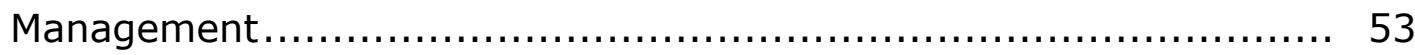

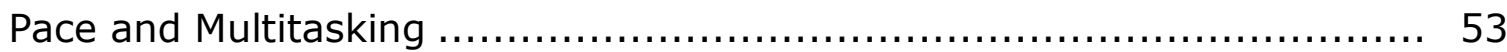

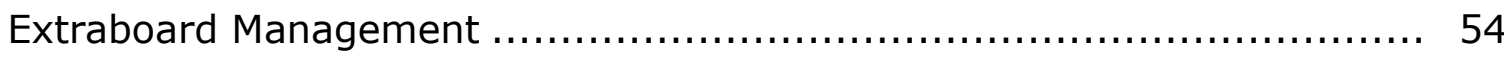

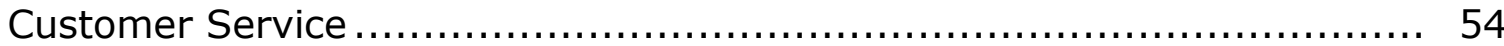

Generalized Job Duties versus Specialization ............................... 54

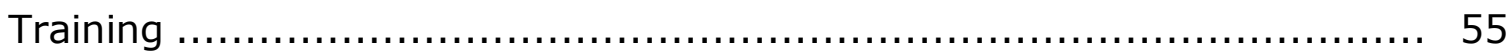

Implications for Operations Managers …................................. 55

Implications for Future Research ........................................ 56

SECTION FIVE-DISPATCH STANDARD OPERATING PROCEDURE $\ldots \ldots \ldots \ldots \ldots . \ldots 57$

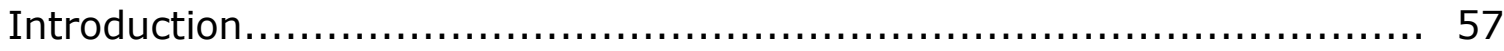

Bus Dispatch - Window Standard Operating Procedure .................... 57

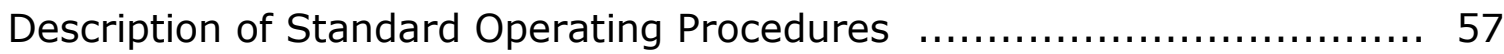

General Daily Timeline of Responsibilities ................................. 58

Window Duties All Shifts....................................................... 59

Evaluation and Management of Manpower ................................. 62 


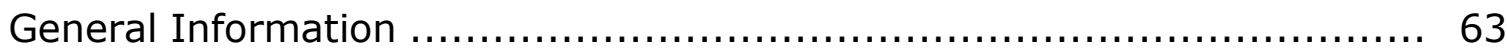

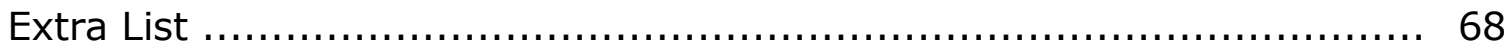

Assignments of Bus Operators .............................................. 71

Scheduling of Football and Special Events List............................... 75

Preparing for Schedule Line-Ups............................................ 76

Office/Workstation Equipment for the Window Dispatch Function............ 78

Lost and Found Procedures .................................................... 79

Forms for the Dispatch Function ............................................ 79

Bus Dispatch - Radio Standard Operating Procedure ...................... 82

Function of the Bus Traffic Controller ...................................... 82

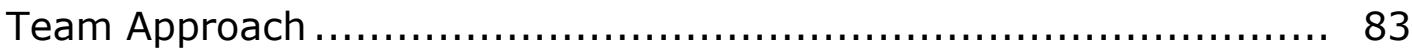

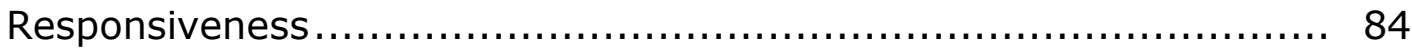

Allocation of Responsibilities in the Control Center ..................... 85

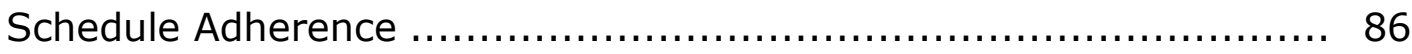

Using the CAD/AVL System to Monitor Schedule Adherence ............ 86

Common Sense Guidelines for Maintaining Service ..................... 89

Maximize Service - Minimize Downtime............................... 89

Logging on and off the CAD/AVL Console ............................... 92

Logging into the CAD/AVL Console ..................................... 92

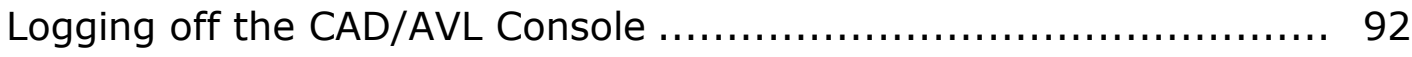

Establishing Communications with Bus Operators ...................... 93

Making a Voice Call to an Individual Vehicle ............................ 94

Making a Voice Call to all Vehicles in a Route or Fleet via the

Driver Speaker ................................................ 94

Making a Voice Call to a Vehicle via the Public Address System ....... 95

Making a Voice Call to All Vehicles in a Route or Fleet via the

Public Address System ............................................ 95

Sending a Text Message to a Single Vehicle .............................. 196

Sending a Text Message to all Vehicles in a Fleet or on a Route....... 97

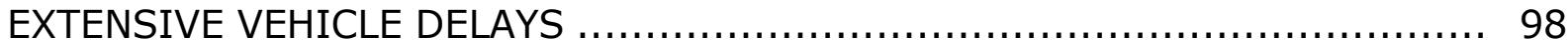

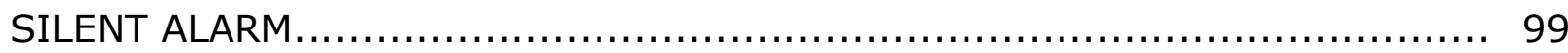

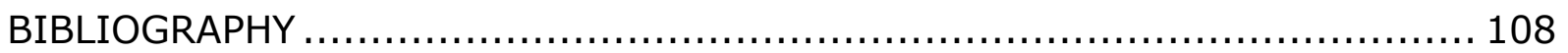




\section{List of Figures}

Figure 3-1: Avail Dispatch System ........................................... 40

Figure 3-2: Radio Control Room - South County Station ....................... 46

Figure 3-3: PSTA Bus Stacking - PSTA Operations Center ..................... 47

\section{List of Tables}

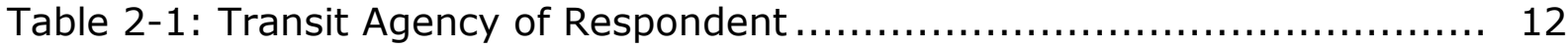

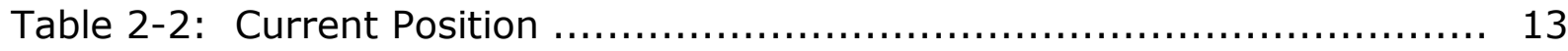

Table 2-3: Current Position Held by Transit Agency ............................. 13

Table 2-4: Position Held Before Becoming a Dispatcher.......................... 14

Table 2-5: Position Held Prior to Current Position by Transit Agency ............ 14

Table 2-6: Type of Service Dispatched ........................................ 15

Table 2-7: Type of Service Dispatched by Transit Agency ....................... 16

Table 2-8: Physical Setup of Dispatch Office .................................... 16

Table 2-9: Physical Setup of Dispatch Office by Transit Agency................. 17

Table 2-10: Relationship between Window, Radio and Road Supervision

Functions ........................................................... 17

Table 2-11: Relationship between Window, Radio and Road Supervision by

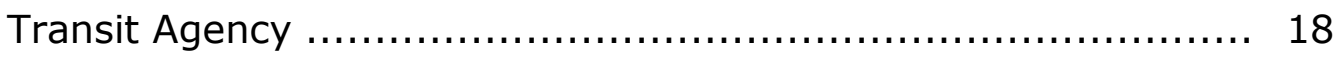

Table 2-12: Top 5 Functions/Duties of Dispatchers.............................. 19

Table 2-13: Remaining Functions and Duties - Average Ratings................ 20

Table 2-14: Average Ratings for Functions by Transit Agency .................. 21

Table 2-15: Top Six Most Important Functions Regardless of Time Spent ..... 22

Table 2-16: Average Ratings - Remaining Functions Regardless of

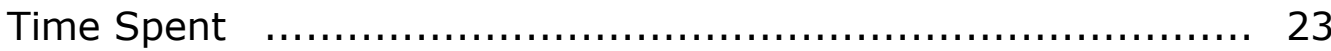

Table 2-17: Importance of Functions Regardless of Time Spent by Transit Agency ............................................................... 24

Table 2-18: How Customer Complaints Are Handled ............................ 25

Table 2-19: How Customer Complaints Are Handled by Transit Agency........ 25

Table 2-20: How Incident Management Is Handled.............................. 26

Table 2-21: Incident Management by Transit Agency.......................... 27

Table 2-22: Extraboard and Overtime Management............................ 27

Table 2-23: Extraboard and Overtime Management by Transit Agency......... 28

Table 2-24: Extraboard Size ...................................................... 28

Table 2-25: Extraboard Size by Transit Agency ................................. 29

Table 2-26: Maintenance Communication - Vehicle Availability ................. 30

Table 2-27: Maintenance Communication - Vehicle Availability by

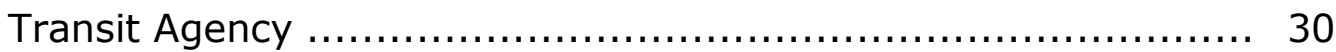


Table 2-28: Frequency of Maintenance Communication $\ldots \ldots \ldots \ldots \ldots \ldots \ldots \ldots \ldots, 31$

Table 2-29: Frequency of Maintenance Communication by Transit Agency..... 31

Table 2-30: Helpfulness of Lot Visibility .................................... 32

Table 2-31: ITS Technologies Available to Dispatchers....................... 32

Table 2-32: Use of Mobile Dispatching (Supervisor vehicles equipped with

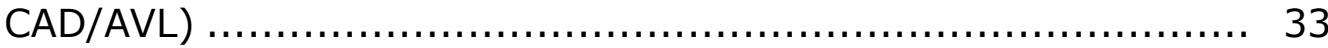

Table 2-33: Use of Mobile Dispatching (Supervisor vehicles equipped with CAD/AVL) by Transit Agency .................................... 33

Table 2-34: How Dispatchers Are Trained................................. 34

Table 2-35: How Dispatchers Are Trained by Transit Agency ................. 35

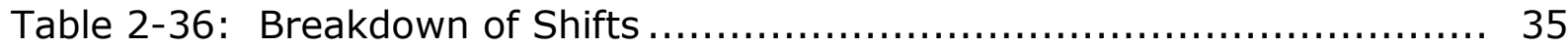

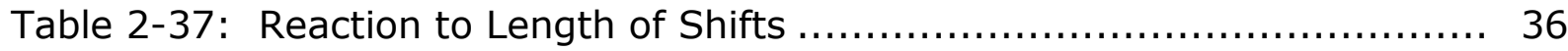

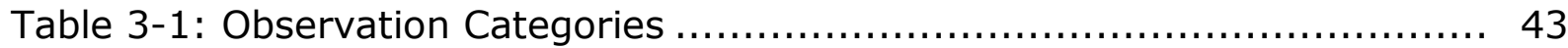

Table 3-2: Observations Totals and Frequencies $\ldots \ldots \ldots \ldots \ldots \ldots \ldots \ldots \ldots \ldots \ldots \ldots, 44$

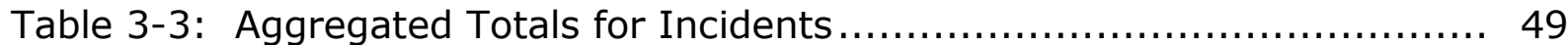

Table 3-4: Observation Categories ....................................... 49

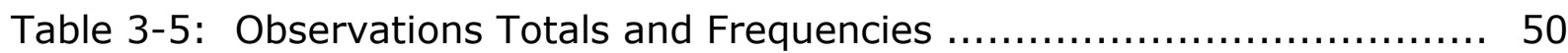




\section{INTRODUCTION}

In 2006 and 2007, the National Center for Transit Research (NCTR) sponsored a study to examine best practices in extraboard operator management (DeAnnuntis and Morris, 2007). In most transit agencies, extraboard manpower is managed by the dispatch function, but extraboard management is only one of the many aspects of operating a transit system managed by Dispatch. The study for extraboard management revealed a need for a greater understanding of operational functions within transit systems and to share optimal practices among transit operations personnel within Florida. This effort is intended to study only fixed-route bus dispatch operations and excludes other forms, such as rail, paratransit, and traffic management centers (TMCs).

The function of dispatch within a transit environment is to serve as the control center of operations to ensure the availability of consistent transit service on the street each day. Dispatchers have the responsibility to ensure that there is sufficient labor and equipment to meet the day's scheduled service, act as the primary source of direction for bus operators via radio communications, coordinate the response and resolution for all incidents that occur in the field, and ensure the safety, security, and performance of the bus system.

Dispatch can be a fast paced, fast moving, and multifaceted function wherein each day presents new challenges from the previous day. The manner in which individual dispatch offices are structured to function is determined by historical influences, longevity of personnel, the management philosophy of operations managers, and in some cases, collective bargaining agreements.

However, while the similarities of dispatch functions across all transit agencies are well known, the differences in operating policies, procedures, and functions of dispatch have not been well researched or documented. In a scan of research on this topic, there is a great deal of research for dispatch in EMS, traffic management, trucking and even milk delivery. Few reports addressed bus transit dispatch, but only tangentially by addressing the impacts of new technologies, such as new communications systems and Computer-Aided Dispatch (CAD) /Automatic Vehicle Location (AVL) packages on dispatch functions. Very little is known about the differences between transit agencies in terms of the manner in which Dispatch is structured, the operational practices and procedures that dispatchers follow, and the complete range of dispatch functions. 


\section{SECTION ONE \\ LITERATURE REVIEW}

The purpose of this study is to investigate best practices, standard operating procedures and uses of technology in dispatch for small, medium, and large transit agencies. Specifically, a survey of all Florida transit agencies was conducted to achieve, at a minimum, the following:

- Catalogue the functions of dispatch

- Investigate the interface of dispatch with other organizational functions

- Summarize standard operating policies, procedures and responsibilities of dispatch

- Identify best practices, including processes and technology

- Assess impacts of new technologies on dispatch efficiency and management

- Identify essential job skills and examine the future of the profession.

A survey of relevant literature was conducted to determine previous work on this topic. Also, transit agencies were contacted requesting job descriptions, training materials, and standard operating procedures. The research team found that a vast majority of literature explores the means by which technology can be used to enhance bus operations and increase customer satisfaction, but no fundamental basic research has been conducted on the functions of dispatch in its entirety. The literature review is divided into three sections:

- Computer-Aided dispatch

- Dispatch operations

- Bus operations

Paratransit is not a part of this study because the nature of real-time dispatching is very different from fixed-route dispatching.

\section{Computer-Aided Dispatch}

In 2008, the Transit Cooperative Research Program (TCRP) commissioned TCRP Synthesis 73, AVL Systems for Bus Transit: Update (Parker, 2008). The study documented, "the state of the practice of computer-aided dispatch/automatic vehicle location (CAD/AVL) systems in fixed-route and demand responsive services...." The study classified the core AVL system as the central software used by dispatchers for operations management. Particularly, the core uses are as follows:

- Dispatchers can receive real-time updates on fleet vehicle locations.

- Dispatchers can communicate with operators using text via an on-board computer called a Mobile Data Terminal. 
- Dispatchers can monitor schedule adherence based on real time bus location.

- Dispatchers can manage voice communications, which means that calls can be queued and prioritized for response as well as be stored by the AVL system for later updates.

The study also provides the expected benefits of a bus AVL system for fixed-route systems. Those benefits unique to dispatch include:

- Improved situational awareness and additional voice communications management capabilities for dispatchers.

- The transmission of schedule adherence feedback to dispatch, operators and supervisors to help maximize on-time performance and reliability.

- Helps dispatchers and supervisors to be proactive in addressing operational issues, including more timely and effective reaction to service disruptions.

- Improvements to dispatch efficiency with text messaging which can provide clearer messages in distributing information to operators.

- Improvements to security with covert alarm monitoring that operators can use to quickly inform dispatch of an onboard emergency with dispatch knowing the precise location of the vehicle.

Dessouky et al. (1999) examined bus dispatching for timed transfers using bus tracking technology. The study noted that dispatchers with no Intelligent Transportation Systems (ITS) must monitor bus arrivals at transfer centers via traditional voice technology. However, the study attempted to determine how Automatic Vehicle Location systems (AVL), Mobile Data Terminals, and transit operations software could enable dispatchers to better monitor and effectuate timed transfers. There were two levels of ITS considered: (1) systems with centralized tracking and (2) system with information on connecting passengers, as well as centralized tracking and tested several strategies related to holding buses. The study concluded that use of ITS strategies has the potential to reduce waiting time for passengers on connecting buses without greatly increasing the number of missed connections, thus reducing passenger delay.

\section{Dispatch Operations Using CAD/AVL}

In 1999, the Federal Transit Administration sponsored a study, conducted by Volpe Transportation Systems Center to document the human consequences of the implementation of Computer Aided Dispatch/Automatic Vehicle Locator (CAD/AVL) technology at the Denver Regional Transit District. The study examined the impacts on dispatchers, street supervisors, and bus operators. For dispatchers, the Volpe report examined the following comparative data from 1992 (before CAD/AVL) and 1996 (after implementation): 
- Staffing

- Procedures

- Workload

- Training

- Usability

\section{Staffing}

Regional Transportation District (RTD) had a total of nine dispatchers in 1992 but total positions increased to eleven by 1996. Though the number of dispatchers increased 22 percent since implementation, there was not an assertion in the report that the CAD/AVL implementation was the cause of the increase. Between the hours of 22:00 and 03:00, there was one dispatcher on duty in 1996. From 04:00 to 06:00, there were two dispatchers on duty. From 06:00 to 10:00 and from 14:00 to $18: 00$, there were five peak dispatchers on duty. The remaining periods had three dispatchers on duty.

\section{Procedures}

Responding to an operator call entails several steps. When a bus operator calls, the dispatcher sees a message showing the bus number on the CAD incident management screen ranked by priority. The dispatcher selects the vehicle calling and refers to the AVL screen for exact location. Upon clicking the bus number, the CAD system prompts the dispatcher to initiate voice communication. Operator calls are then coded based on a set of pre-established problem codes. If the problem is equipment-related, the code will then enable information to become available to the maintenance department.

The CAD/AVL system allows dispatchers to leave calls open for a long period of time until resolution is complete. In this way, dispatchers always have a visual reminder that a call remains open. The system also makes communications more efficient because dispatchers make less use of intermediaries and can relay messages from street supervisors to bus operators. Dispatchers use the system to monitor on-time performance and can use data communications to communicate with buses by route, individually, collectively, or in groups.

\section{Workload}

Dispatchers described their work as complex and stressful when "handling emergency type calls, accidents, or worse fatality, and snowstorms." One dispatcher was quoted as describing the job in the following way: "... like being a part of the whole mess, being involved in trying to resolve problems." 
Using the "Dispatchers Daily Activity Record," calls to dispatch for each hour of the service day were catalogued. As expected, calls peaked at 7:00 a.m. at greater than 20 , and at 5:00 p.m. with greater than 25 .

The nature of calls to dispatch also changed between 1992 and 1996. Regional Transportation District (RTD) bus operators began requesting more information for customers because of the increased capacity of the CAD/AVL system to receive calls from the operators. A total of 23 percent of calls were "Policy Information/ Direction" compared to 11 percent in 1992. Also, operators requesting bus holds for transfers increased to 9 percent of all calls, up from 1 percent in 1992. Dispatchers received fewer calls from road supervisors because they could retrieve real time information from their mobile data terminals.

\section{Training}

Dispatchers underwent three rounds of training. The first training centered around acquainting dispatchers with the new radio console. The second centered around use of the CAD/AVL screens, and in the third round dispatchers learned the integration functions of the radio and CAD/AVL. Dispatchers reported that the equipment was not too different from their prior procedures and equipment.

\section{Usability}

When complete, dispatchers had a total of five monitors and three keyboards to use in operating the system. CAD/AVL had two side-by-side screens, the VAX system had two screens, and the Operations Center's security cameras provided images seen on the fifth screen. Although dispatchers can select how much detail they want to show on screens, dispatchers did request modifications over time to make the system more usable.

\section{Miami-Dade TOS Manual}

In 2004, Miami-Dade Transit commissioned the Center for Urban Transportation Research to prepare a comprehensive manual for Transit Operations Supervisors (TOS). Below is a description of the purpose of the manual, and Section 200 of the manual specifically addresses the dispatch functions.

Transit Operations Supervisors are the first line of supervision. Their duties require sound judgment, knowledge, skill, and discretion. The essence is quality control, through observing the operations, correcting deficiencies, and reporting conditions of service and actions taken to the proper authorities. The Transit Operations Supervisor (TOS) must also take a proactive approach to customer service. Effective supervision results from good communication skills, a thorough knowledge and understanding of policies and procedures, and a willingness to understand the 
problems confronting employees. The objective of the Supervisor is to instill a desire to improve, rather than a desire to defend inappropriate actions.

In the past, there were three separate supervisory classifications in bus operations (supervisor, dispatcher, and radio dispatcher) each with separate job descriptions. In recent times, to improve the effectiveness and efficiency of staff, the TOS classification was created that allows for a supervisor to perform any and all duties of the former three classifications, as well as additional supervisory duties.

The Transit Operations Supervisor is responsible for direct and/or indirect supervision of bus operators. Duties include coordinating and controlling operations on all bus routes with supervisors and other field units at the direction of Bus Central Control; initial and subsequent dispatching of operators to assigned vehicles and routes, special assignments, and charters; observing and supervising operators and bus operations. Assignments may include disseminating information regarding routes, schedules, and fares to bus customers at terminal points, major route junctions, park-and-ride locations, and other points in the system.

The overall duties of dispatchers, separate from the duties of supervisors as a whole, are as follows:

- Plan, assign, and review the work of bus operators to assure compliance with departmental rules/regulations, including ADA (Americans with Disabilities Act).

- Assign bus operators according to departmental rules, regulations, and procedures; calculate personnel needs based on level of service required, and availability of equipment and personnel.

- Assure the availability of operators and equipment for posting work assignments.

- Before giving out work, double-check for correct work assignments

- Assign all regular runs and trippers to bus operators on assigned shifts.

- Assemble and distribute schedule cards, transfers, and other related forms.

- Maintain operator attendance records.

- Check operators reporting for duty on uniform regulation compliance.

- Account for bus-to-rail transfers disbursed to bus operators.

- Maintain adequate supply of bus-to-bus transfers.

- Assure adequate supply of all transit operations forms.

- Manage distribution and receipt of toll collection data and apparatus.

- Inspect charter reports, defect cards, and other forms upon completion of operators' assignments and place material in the proper location.

- Account for all lost-and-found items turned in by bus operators.

- Maintain close coordination with Maintenance for exchange of defective coaches and for vehicle availability. 
- Communicate and coordinate with other Supervisors and Bus Central Control regarding vehicle and manpower availability and other issues.

- Ensure schedule adherence for operators upon leaving and returning to the garage, on the lot, and in the dispatch office.

The Window Dispatch Function completes the process of matching bus schedules to vehicles and to operators. In this function, it is necessary to anticipate, on a continual basis, operator and equipment needs and changes in supply. The window dispatcher should always be able to answer the questions: "What is the operator availability?"; "Who is the next operator?"; and "What is the status of bus availability?"

In addition to ensuring that current bus service is met, the window dispatcher must also deal with service failures, new services/schedules that are added, schedule changes, route alignment (map) changes, bus assignment changes (route, run, or division), changes in operator assignments (such as open run bids and deletions), and prepare for additional service requests such as special services, and emergency variations from scheduled work (such as evacuation/hurricane procedures). When performing this function, the window dispatcher must always be sure to keep all proper records, work to prevent favoritism, errors, and misjudgments among operators, supervisors, and other employees.

- Relay messages to operators from superintendents.

- Pass out paychecks when needed.

- Coordinate manpower needs with other divisions

- Other duties as required.

\section{Evaluation and Management of Manpower}

Availability of operators is critical for the window dispatcher to know at all times. Operator needs should be checked according to a designated buffer (for each Division) that has been developed by management. The buffer will help ensure that missed service is kept at an absolute minimum, with a goal of zero. Any extra operators remaining after all needs are met at a given Division can be used to cover shortages at other Divisions.

Checking on operators and handing them work is the simple part of the window dispatch function. The more challenging tasks for the window supervisor involve evaluating manpower, creating the extra list, distributing extra list report times as evenly as possible to avoid high volumes of operators reporting at the same times, and managing the list so that operators are sent home at the appropriate time.

It is appropriate and absolutely essential for the window supervisor, upon reporting to work at the window, whether in the morning or when relieving another, to 
evaluate manpower. Manpower must be continually monitored and evaluated throughout the shift and into the next shift.

\section{Operator Check-In (Pull-Outs)}

Operators are required to check-in directly with the window supervisor and record the check-in electronically with the badge reader. Failure of an operator to run his or her badge or failure of the electronic reader to register a successful check-in must be recorded and reported. This electronic check-in must be done with every report to the window (not just the first report of the day, but every report). It also must be done even when operators report late to the window with a reasonable explanation.

\section{Extra List}

The Extra List is a list of operators and report times scheduled for overtime pay, used to supplement the report boards to achieve the anticipated manpower needs of the day. Operators may volunteer to be placed on the extra list throughout the day; however, every morning at 4:30 a.m., the supervisor takes names of volunteers for the afternoon of that day and the morning of the next day (p.m. and a.m. extra lists). Operators may volunteer until the list, or the period being requested, is completed. Names may not be taken earlier than 4:30 a.m.

\section{Management of the Extra List}

Operators on the extra list will report to work but may not be needed. Those operators whose names are posted on the extra list, and who report, are paid a minimum of two (2) hours (that is a minimum two-hours' pay if they report and work up to one hour and 20 minutes, due to the time-and-a-half rate). Sometimes, operators just need to come in and check with the dispatcher to see if they will be needed, and then are sent home. They may accrue one minute of stand-by time, but will still be paid the two-hour minimum.

\section{Job Descriptions}

The research team gathered job descriptions for dispatchers available via the Internet. In some transit agencies, dispatchers are a unique classification of employee whereas in others dispatchers fall into an overall category of operations supervisor. The advantage of combining classifications is that there is a fully trained work force that can manage dispatch functions, field operations, or employee disciplinary duties. However, job descriptions are more generalized and do not focus as heavily on essential duties, qualifications, and work environment/physical requirements. 
Job descriptions were obtained from Mesquite, Texas, Simi Valley, CA, Denver Regional Transit District, Sacramento, CA and Pace in the Chicago area. Common duties and responsibilities include:

- Supervising bus operations and bus operators

- Responsible for radio communications

- Responsible for record-keeping

- Responsible for coordinating all emergency situations

- Coordinates all special event/extra services

- Coordination with and/or provision of customer service

- Responsible for knowing and communicating detours

- Coordinate communications between operators, supervisors, and other employees

Common qualifications include:

- Knowledge of agency policies and procedures, including provisions of the labor agreement

- Knowledge of transit services

- Effective oral and written communications skills

- Computer literacy

- Ability to multi-task

- Ability to make quick, accurate decisions

\section{Bus Operations}

One important function of dispatch is to ensure transit service is running on time to achieve the highest customer satisfaction. In Champaign-Urbana, Illinois, the transit agency, Mass Transit District (MTD), installed a computer-aided dispatch/automatic vehicle location (CAD/AVL) system, "to support vehicle location, timetable adherence, real-time bus arrival and departure information, and onboard next-stop displays and announcements" (Derby and Kijowski, 2011). Changes in Dispatch were immediate such that they even changed the name from Dispatch to the Control Center. Dispatchers had "the ability to provide timely responses to delays or incidents by means of service restoration actions, connection protection, transfers, and headway control."

For passengers, the system was used to create real time information via text messaging beginning in 2006. In October 2010, the system had an all-time record of 104,900 text messages for real time bus arrival and departure information. Once real-time information was possible, MTD staff began to manage their service proactively rather than reactively. 


\section{Conclusions}

As expected, the literature displays that most research on this topic is relative to technology and how Dispatch relates to service provision, on-time performance, and customer satisfaction. Only the case study at Regional Transportation District (RTD) in Denver delved extensively into the functions and human-related factors in

Dispatch, but that was still in conjunction with a deployment of major technology. The Miami-Dade Transit TOS manual, while not a research report, delves most deeply into categorizing dispatch functions and providing detailed procedures for dispatchers to follow. This study is designed to explore the actual functions of Dispatch within a transit operations environment and differences between agencies in completing those functions. 


\section{SECTION TWO \\ DISPATCH SURVEY OF TRANSIT AGENCIES}

In October, November, and December 2011, a survey of transit agencies was developed to probe a number of functions of Dispatch. Below is a description of the survey, the responses and the overall survey results.

\section{Survey Design}

A number of inputs were utilized to develop a survey instrument for dispatchers, supervisors, and operations managers at transit agencies. First, data from the CUTR report entitled Best Practices in Extraboard Management, Optimum Sizing and Strategies (DeAnnuntis and Morris, 2007), were used to develop questions regarding management of the extraboard. Next, the literature review and, especially, the Miami-Dade TOS Manual were used to develop questions for the survey. Finally, general knowledge of dispatch functions from previous experiences of the research team helped form the development of the survey instrument.

The final draft survey consisted of 28 questions and was administered using SurveyMonkey, which is an Internet-based survey company from which the Center for Urban Transportation Research (CUTR) holds a license. The survey instrument was then submitted to the Florida Department of Transportation for approval.

\section{Survey Implementation}

An e-mail was sent to the Florida Operations Network (FON) requesting participation in the survey with a link to the SurveyMonkey instrument. Operations Managers were asked to forward the e-mail to appropriate employees to maximize participation. Additional follow-up was required in order to increase participation.

\section{Survey Response}

A total of 48 operations professionals from 9 of the 30 Florida transit agencies participated in the survey. The response rate cannot be considered a statistically valid sampling of the overall population of dispatchers. However, similar to the methodology used in the extraboard study, the survey did garner responses from small ( $<50$ buses), medium ( 50 to 249 buses) and large ( $>249$ buses) agencies.

The small agencies include:

- Bay Town Trolley (BTT) in Panama City, FL

- LeeTran in Ft. Myers/Cape Coral, FL

- VOTRAN in Daytona Beach/DeLand, FL

- Manatee County Area Transit (MCAT) in Bradenton, FL 
The medium transit agencies include:

- Hillsborough Area Regional Transit (HART) in Tampa, FL

- Pinellas Suncoast Transit Authority (PSTA) in Clearwater/St. Petersburg, FL

- Regional Transit System (RTS) in Gainesville, FL

- PalmTran in West Palm Beach, FL

The large transit agency is:

- Miami-Dade Transit (MDT) in Miami, FL

\section{Survey Results}

The survey results presented below are the frequencies for each question and a series of crosstabs for each transit agency. Noted here is that not all dispatchers within an agency agree on each question. However, the positions for each respondent were not the same. Most respondents were bus dispatchers; however, some were operations managers, supervisors, and paratransit dispatchers. Also, larger transit agencies have more than one operating base, which can impact the manner in which dispatchers from the same agency answer a particular question. Variations within responses will be noted below.

Question 1 of the survey asked respondents to indicate the agency for which they work. Table 2-1 below displays the frequencies for this question.

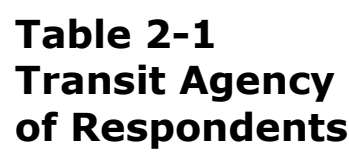

\begin{tabular}{|c|c|}
\hline Transit Agency & Total \\
\hline Bay Town Trolley & 1 \\
& $0.0 \%$ \\
\hline HART & 1 \\
& $2.3 \%$ \\
\hline LeeTran & 8 \\
& $18.2 \%$ \\
\hline MCAT & 3 \\
& $6.8 \%$ \\
\hline MDT & 5 \\
& $11.4 \%$ \\
\hline PalmTran & 9 \\
& $20.5 \%$ \\
\hline PSTA & 9 \\
& $20.5 \%$ \\
\hline RTS & 4 \\
& $9.1 \%$ \\
\hline Votran & 4 \\
& $9.1 \%$ \\
\hline
\end{tabular}


Question 2 asked respondents to identify their current position. A total of 41 percent indicated they were dispatchers while 39 percent indicated they were a transportation or operations supervisor. The literature review clearly indicates that in some systems, the positions of dispatcher and supervisor are combined such that each can fulfill the necessary functions. Table 2-2 below displays the positions held by respondents.

Table 2-2

Current Position

\begin{tabular}{|l|r|r|}
\hline \multicolumn{1}{|c|}{ Response } & Number & Percent \\
\hline Operations Manager & 3 & 6.8 \\
\hline Supervisor Manager & 6 & 13.6 \\
\hline Dispatcher & 18 & 41.0 \\
\hline Transportation or Operations Supervisor & 17 & 38.6 \\
\hline Total & 44 & 100.0 \\
\hline
\end{tabular}

Table 2-3 below displays a crosstab at the agency level for current position held. A total of 17 respondents indicated they are exclusive to dispatch.

Table 2-3

\section{Current Position Held by Transit Agency}

\begin{tabular}{|c|c|c|c|c|c|c|c|c|c|}
\hline ob Title & \begin{tabular}{|c} 
Bay \\
Town \\
Trolley
\end{tabular} & HART & LeeTran & МСАТ & MDT & PalmTran & PSTA & RTS & Votran \\
\hline Operati & $\begin{array}{c}1 \\
100.0 \% \\
\end{array}$ & $\begin{array}{c}0 \\
0.0 \% \\
\end{array}$ & $\begin{array}{c}0 \\
0.0 \% \\
\end{array}$ & $\begin{array}{c}0 \\
0.0 \% \\
\end{array}$ & $\begin{array}{c}0 \\
0.0 \% \\
\end{array}$ & $\begin{array}{c}0 \\
0.0 \% \\
\end{array}$ & $\begin{array}{c}1 \\
11.1 \% \\
\end{array}$ & $\begin{array}{c}1 \\
25.0 \% \\
\end{array}$ & $\begin{array}{c}1 \\
25.0 \% \\
\end{array}$ \\
\hline Superv & $\begin{array}{c}0 \\
0.0 \%\end{array}$ & $\begin{array}{c}0 \\
0.0 \% \\
\end{array}$ & $\begin{array}{c}1 \\
12.5 \%\end{array}$ & $\begin{array}{c}1 \\
33.3 \% \\
\end{array}$ & $\begin{array}{c}3 \\
60.0 \% \\
\end{array}$ & $\begin{array}{c}1 \\
11.1 \% \\
\end{array}$ & $\begin{array}{c}0 \\
0.0 \% \\
\end{array}$ & $\begin{array}{c}0 \\
0.0 \% \\
\end{array}$ & $\begin{array}{c}0 \\
0.0 \% \\
\end{array}$ \\
\hline Dispatcher & $\begin{array}{c}0 \\
0.0 \% \\
\end{array}$ & $\begin{array}{c}1 \\
100.0 \%\end{array}$ & $\begin{array}{c}1 \\
12.5 \%\end{array}$ & $\begin{array}{c}1 \\
33.3 \% \\
\end{array}$ & $\begin{array}{c}0 \\
0.0 \% \\
\end{array}$ & $\begin{array}{c}6 \\
66.7 \%\end{array}$ & $\begin{array}{c}2 \\
22.2 \%\end{array}$ & $\begin{array}{c}3 \\
75.0 \%\end{array}$ & $\begin{array}{c}3 \\
75.0 \% \\
\end{array}$ \\
\hline $\begin{array}{l}\text { Transportation or } \\
\text { Operations } \\
\text { Supervisor }\end{array}$ & $\begin{array}{c}0 \\
0.0 \% \\
\end{array}$ & $\begin{array}{c}0 \\
0.0 \% \\
\end{array}$ & $\begin{array}{c}6 \\
75.0 \% \\
\end{array}$ & $\begin{array}{c}1 \\
33.3 \% \\
\end{array}$ & $\begin{array}{c}2 \\
40.0 \% \\
\end{array}$ & $\begin{array}{c}2 \\
22.2 \% \\
\end{array}$ & $\begin{array}{c}6 \\
66.7 \% \\
\end{array}$ & $\begin{array}{c}0 \\
0.0 \% \\
\end{array}$ & $\begin{array}{c}0 \\
0.0 \% \\
\end{array}$ \\
\hline Tot & $\begin{array}{c}1 \\
100 \%\end{array}$ & $\begin{array}{c}1 \\
100 \%\end{array}$ & $\begin{array}{c}8 \\
100 \%\end{array}$ & $\begin{array}{c}3 \\
100 \%\end{array}$ & $\begin{array}{c}5 \\
100 \%\end{array}$ & $\begin{array}{c}9 \\
100 \%\end{array}$ & $\begin{array}{c}9 \\
100 \%\end{array}$ & $\begin{array}{c}4 \\
100 \%\end{array}$ & $\begin{array}{c}4 \\
100 \%\end{array}$ \\
\hline
\end{tabular}


Question 3 asked respondents to provide the position they held prior to becoming a dispatcher. Table 2-4 below shows that 55 percent were a bus operator and 22 percent held another position before becoming a dispatcher, and Table 2-5 displays previous position by transit agency.

\section{Table 2-4 \\ Position Held Before Becoming a Dispatcher}

\begin{tabular}{|l|r|r|}
\hline \multicolumn{1}{|c|}{ Response } & Number & \multicolumn{2}{|c|}{ Percent } \\
\hline $\begin{array}{l}\text { A dispatcher at another } \\
\text { transit agency }\end{array}$ & 1 & $2.5 \%$ \\
\hline $\begin{array}{l}\text { A dispatcher in the private } \\
\text { sector }\end{array}$ & 1 & $2.5 \%$ \\
\hline A road supervisor & 7 & $17.5 \%$ \\
\hline A bus operator & 22 & $55.0 \%$ \\
\hline Other & 9 & $22.5 \%$ \\
\hline Total & 40 & $100.0 \%$ \\
\hline
\end{tabular}

Table 2-5

Position Held Prior to Current Position by Transit Agency

\begin{tabular}{|c|c|c|c|c|c|c|c|c|c|}
\hline \begin{tabular}{|l} 
Previous \\
Position
\end{tabular} & $\begin{array}{l}\text { Bay } \\
\text { Town }\end{array}$ & HART & LeeTran & MCAT & MDT & PalmTran & PSTA & RTS & Votran \\
\hline $\begin{array}{l}\text { A dispatcher at } \\
\text { another transit } \\
\text { agency }\end{array}$ & $\begin{array}{c}0 \\
0.0 \% \\
\end{array}$ & $\begin{array}{c}0 \\
0.0 \% \\
\end{array}$ & $\begin{array}{c}0 \\
0.0 \% \\
\end{array}$ & $\begin{array}{c}0 \\
0.0 \% \\
\end{array}$ & $\begin{array}{c}0 \\
0.0 \% \\
\end{array}$ & $\begin{array}{c}0 \\
0.0 \% \\
\end{array}$ & $\begin{array}{c}1 \\
11.1 \% \\
\end{array}$ & $\begin{array}{c}0 \\
0.0 \% \\
\end{array}$ & $\begin{array}{c}0 \\
0.0 \% \\
\end{array}$ \\
\hline $\begin{array}{l}\text { A dispatcher in } \\
\text { the private } \\
\text { sector }\end{array}$ & $\begin{array}{c}0 \\
0.0 \% \\
\end{array}$ & $\begin{array}{c}0 \\
0.0 \% \\
\end{array}$ & $\begin{array}{c}1 \\
12.5 \% \\
\end{array}$ & $\begin{array}{c}0 \\
0.0 \% \\
\end{array}$ & $\begin{array}{c}0 \\
0.0 \% \\
\end{array}$ & $\begin{array}{c}0 \\
0.0 \% \\
\end{array}$ & $\begin{array}{c}0 \\
0.0 \% \\
\end{array}$ & $\begin{array}{c}0 \\
0.0 \% \\
\end{array}$ & $\begin{array}{c}0 \\
0.0 \% \\
\end{array}$ \\
\hline $\begin{array}{c}\text { A road } \\
\text { supervisor }\end{array}$ & $\begin{array}{c}0 \\
0.0 \% \\
\end{array}$ & $\begin{array}{c}0 \\
0.0 \% \\
\end{array}$ & $\begin{array}{c}2 \\
25.0 \% \\
\end{array}$ & $\begin{array}{c}0 \\
0.0 \% \\
\end{array}$ & $\begin{array}{c}0 \\
0.0 \% \\
\end{array}$ & $\begin{array}{c}2 \\
22.2 \% \\
\end{array}$ & $\begin{array}{c}2 \\
22.2 \% \\
\end{array}$ & $\begin{array}{c}0 \\
0.0 \% \\
\end{array}$ & $\begin{array}{c}1 \\
25.0 \% \\
\end{array}$ \\
\hline A bus operator & $\begin{array}{c}1 \\
100.0 \% \\
\end{array}$ & $\begin{array}{c}1 \\
100.0 \% \\
\end{array}$ & $\begin{array}{c}2 \\
25.0 \% \\
\end{array}$ & $\begin{array}{c}1 \\
33.3 \% \\
\end{array}$ & $\begin{array}{c}5 \\
71.4 \% \\
\end{array}$ & $\begin{array}{c}5 \\
55.6 \% \\
\end{array}$ & $\begin{array}{c}4 \\
44.4 \% \\
\end{array}$ & $\begin{array}{c}3 \\
100.0 \% \\
\end{array}$ & $\begin{array}{c}3 \\
75.0 \% \\
\end{array}$ \\
\hline Other & $\begin{array}{c}0 \\
0.0 \%\end{array}$ & $\begin{array}{c}0 \\
0.0 \% \\
\end{array}$ & $\begin{array}{c}3 \\
37.5 \% \\
\end{array}$ & $\begin{array}{c}2 \\
66.7 \% \\
\end{array}$ & $\begin{array}{c}2 \\
28.6 \% \\
\end{array}$ & $\begin{array}{c}2 \\
22.2 \% \\
\end{array}$ & $\begin{array}{c}2 \\
22.2 \% \\
\end{array}$ & $\begin{array}{c}0 \\
0.0 \% \\
\end{array}$ & $\begin{array}{c}0 \\
0.0 \%\end{array}$ \\
\hline Total & $\begin{array}{c}1 \\
100 \%\end{array}$ & $\begin{array}{c}1 \\
100 \%\end{array}$ & $\begin{array}{c}8 \\
100 \%\end{array}$ & $\begin{array}{c}7 \\
100 \%\end{array}$ & $\begin{array}{c}7 \\
100 \%\end{array}$ & $\begin{array}{c}9 \\
100 \%\end{array}$ & $\begin{array}{c}9 \\
100 \%\end{array}$ & $\begin{array}{c}3 \\
100 \%\end{array}$ & $\begin{array}{c}4 \\
100 \%\end{array}$ \\
\hline
\end{tabular}


Question 4 asked respondents to provide the number of years of experience in their dispatch position. The average years of experience for all 45 respondents is 8.02 years. The minimum experience is two weeks (.038 year) and the maximum years of experience is 31.5 years.

Questions 5, 6, and 7 were open ended questions. The research team was not expecting that so many professionals working for the same agency would be responding to the survey. Therefore there are no consistent results to report for these three questions:

Question 5: How many full time equivalent bus operators does your agency employ?

Question 6: How many full time equivalent dispatchers does your agency employ?

Question 7: How many dispatchers are on duty at one time during peak service on weekdays?

Question 8 asked respondents the type of service they dispatch. A total of 83 percent of respondents dispatch bus while 15 percent dispatch paratransit. The six paratransit dispatchers are at HART, Manatee County Area Transit (MCAT), PalmTran and VOTRAN. Table 2-6 shows the types of service dispatched and Table 2-7 displays the type of service dispatched by Transit Agency.

Table 2-6

Type of Service Dispatched

\begin{tabular}{|l|r|r|}
\hline \multicolumn{1}{|c|}{ Type of Service } & Frequency & Percent \\
\hline Bus & 34 & $82.9 \%$ \\
\hline Demand Response/Paratransit & 6 & $14.6 \%$ \\
\hline Streetcar/Rail & 1 & $2.4 \%$ \\
\hline Other & 0 & $0.0 \%$ \\
\hline Total & 41 & $100.0 \%$ \\
\hline
\end{tabular}


Table 2-7

Type of Service Dispatched by Transit Agency

\begin{tabular}{|c|c|c|c|c|c|c|c|c|c|}
\hline Types of service & $\begin{array}{c}\text { Bay Town } \\
\text { Trolley }\end{array}$ & HART & LeeTran & MCAT & MDT & PalmTran & PSTA & RTS & Votran \\
\hline Bus & $\begin{array}{c}1 \\
100.0 \%\end{array}$ & $\begin{array}{c}1 \\
33.3 \% \\
\end{array}$ & $\begin{array}{c}8 \\
100.0 \%\end{array}$ & $\begin{array}{c}3 \\
75.0 \%\end{array}$ & $\begin{array}{c}3 \\
100.0 \%\end{array}$ & $\begin{array}{c}8 \\
100.0 \%\end{array}$ & $\begin{array}{c}7 \\
100.0 \%\end{array}$ & $\begin{array}{c}4 \\
100.0 \%\end{array}$ & $\begin{array}{c}3 \\
50.0 \%\end{array}$ \\
\hline $\begin{array}{c}\text { Demand } \\
\text { Response/Paratransit }\end{array}$ & $\begin{array}{c}0 \\
0.0 \%\end{array}$ & $\begin{array}{c}1 \\
33.3 \%\end{array}$ & $\begin{array}{c}0 \\
0.0 \%\end{array}$ & $\begin{array}{c}1 \\
25.0 \%\end{array}$ & $\begin{array}{c}0 \\
0.0 \%\end{array}$ & $\begin{array}{c}1 \\
0.0 \%\end{array}$ & $\begin{array}{c}0 \\
0.0 \%\end{array}$ & $\begin{array}{c}0 \\
0.0 \%\end{array}$ & $\begin{array}{c}3 \\
50.0 \%\end{array}$ \\
\hline Streetcar/Rail & $0.0 \%$ & $\begin{array}{c}1 \\
33.3 \% \\
\end{array}$ & $\begin{array}{c}0 \\
0.0 \% \\
\end{array}$ & $\begin{array}{c}0 \\
0.0 \% \\
\end{array}$ & $\begin{array}{c}0 \\
0.0 \% \\
\end{array}$ & $\begin{array}{c}0 \\
0.0 \% \\
\end{array}$ & $\begin{array}{c}0 \\
0.0 \% \\
\end{array}$ & $\begin{array}{c}0 \\
0.0 \% \\
\end{array}$ & $\begin{array}{c}0 \\
0.0 \% \\
\end{array}$ \\
\hline Other & $\begin{array}{c}0 \\
0.0 \% \\
\end{array}$ & $\begin{array}{c}0 \\
0.0 \% \\
\end{array}$ & $\begin{array}{c}0 \\
0.0 \% \\
\end{array}$ & $\begin{array}{c}0 \\
0.0 \% \\
\end{array}$ & $\begin{array}{c}0 \\
0.0 \% \\
\end{array}$ & $\begin{array}{c}0 \\
0.0 \% \\
\end{array}$ & $\begin{array}{c}0 \\
0.0 \% \\
\end{array}$ & $\begin{array}{c}0 \\
0.0 \% \\
\end{array}$ & $\begin{array}{c}0 \\
0.0 \% \\
\end{array}$ \\
\hline Total & $\begin{array}{c}1 \\
100 \%\end{array}$ & $\begin{array}{c}3 \\
100 \%\end{array}$ & $\begin{array}{c}8 \\
100 \%\end{array}$ & $\begin{array}{c}4 \\
100 \%\end{array}$ & $\begin{array}{c}3 \\
100 \%\end{array}$ & $\begin{array}{c}9 \\
100 \%\end{array}$ & $\begin{array}{c}7 \\
100 \%\end{array}$ & $\begin{array}{c}4 \\
100 \%\end{array}$ & $\begin{array}{c}6 \\
100 \%\end{array}$ \\
\hline
\end{tabular}

Question 9 asked respondents about the physical setup of their Dispatch office. The response is evenly split between window functions and radio functions either colocated or separate. Six percent responded with an answer of "other" for this question. Table 2-8 below displays the physical setup of Dispatch and Table 2-9 displays the physical setup by transit agency. In the cases of MCAT, Miami-Dade and PalmTran some respondents gave different answers. Miami-Dade and PalmTran have more than one operating base which could explain the variation. MCAT had a mix of bus and paratransit dispatchers which could explain this variation.

Table 2-8

Physical Setup of Dispatch Office

\begin{tabular}{|l|r|r|}
\hline \multicolumn{1}{|c|}{ Response } & Number & Percent \\
\hline $\begin{array}{l}\text { Window and radio dispatch are } \\
\text { located together }\end{array}$ & 16 & $45.7 \%$ \\
\hline $\begin{array}{l}\text { Window and radio dispatch are } \\
\text { separate }\end{array}$ & 17 & $48.6 \%$ \\
\hline Other & 2 & $5.7 \%$ \\
\hline Total & 35 & $100.0 \%$ \\
\hline
\end{tabular}


Table 2-9

Physical Setup of Dispatch Office by Transit Agency

\begin{tabular}{|c|c|c|c|c|c|c|c|c|c|}
\hline Physical Set-up & $\begin{array}{c}\text { Bay Town } \\
\text { Trolley }\end{array}$ & HART & LeeTran & MCAT & MDT & PalmTran & PSTA & RTS & Votran \\
\hline $\begin{array}{c}\text { Window and radio } \\
\text { dispatch are } \\
\text { located together }\end{array}$ & $100.0 \%$ & $0.0 \%$ & $100.0 \%$ & $66.7 \%$ & $0.0 \%$ & $12.5 \%$ & $0.0 \%$ & $0.0 \%$ & $100.0 \%$ \\
\hline $\begin{array}{c}\text { Window and radio } \\
\text { dispatch are } \\
\text { separate }\end{array}$ & $0.0 \%$ & $100.0 \%$ & $0.0 \%$ & $0.0 \%$ & $66.7 \%$ & $87.5 \%$ & $100.0 \%$ & $100.0 \%$ & $0.0 \%$ \\
\hline Other & 0 & 0 & 0 & 1 & 1 & 0 & 0 & 0 & 0 \\
\hline Total & 1 & 1 & 8 & 3 & 3 & 8 & 7 & 7 & 0 \\
$0.0 \%$ & $100 \%$ & $100 \%$ & $100 \%$ & $100 \%$ & $100 \%$ & $100 \%$ & $100 \%$ & $100 \%$ \\
\hline
\end{tabular}

One of the key objectives of this research is to understand the similarities and the differences of how transit agencies approach the dispatch function. Question 10 asked respondents to describe the relationship between window, radio, and road supervision functions. A total of 58.9 percent of respondents indicate that the position of supervisor is interchangeable between window, radio and road supervision duties. At the agency level, respondents sometimes gave different answers to this question; however, the majority of respondents from each agency gave a consistent response. Variations are possible based on service type and location. Table 2-10 below displays the relationship between window, radio, and road supervision functions and Table 2-11 shows the relationship by transit agency.

Table 2-10

Relationship between Window, Radio, and Road Supervision Functions

\begin{tabular}{|l|r|r|}
\hline \multicolumn{1}{|c|}{ Response } & \multicolumn{1}{|c|}{ Number } & \multicolumn{1}{c|}{ Percent } \\
\hline Dispatchers work window only and/or radio only & 8 & $20.5 \%$ \\
\hline Dispatchers work both on a rotating basis & 5 & $12.8 \%$ \\
\hline $\begin{array}{l}\text { Dispatchers are considered supervisors and } \\
\text { can work window, radio and road supervision } \\
\text { on a rotating or as needed basis }\end{array}$ & 23 & $58.9 \%$ \\
\hline Other & & $7.7 \%$ \\
\hline Total & 39 & $100.0 \%$ \\
\hline
\end{tabular}


Table 2-11

Relationship between Window, Radio, and Road Supervision by

Transit Agency

\begin{tabular}{|c|c|c|c|c|c|c|c|c|c|}
\hline Operational Set-up & $\begin{array}{l}\text { Bay Town } \\
\text { Trolley }\end{array}$ & HART & LeeTran & MCAT & MDT & PalmTran & PSTA & RTS & Votran \\
\hline $\begin{array}{l}\text { Dispatchers work window only and/or } \\
\text { radio only }\end{array}$ & $\begin{array}{c}0 \\
0.0 \%\end{array}$ & $\begin{array}{c}0 \\
0.0 \%\end{array}$ & $\begin{array}{c}1 \\
12.5 \%\end{array}$ & $\begin{array}{c}2 \\
66.7 \%\end{array}$ & $\begin{array}{c}0 \\
0.0 \%\end{array}$ & $\begin{array}{c}1 \\
12.5 \%\end{array}$ & $\begin{array}{c}0 \\
0.0 \%\end{array}$ & $\begin{array}{c}2 \\
50.0 \%\end{array}$ & $\begin{array}{c}2 \\
66.7 \%\end{array}$ \\
\hline $\begin{array}{l}\text { Dispatchers work both on a rotating } \\
\text { basis }\end{array}$ & $\begin{array}{c}0 \\
0.0 \%\end{array}$ & $\begin{array}{c}1 \\
100.0 \%\end{array}$ & $\begin{array}{c}0 \\
0.0 \%\end{array}$ & $\begin{array}{c}1 \\
33.3 \%\end{array}$ & $\begin{array}{c}0 \\
0.0 \%\end{array}$ & $\begin{array}{c}0 \\
0.0 \%\end{array}$ & $\begin{array}{c}0 \\
0.0 \%\end{array}$ & $\begin{array}{c}1 \\
25.0 \%\end{array}$ & $\begin{array}{c}1 \\
33.3 \%\end{array}$ \\
\hline $\begin{array}{l}\text { Dispatchers are considered } \\
\text { supervisors and can work window, } \\
\text { radio, and road supervision on a } \\
\text { rotating or as needed basis }\end{array}$ & $\begin{array}{c}0 \\
0.0 \%\end{array}$ & $\begin{array}{c}0 \\
0.0 \%\end{array}$ & $\begin{array}{c}6 \\
75.0 \%\end{array}$ & $\begin{array}{c}0 \\
0.0 \%\end{array}$ & $\begin{array}{c}3 \\
100.0 \%\end{array}$ & $\begin{array}{c}7 \\
87.5 \%\end{array}$ & $\begin{array}{c}7 \\
100.0 \%\end{array}$ & $\begin{array}{c}0 \\
0.0 \%\end{array}$ & $\begin{array}{c}0 \\
0.0 \%\end{array}$ \\
\hline Other & $\begin{array}{c}1 \\
100.0 \%\end{array}$ & $\begin{array}{c}0 \\
0.0 \%\end{array}$ & $\begin{array}{c}1 \\
12.5 \%\end{array}$ & $\begin{array}{c}0 \\
0.0 \%\end{array}$ & $\begin{array}{c}0 \\
0.0 \%\end{array}$ & $\begin{array}{c}0 \\
0.0 \%\end{array}$ & $\begin{array}{c}0 \\
0.0 \%\end{array}$ & $\begin{array}{c}1 \\
25.0 \%\end{array}$ & $\begin{array}{c}0 \\
0.0 \%\end{array}$ \\
\hline Total & $\begin{array}{c}1 \\
100 \%\end{array}$ & $\begin{array}{c}1 \\
100 \%\end{array}$ & $\begin{array}{c}8 \\
100 \%\end{array}$ & $\begin{array}{c}3 \\
100 \%\end{array}$ & $\begin{array}{c}3 \\
100 \%\end{array}$ & $\begin{array}{c}8 \\
100 \%\end{array}$ & $\begin{array}{c}7 \\
100 \%\end{array}$ & $\begin{array}{c}4 \\
100 \%\end{array}$ & $\begin{array}{c}3 \\
100 \%\end{array}$ \\
\hline
\end{tabular}

Question 11 included a list of 15 duties and functions that may apply to survey respondents. Respondents were asked to put a check next to the functions that are primary (3), secondary (2) or minimal (1), based on the amount of time is spent on each task daily. The top 5 functions are listed in Table 2-12 below. Clearly the top two issues dispatchers deal with is labor management and equipment management. The number one function with an average rating of 2.69 is to coordinate the availability of manpower and equipment. The number two function with an average rating of 2.68 is maintaining close coordination with Maintenance to exchange defective buses and vehicle availability in real time. 


\section{Table 2-12}

\section{Top 5 Functions/Duties of Dispatchers}

\begin{tabular}{|l|c|}
\hline \multicolumn{1}{|c|}{ Function/Duty } & $\begin{array}{c}\text { Average } \\
\text { Rating }\end{array}$ \\
\hline $\begin{array}{l}\text { Communicate and coordinate with other Supervisors and Bus Central } \\
\text { Control regarding vehicle and manpower availability and other issues. }\end{array}$ & 2.69 \\
\hline $\begin{array}{l}\text { Maintain close coordination with Maintenance for exchange of defective } \\
\text { coaches and for vehicle availability. }\end{array}$ & 2.68 \\
\hline Double-check for correct work assignments before giving out work. & 2.65 \\
\hline $\begin{array}{l}\text { Ensure schedule adherence for Operators upon leaving and returning to } \\
\text { the garage, on the lot, and in the dispatch office. }\end{array}$ & 2.59 \\
\hline Check Operators reporting for duty on uniform appearance. & 2.52 \\
\hline
\end{tabular}

Table 2-13 below displays the average ratings for the remaining functions.

Table 2-14 below displays the average ratings by transit agency. Of the top two responses given in the survey as a whole, both Bay Town Trolley and HART did not see these two areas as being the most important, both giving a rating of 1 . However, Bay Town Trolley and HART were also the only systems that had only one respondent to the survey. 
Table 2-13

Remaining Functions and Duties - Average Ratings

\begin{tabular}{|c|c|}
\hline Function/Duty & Average Rating \\
\hline $\begin{array}{l}\text { Maintain close coordination with Maintenance for } \\
\text { exchange of defective coaches and for vehicle } \\
\text { availability. }\end{array}$ & 2.68 \\
\hline $\begin{array}{l}\text { Communicate and coordinate with other } \\
\text { supervisors and Bus Central Control regarding } \\
\text { vehicle and manpower availability and other issues. }\end{array}$ & 2.69 \\
\hline $\begin{array}{l}\text { Double-check for correct work assignments before } \\
\text { giving out work. }\end{array}$ & 2.65 \\
\hline $\begin{array}{l}\text { Ensure schedule adherence for operators upon } \\
\text { leaving and returning to the garage, on the lot, and } \\
\text { in the dispatch office. }\end{array}$ & 2.59 \\
\hline $\begin{array}{l}\text { Check operators reporting for duty on uniform } \\
\text { appearance. }\end{array}$ & 2.52 \\
\hline $\begin{array}{l}\text { Assign bus operators according to departmental } \\
\text { rules, regulations, and procedures; calculate } \\
\text { personnel needs based on level of service required, } \\
\text { and availability of equipment and personnel }\end{array}$ & 2.44 \\
\hline $\begin{array}{l}\text { Assure the availability of operators and equipment } \\
\text { for posting work assignments. }\end{array}$ & 2.42 \\
\hline Maintain operator daily attendance records. & 2.41 \\
\hline $\begin{array}{l}\text { Plan, assign, and review the work of bus operators } \\
\text { to assure compliance with departmental rules and } \\
\text { regulations, including ADA (Americans with } \\
\text { Disabilities Act). }\end{array}$ & 2.35 \\
\hline $\begin{array}{l}\text { Verify and submit operator work hours to } \\
\text { payroll/human resources }\end{array}$ & 2.32 \\
\hline $\begin{array}{l}\text { Assign all regular runs and trippers to bus operators } \\
\text { on assigned shifts. }\end{array}$ & 2.29 \\
\hline $\begin{array}{l}\text { Account for all lost-and-found items turned in by } \\
\text { bus operators. }\end{array}$ & 2.24 \\
\hline $\begin{array}{l}\text { Inspect special events/charter reports, defect coach } \\
\text { reports, and other forms upon completion of } \\
\text { operators' assignments and place material in the } \\
\text { properlocation. }\end{array}$ & 2.03 \\
\hline $\begin{array}{l}\text { Assemble and distribute schedule cards, transfers, } \\
\text { and other related forms. }\end{array}$ & 1.68 \\
\hline $\begin{array}{l}\text { Account for transfers disbursed to bus operators } \\
\text { and assure adequate supply of all transit operations } \\
\text { forms. }\end{array}$ & 1.38 \\
\hline $\begin{array}{l}\text { Manage distribution and receipt of toll collection } \\
\text { data and apparatus. }\end{array}$ & 1.31 \\
\hline
\end{tabular}




\section{Table 2-14 \\ Average Ratings for Functions by Transit Agency}

\begin{tabular}{|c|c|c|c|c|c|c|c|c|c|}
\hline Function/Duty & $\begin{array}{l}\text { Bay Town } \\
\text { Trolley }\end{array}$ & HART & LeeTran & MCAT & MDT & PalmTran & PSTA & RTS & Votran \\
\hline $\begin{array}{l}\text { Plan, assign, and review the work of bus operators } \\
\text { to assure compliance with departmental rules and } \\
\text { regulations, including ADA (Americans with } \\
\text { Disabilities Act). }\end{array}$ & 2.00 & 2.00 & 2.00 & 2.33 & 3.00 & 3.00 & 2.43 & 2.50 & 1.00 \\
\hline $\begin{array}{l}\text { Assign bus operators according to departmental } \\
\text { rules, regulations, and procedures; calculate } \\
\text { personnel needs based on level of service required, } \\
\text { and availability of equipment and personnel. }\end{array}$ & 3.00 & 1.00 & 2.13 & 2.33 & 3.00 & 3.00 & 2.71 & 2.80 & 1.00 \\
\hline $\begin{array}{l}\text { Assure the availability of operators and equipment } \\
\text { for posting work assignments. }\end{array}$ & 2.00 & 1.00 & 2.25 & 2.33 & 3.00 & 3.00 & 2.29 & 2.80 & 1.33 \\
\hline $\begin{array}{l}\text { Double-check for correct work assignments before } \\
\text { giving out work. }\end{array}$ & 3.00 & $\mathrm{n} / \mathrm{a}$ & 2.50 & 2.00 & 2.67 & 2.88 & 2.86 & 2.00 & 3.00 \\
\hline $\begin{array}{l}\text { Assign all regular runs and trippers to bus operators } \\
\text { on assigned shifts. }\end{array}$ & 3.00 & $\mathrm{n} / \mathrm{a}$ & 1.88 & 1.67 & 2.67 & 3.00 & 2.71 & 3.00 & 1.00 \\
\hline $\begin{array}{l}\text { Assemble and distribute schedule cards, transfers, } \\
\text { and other related forms. }\end{array}$ & 2.00 & 2.00 & 1.13 & 2.33 & 2.33 & 1.63 & 1.14 & 1.80 & 3.00 \\
\hline Maintain operator daily attendance records. & 1.00 & 1.00 & 2.00 & 1.67 & 2.00 & 2.63 & 2.71 & 2.50 & 3.00 \\
\hline $\begin{array}{l}\text { Check operators reporting for duty on uniform } \\
\text { appearance. }\end{array}$ & 2.00 & 1.00 & 2.88 & 1.67 & 2.50 & 2.88 & 2.29 & 2.00 & 2.00 \\
\hline $\begin{array}{l}\text { Account for transfers disbursed to Bus Operators } \\
\text { and assure adequate supply of all transit operations } \\
\text { forms. }\end{array}$ & 2.00 & 2.00 & 1.00 & 1.67 & 1.67 & 1.33 & 1.00 & 2.00 & 2.33 \\
\hline $\begin{array}{l}\text { Manage distribution and receipt of toll collection } \\
\text { data and apparatus. }\end{array}$ & 2.00 & 3.00 & 1.13 & 1.67 & 1.00 & 1.17 & 1.71 & 2.30 & 1.00 \\
\hline $\begin{array}{l}\text { Inspect special events/charter reports, defect coach } \\
\text { reports, and other forms upon completion of } \\
\text { operators' assignments and place material in the } \\
\text { proper location. }\end{array}$ & 3.00 & 3.00 & 2.50 & 1.67 & 2.33 & 2.00 & 1.29 & 2.80 & 3.00 \\
\hline $\begin{array}{l}\text { Account for all lost-and-found items turned in by } \\
\text { bus operators. }\end{array}$ & 2.00 & 1.00 & 2.50 & 2.67 & 3.00 & 2.14 & 1.92 & 1.80 & 2.00 \\
\hline $\begin{array}{l}\text { Maintain close coordination with Maintenance for } \\
\text { exchange of defective coaches and for vehicle } \\
\text { availability. }\end{array}$ & 1.00 & 1.00 & 2.88 & 1.67 & 3.00 & 2.57 & 2.67 & 1.00 & 3.00 \\
\hline $\begin{array}{l}\text { Communicate and coordinate with other } \\
\text { Supervisors and Bus Central Control regarding } \\
\text { vehicle and manpower availability and other issues. }\end{array}$ & 1.00 & 1.00 & 2.88 & 2.67 & 3.00 & 2.50 & 2.29 & 1.00 & 3.00 \\
\hline $\begin{array}{l}\text { Ensure schedule adherence for operators upon } \\
\text { leaving and returning to the garage, on the lot, and } \\
\text { in the dispatch office. }\end{array}$ & 1.00 & 1.00 & 2.88 & 2.33 & 2.67 & 2.25 & 2.71 & 1.30 & 2.33 \\
\hline $\begin{array}{l}\text { Verify and submit operator work hours to } \\
\text { payroll/human resources }\end{array}$ & 2.00 & 1.00 & 2.13 & 1.67 & 2.67 & 2.86 & 2.80 & 2.30 & 1.00 \\
\hline
\end{tabular}


Question 12 presented the same 16 functions as Question 11; however, in this question, respondents were asked to rank the importance of each, regardless of the amount of time spent on them each day. The rating scale was a 4-point scale: Primarily Important (4), Secondarily Important (3), Somewhat Important (2), and Minimally or Not Important (1). Table 2-15 displays the top six responses given by dispatchers. Labor and equipment management functions took the top spots with dispatchers indicating the most important function is to ensure schedule adherence for operators (3.70) and maintaining close coordination with Maintenance for bus availability (3.66). Ensuring correct work assignments for operators before giving out work was the third most important function (3.58). Table 2-16 presents the remaining average ratings for importance of functions in the dispatch environment.

Table 2-15

Top Six Most Important Functions Regardless of Time Spent

\begin{tabular}{|l|r|}
\hline Function/Duty & $\begin{array}{l}\text { Average } \\
\text { Rating }\end{array}$ \\
\hline $\begin{array}{l}\text { Ensure schedule adherence for Operators upon leaving and } \\
\text { returning to the garage, on the lot, and in the dispatch office. }\end{array}$ & 3.70 \\
\hline $\begin{array}{l}\text { Maintain close coordination with Maintenance for exchange } \\
\text { of defective coaches and for vehicle availability. }\end{array}$ & 3.66 \\
\hline $\begin{array}{l}\text { Double-check for correct work assignments before giving out } \\
\text { work. }\end{array}$ & 3.58 \\
\hline $\begin{array}{l}\text { Communicate and coordinate with other Supervisors and Bus } \\
\text { Central Control regarding vehicle and manpower availability } \\
\text { and other issues. }\end{array}$ & 3.48 \\
\hline Check Operators reporting for duty on uniform appearance. & 3.43 \\
\hline $\begin{array}{l}\text { Assure the availability of Operators and equipment for } \\
\text { posting work assignments. }\end{array}$ & 3.42 \\
\hline
\end{tabular}


Table 2-16

Average Ratings - Remaining Functions Regardless of Time Spent

\begin{tabular}{|l|r|}
\hline \multicolumn{1}{|c|}{ Function/Duty } & \multicolumn{1}{|c|}{$\begin{array}{c}\text { Average } \\
\text { Rating }\end{array}$} \\
\hline Maintain Operator daily attendance records. & 3.38 \\
\hline $\begin{array}{l}\text { Assign Bus Operators according to departmental rules, } \\
\text { regulations, and procedures; calculate personnel needs based } \\
\text { on level of service required, and availability of equipment and } \\
\text { personnel. }\end{array}$ & 3.36 \\
\hline $\begin{array}{l}\text { Plan, assign, and review the work of Bus Operators to assure } \\
\text { compliance with departmental rules and regulations, } \\
\text { including ADA (Americans with Disabilities Act). }\end{array}$ & 3.30 \\
\hline $\begin{array}{l}\text { Assign all regular runs and trippers to Bus Operators on } \\
\text { assigned shifts. }\end{array}$ & 3.30 \\
\hline $\begin{array}{l}\text { Assemble and distribute schedule cards, transfers, and other } \\
\text { related forms. }\end{array}$ & 3.30 \\
\hline $\begin{array}{l}\text { Manage distribution and receipt of toll collection data and } \\
\text { apparatus. }\end{array}$ & 2.97 \\
\hline $\begin{array}{l}\text { Inspect special events/charter reports, defect coach reports, } \\
\text { and other forms upon completion of Operators' assignments } \\
\text { and place material in the proper location. }\end{array}$ & 2.79 \\
\hline $\begin{array}{l}\text { Account for all lost-and-found items turned in by Bus } \\
\text { Operators. }\end{array}$ & 2.75 \\
\hline $\begin{array}{l}\text { Make safety and other general types of announcements on } \\
\text { buses through an onboard PA system. }\end{array}$ \\
\hline $\begin{array}{l}\text { Record wheelchair boardings as bus operators identify them } \\
\text { through the communications system. }\end{array}$ \\
\hline $\begin{array}{l}\text { Account for transfers disbursed to Bus Operators and assure } \\
\text { adequate supply of all transit operations forms. }\end{array}$ \\
\hline
\end{tabular}

Table 2-17 below displays the average ratings by transit agency. Only RTS did not rate the overall top functions as being the most important 
Table 2-17

Importance of Functions Regardless of Time Spent by Transit Agency

\begin{tabular}{|c|c|c|c|c|c|c|c|c|c|}
\hline Function/Duty & $\begin{array}{c}\text { Bay Town } \\
\text { Trolley }\end{array}$ & HART & LeeTran & MCAT & MDT & PalmTran & PSTA & RTS & Votran \\
\hline $\begin{array}{l}\text { Plan, assign, and review the work of Bus } \\
\text { Operators to assure compliance with } \\
\text { departmental rules and regulations, }\end{array}$ & 2.00 & 4.00 & 3.38 & 3.67 & 3.33 & 4.00 & 3.43 & \multirow[t]{2}{*}{3.00} & \multirow[t]{2}{*}{1.00} \\
\hline $\begin{array}{l}\text { including } \\
\text { Act). }\end{array}$ & & & & & & & & & \\
\hline \begin{tabular}{|l|llr|} 
Assign & Bus & Operators according to \\
departmental rules, regulations, and \\
procedures; calculate personnel needs \\
based on level of service required, and \\
availability of equipment and personnel.
\end{tabular} & 2.00 & 4.00 & 3.38 & 3.33 & 3.33 & 4.00 & 3.86 & 2.50 & 1.00 \\
\hline $\begin{array}{l}\text { Assure the availability of Operators and } \\
\text { equipment for posting work assignments. }\end{array}$ & 3.00 & 4.00 & 3.63 & 3.00 & 4.00 & 3.86 & 3.71 & 1.50 & 1.00 \\
\hline $\begin{array}{l}\text { Double-check for correct work assignments } \\
\text { before giving out work. }\end{array}$ & 2.00 & 3.00 & 3.38 & 2.67 & 4.00 & 3.86 & 3.86 & 2.30 & 4.00 \\
\hline $\begin{array}{l}\text { Assign a regular runs and trippers to Bus } \\
\text { Operators on assigned shifts. }\end{array}$ & 2.00 & 4.00 & 3.00 & 3.00 & 4.00 & 4.00 & 3.86 & 3.30 & 1.00 \\
\hline $\begin{array}{l}\text { Assemble and distribute schedule cards, } \\
\text { transfers, and other related forms. }\end{array}$ & 3.00 & 3.00 & 2.00 & 1.75 & 3.00 & 3.67 & 1.57 & 2.30 & 4.00 \\
\hline Maintain Operator daily attendance records. & 4.00 & 4.00 & 3.00 & 2.67 & 3.00 & 4.00 & 3.22 & 2.50 & 4.00 \\
\hline $\begin{array}{l}\text { Check Qperators reporting for duty on } \\
\text { uniform appearance. }\end{array}$ & 4.00 & 4.00 & 3.63 & 2.00 & 4.00 & 3.83 & 3.17 & 2.80 & 3.00 \\
\hline $\begin{array}{l}\text { Account for transfers disbursed to Bus } \\
\text { Operators and assure adequate supply of all } \\
\text { transit operations forms. }\end{array}$ & 4.00 & 4.00 & 1.63 & 2.00 & 2.00 & 2.43 & 1.71 & 2.80 & 4.00 \\
\hline \begin{tabular}{l|l|} 
Manage & distribution and receipt of toll \\
collection data and apparatus.
\end{tabular} & 2.00 & 2.00 & 2.38 & 3.00 & 4.00 & 4.00 & 3.14 & 3.00 & 1.00 \\
\hline \begin{tabular}{|l|l|} 
Inspect & special events/charter reports, \\
defect coach reports, and other forms upon \\
completion of Operators' assignments and \\
place material in the proper location.
\end{tabular} & 0.00 & 2.00 & 3.25 & 2.57 & 4.00 & 2.78 & 2.29 & 3.50 & 4.00 \\
\hline $\begin{array}{l}\text { Account for all lost-and-found items turned } \\
\text { in by Bus Operators. }\end{array}$ & 2.00 & 2.00 & 3.25 & 3.33 & 3.50 & 2.57 & 1.57 & 2.70 & 4.00 \\
\hline $\begin{array}{l}\text { Maintain close coordination with } \\
\text { Mainten ance for exchange of defective } \\
\text { coaches and for vehicle availability. }\end{array}$ & 4.00 & 4.00 & 3.88 & 2.33 & 4.00 & 3.33 & 3.86 & 1.00 & 4.00 \\
\hline $\begin{array}{l}\text { Communticate and coordinate with other } \\
\text { Supervis ors and Bus Central Control } \\
\text { regardin } \$ \text { vehicle and manpower availability } \\
\text { and other issues. }\end{array}$ & 4.00 & 4.00 & 3.63 & 3.00 & 4.00 & 2.86 & 3.57 & 1.80 & 4.00 \\
\hline $\begin{array}{l}\text { Ensure schedule adherence for Operators } \\
\text { upon leaving and returning to the garage, on } \\
\text { the lot, ahd in the dispatch office. }\end{array}$ & 4.00 & 4.00 & 3.75 & 3.67 & 3.67 & 3.43 & 3.86 & 2.00 & 3.67 \\
\hline $\begin{array}{l}\text { Record wheelchair boardings as bus } \\
\text { operators identify them through the } \\
\text { communications system. }\end{array}$ & 1.00 & 1.00 & 3.63 & 3.00 & 1.67 & 1.50 & 1.29 & 1.80 & 4.00 \\
\hline $\begin{array}{l}\text { Make safety and other general types of } \\
\text { announcements on buses through an } \\
\text { onboard PA system. }\end{array}$ & 2.00 & 3.00 & 3.38 & 3.67 & 1.33 & 2.67 & 1.86 & 1.80 & 4.00 \\
\hline
\end{tabular}


One key variation in the dispatch function across transit agencies is whether dispatchers have a role in handling customer inquiries and complaints. Question 13 asked dispatchers how customer complaints are handled in their agencies. A small majority, 52.2 percent, of respondents indicate they are contacted by customer service representatives to answer questions about bus locations and times. One quarter of respondents indicate they have no role in handling customer information and 20.45 percent say that calls from customers come directly to Dispatch. However, six transit agencies had respondents who gave different responses to this question. No explanations or interpretations are made regarding why these variations occurred. Table 2-18 displays how customer complaints are handled and Table 2-19 shows how complaints are handled by Transit Agency.

Table 2-18

How Customer Complaints Are Handled

\begin{tabular}{|l|r|r|}
\hline \multicolumn{1}{|c|}{ How customer complaints are handled } & Number & Percent \\
\hline Directly, as customer calls are routed to dispatch & 9 & $20.45 \%$ \\
\hline $\begin{array}{l}\text { I am contacted by customer service to answer } \\
\text { questions regarding bus locations }\end{array}$ & 23 & $52.27 \%$ \\
\hline $\begin{array}{l}\text { I do not handle customer or information request } \\
\text { calls }\end{array}$ & 11 & $25.00 \%$ \\
\hline Other & 1 & $2.27 \%$ \\
\hline Total & 44 & $100.00 \%$ \\
\hline
\end{tabular}

Table 2-19

How Customer Complaints Are Handled by Transit Agency

\begin{tabular}{|c|c|c|c|c|c|c|c|c|c|}
\hline $\begin{array}{c}\text { Customer complaint and } \\
\text { information request calls }\end{array}$ & $\begin{array}{c}\text { Bay Town } \\
\text { Trolley }\end{array}$ & HART & LeeTran & MCAT & MDT & PalmTran & PSTA & RTS & Votran \\
\hline $\begin{array}{c}\text { Directly, as customer calls are } \\
\text { routed to dispatch }\end{array}$ & 1 & 0 & 0 & 2 & 0 & 3 & 1 & 0 & 1 \\
& $100.0 \%$ & $0.0 \%$ & $0.0 \%$ & $50.0 \%$ & $0.0 \%$ & $30.0 \%$ & $12.5 \%$ & $0.0 \%$ & $25.0 \%$ \\
\hline $\begin{array}{c}\text { I am contacted by customer } \\
\text { service to answer questions } \\
\text { regarding bus locations }\end{array}$ & 0 & 1 & 6 & 1 & 2 & 3 & 4 & 3 & 3 \\
\hline $\begin{array}{c}\text { Ido not handle customer or } \\
\text { information request calls }\end{array}$ & $0.0 \%$ & $100.0 \%$ & $75.0 \%$ & $25.0 \%$ & $66.7 \%$ & $30.0 \%$ & $50.0 \%$ & $75.0 \%$ & $75.0 \%$ \\
\hline Other & 0 & 2 & 1 & 0 & 4 & 3 & 1 & 0 \\
\hline Total & 0 & $0.0 \%$ & $25.0 \%$ & $25.0 \%$ & $0.0 \%$ & $40.0 \%$ & $37.5 \%$ & $25.0 \%$ & $0.0 \%$ \\
\hline & 1 & 0 & 0 & 0 & 1 & 0 & 0 & 0 & 0 \\
& $100 \%$ & $100 \%$ & $100 \%$ & $100 \%$ & $100 \%$ & $100 \%$ & $100 \%$ & $100 \%$ & $100 \%$ \\
\hline
\end{tabular}


Another key variation in the dispatch function is the level of empowerment the Dispatch office has in leading incident response management. Question 14 asked respondents how dispatchers handle incident management. Table 2-20 below shows that 42.2 percent state that dispatchers act in a support function to road supervisors who are in the lead. However, 26.7 percent of respondents indicated dispatchers have primary responsibility for managing incidents and 26.7 percent indicated that primary responsibility can be either a dispatcher or a road supervisor. Table 2-20 below displays Incident Management by question.

Table 2-20

How Incident Management Is Handled

\begin{tabular}{|l|c|c|}
\hline \multicolumn{1}{|c|}{ Response } & Number & Percent \\
\hline $\begin{array}{l}\text { Dispatchers have the lead } \\
\text { responsibility for road cals, accidents, } \\
\text { and other incidents with support from } \\
\text { road supervisors }\end{array}$ & 12 & $26.67 \%$ \\
\hline $\begin{array}{l}\text { Dispatchers act in a support function to } \\
\text { road supervisors who are the lead. }\end{array}$ & 19 & $42.22 \%$ \\
\hline $\begin{array}{l}\text { Primary responsibility for incident } \\
\text { management may at times be either a } \\
\text { dispatcher or road supervisor. }\end{array}$ & 12 & $26.67 \%$ \\
\hline Other & 2 & $4.44 \%$ \\
\hline Total & 45 & $100.00 \%$ \\
\hline
\end{tabular}

When comparing the results of this question by transit agency, there is considerable variation in how respondents interpreted this question. LeeTran, MCAT, and PalmTran had respondents who answered all three options for incident management while PSTA and RTS had respondents who picked two of the three. From the perspective of respondents, it is possible that based on the situation and/or the incident, all three options could be true at one time or another. Table 221 below displays Incident Management by Transit Agency. 
Table 2-21

Incident Management by Transit Agency

\begin{tabular}{|c|c|c|c|c|c|c|c|c|c|}
\hline Incident Management & $\begin{array}{l}\text { Bay Town } \\
\text { Trolley }\end{array}$ & HART & LeeTran & MCAT & MDT & PalmTran & PSTA & RTS & Votran \\
\hline $\begin{array}{c}\text { Dispatchers have the lead responsibility for } \\
\text { road cals, accidents, and other incidents with } \\
\text { support from road supervisors. }\end{array}$ & $0.0 \%$ & $100.0 \%$ & $22.2 \%$ & $25.0 \%$ & $\begin{array}{c}0 \\
0.0 \% \\
\end{array}$ & $12.5 \%$ & $\begin{array}{c}4 \\
66.7 \% \\
\end{array}$ & $\begin{array}{r}4 \\
66.6 \% \\
\end{array}$ & $\begin{array}{c}0 \\
0.0 \% \\
\end{array}$ \\
\hline $\begin{array}{c}\text { Dispatchers act in a support function to road } \\
\text { supervisors who are the lead. }\end{array}$ & $\begin{array}{c}1 \\
100.0 \%\end{array}$ & $\begin{array}{c}0 \\
0.0 \%\end{array}$ & $\begin{array}{c}2 \\
22.2 \%\end{array}$ & $\begin{array}{c}1 \\
25.0 \%\end{array}$ & $\begin{array}{c}3 \\
75.0 \%\end{array}$ & $\begin{array}{c}4 \\
50.0 \%\end{array}$ & $\begin{array}{c}1 \\
16.7 \%\end{array}$ & $\begin{array}{c}1 \\
16.7 \%\end{array}$ & $\begin{array}{c}3 \\
100.0 \%\end{array}$ \\
\hline $\begin{array}{l}\text { Primary responsibility for incident } \\
\text { management may at times be either a } \\
\text { dispatcher or road supervisor. }\end{array}$ & $\begin{array}{c}0 \\
0.0 \%\end{array}$ & $\begin{array}{c}0 \\
0.0 \%\end{array}$ & $\begin{array}{c}5 \\
55.6 \%\end{array}$ & 2 & $\begin{array}{c}0 \\
0.0 \%\end{array}$ & $\begin{array}{c}3 \\
37.5 \%\end{array}$ & $\begin{array}{c}0 \\
0.0 \%\end{array}$ & $\begin{array}{c}0 \\
0.0 \%\end{array}$ & $\begin{array}{c}0 \\
0.0 \%\end{array}$ \\
\hline Other & $\begin{array}{c}0 \\
0.0 \% \\
\end{array}$ & $\begin{array}{c}0 \\
0.0 \% \\
\end{array}$ & $\begin{array}{c}0 \\
0.0 \% \\
\end{array}$ & $\begin{array}{c}0 \\
0.0 \% \\
\end{array}$ & $\begin{array}{c}1 \\
25.0 \% \\
\end{array}$ & $\begin{array}{c}0 \\
0.0 \% \\
\end{array}$ & $\begin{array}{c}1 \\
16.7 \% \\
\end{array}$ & $\begin{array}{c}1 \\
16.7 \% \\
\end{array}$ & $\begin{array}{c}0 \\
0.0 \% \\
\end{array}$ \\
\hline Total & $\begin{array}{c}1 \\
100 \%\end{array}$ & $\begin{array}{c}1 \\
100 \%\end{array}$ & $\begin{array}{c}9 \\
100 \%\end{array}$ & $\begin{array}{c}4 \\
100 \%\end{array}$ & $\begin{array}{c}4 \\
100 \%\end{array}$ & $\begin{array}{c}8 \\
100 \%\end{array}$ & $\begin{array}{c}6 \\
100 \%\end{array}$ & $\begin{array}{c}6 \\
100 \%\end{array}$ & $\begin{array}{c}3 \\
100 \%\end{array}$ \\
\hline
\end{tabular}

The next question in the survey dealt with extraboard and overtime management. One finding from the Best Practices in Extraboard Management study is that sizing the extraboard work force can have a major impact on overtime. Too few extraboard operators will result in more overtime while too many extraboard operators will result in higher costs and lower productivity for the agency. Therefore, it is important to know the degree to which Dispatch plays a role in extraboard and overtime management. A majority of respondents, 55 percent, indicate that dispatchers do have total management authority for extraboard and overtime assignments while 27.5 percent indicated that dispatchers have no authority. Another 12.5 percent reported that dispatchers must coordinate with Operations Managers for overtime assignments. Table 2-22 below displays the results for this question. Table 2-23 displays the results by transit agency.

Table 2-22

Extraboard and Overtime Management

\begin{tabular}{|l|c|c|}
\hline \multicolumn{1}{|c|}{ Extraboard and Overtime Management } & Number & Percent \\
\hline $\begin{array}{l}\text { Dispatchers have total management } \\
\text { authority for extra-board and overtime } \\
\text { assignments }\end{array}$ & 22 & $55.00 \%$ \\
\hline $\begin{array}{l}\text { Dispatchers must coordinate with Operations } \\
\text { Managers on overtime assignments }\end{array}$ & 5 & $12.50 \%$ \\
\hline $\begin{array}{l}\text { Dispatchers have no management authority } \\
\text { for overtime assignments }\end{array}$ & 11 & $27.50 \%$ \\
\hline Other & 2 & $5.00 \%$ \\
\hline Total & 40 & $100.00 \%$ \\
\hline
\end{tabular}


Table 2-23

Extraboard and Overtime Management by Transit Agency

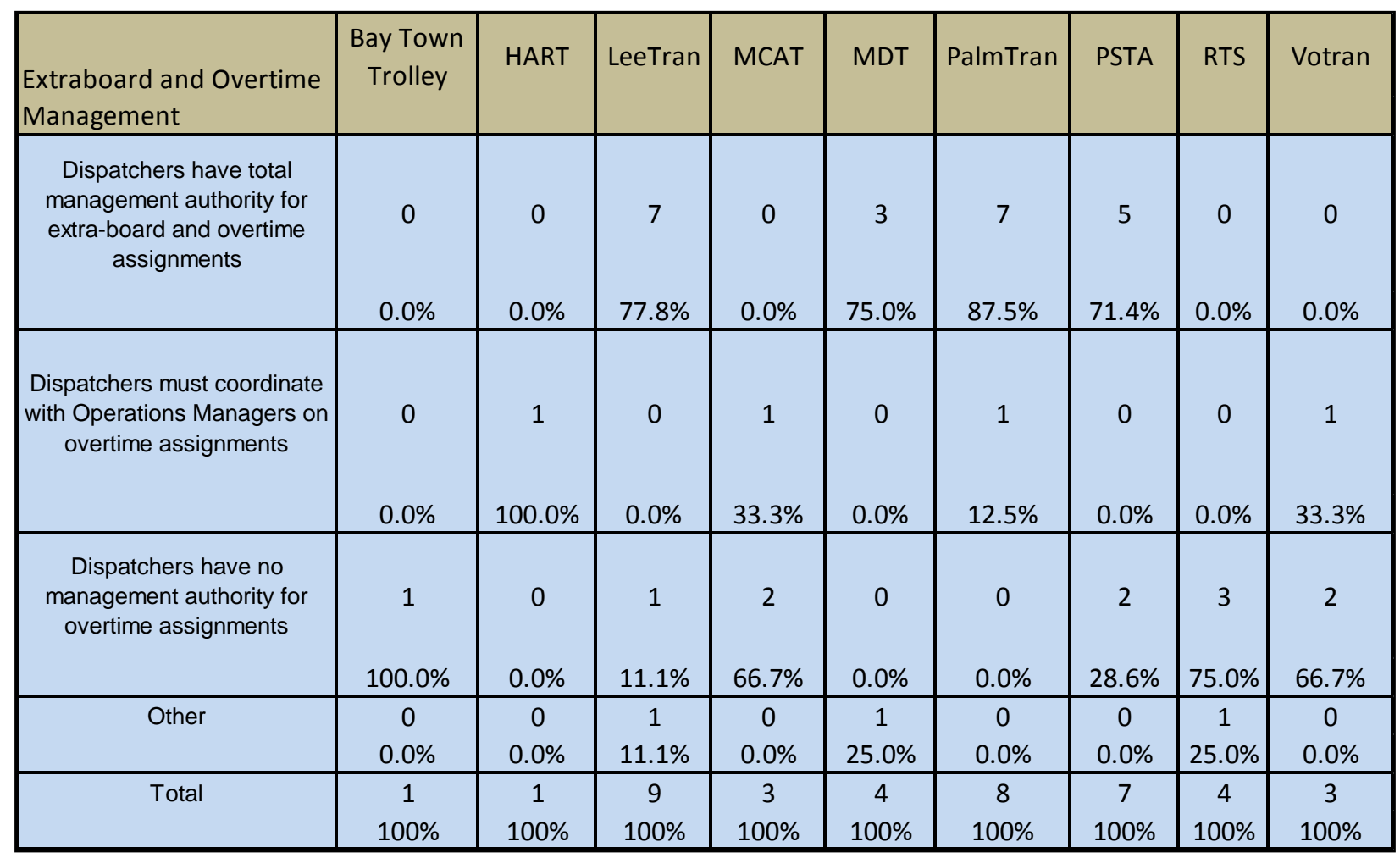

The next question dealt with whether the size of the extraboard workforce is sufficient from the perspective of dispatchers. A majority, 54 percent, stated that they have too few extraboard while 39 percent stated the size of the extraboard is at the right number. Only 7 percent indicate they have too many extraboard operators. Bay Town Trolley, MCAT, Miami Dade Transit, PSTA, and RTS are in agreement that they have too few extraboard while LeeTran, MCAT and VOTRAN are split on the subject. Only respondents from PalmTran consistently agree that the extraboard is the right size. Table 2-24 below displays the results for this question, Table 2-25 displays Extraboard Size by Transit Agency.

Table 2-24

Extraboard Size

\begin{tabular}{|l|c|c|}
\hline \multicolumn{1}{|c|}{ Extraboard Size } & Number & Percent \\
\hline Too few extra board & 22 & $53.66 \%$ \\
\hline $\begin{array}{l}\text { Just the right number of extra } \\
\text { board }\end{array}$ & 16 & $39.02 \%$ \\
\hline Too many extra board & 3 & $7.32 \%$ \\
\hline Total & 41 & $100.00 \%$ \\
\hline
\end{tabular}


Table 2-25

Extraboard Size by Transit Agency

\begin{tabular}{|c|c|c|c|c|c|c|c|c|c|}
\hline & $\begin{array}{c}\text { Bay Town } \\
\text { Trolley }\end{array}$ & HART & LeeTran & MCAT & MDT & PalmTran & PSTA & RTS & Votran \\
Extraboard Size & 1 & 0 & 3 & 2 & 3 & 1 & 5 & 4 & 3 \\
\hline Too few extra board & $\begin{array}{c}100.0 \% \\
0.0 \%\end{array}$ & $37.5 \%$ & $66.7 \%$ & $100.0 \%$ & $12.5 \%$ & $71.4 \%$ & $100.0 \%$ & $50.0 \%$ \\
\hline $\begin{array}{c}\text { Just the right } \\
\text { number of extra } \\
\text { board }\end{array}$ & 0 & 1 & 5 & 1 & 0 & 7 & 2 & 0 & 0 \\
\hline $\begin{array}{c}\text { Too many extra } \\
\text { board }\end{array}$ & 0 & 0 & 0 & 0 & 0 & 0 & 0 & 0 & 3 \\
\hline Total & $10.0 \%$ & $62.5 \%$ & $33.3 \%$ & $0.0 \%$ & $87.5 \%$ & $28.6 \%$ & $0.0 \%$ & $0.0 \%$ \\
\hline & $100 \%$ & $100 \%$ & $100 \%$ & $100 \%$ & $100 \%$ & $100 \%$ & $100 \%$ & $100 \%$ & $100 \%$ \\
\hline
\end{tabular}

A common problem facing all transit agencies is the means by which Maintenance communicates with Operations regarding vehicle availability. There is the usual practice of Maintenance pulling coaches for PMs or repairs for the entire service day. However, there are also real time incidents that can occur that will cause a coach to be pulled from service. Because the research team has worked in many operations environments over the years through other projects, it has been observed that some systems are very efficient in communications while others have major problems with communication between Maintenance and Operations. Question 17 was designed to ascertain the means of communication. While 37 percent indicate vehicle availability is communicated by phone, 21 percent indicate that communication is via e-mail or messaging system and 15 percent by a log management software. However, 27 percent responded, "Other" for this question. As such, the "other" responses are presented below. Table 2-26 shows the response to this question. Table 2-27 displays the Maintenance Communications for Vehicle Availability by Transit Agency. 
Table 2-26

Maintenance Communication - Vehicle Availability

\begin{tabular}{|l|c|c|}
\hline \multicolumn{1}{|c|}{$\begin{array}{c}\text { Maintenance Communication - Vehicle } \\
\text { Availability }\end{array}$} & Number & Percent \\
\hline Phone Call & 18 & $37.50 \%$ \\
\hline Email or messaging system & 10 & $20.83 \%$ \\
\hline $\begin{array}{l}\text { Lot management or maintenance computer } \\
\text { software }\end{array}$ & 7 & $14.58 \%$ \\
\hline Other & 13 & $27.08 \%$ \\
\hline Total & 48 & $100.00 \%$ \\
\hline
\end{tabular}

Table 2-27

Maintenance Communication - Vehicle Availability by Transit Agency

\begin{tabular}{|c|c|c|c|c|c|c|c|c|c|}
\hline $\begin{array}{l}\text { Maintenance } \\
\begin{array}{l}\text { Communication - } \\
\text { Vehicle Availability }\end{array}\end{array}$ & $\begin{array}{c}\text { Bay Town } \\
\text { Trolley }\end{array}$ & HART & LeeTran & MCAT & MDT & PalmTran & PSTA & RTS & Votran \\
\hline Phone Call & 1 & 0 & 1 & 1 & 1 & 3 & 5 & 3 & 0 \\
& $50.0 \%$ & $0.0 \%$ & $12.5 \%$ & $33.3 \%$ & $33.3 \%$ & $27.3 \%$ & $71.4 \%$ & $42.9 \%$ & $0.0 \%$ \\
\hline $\begin{array}{c}\text { Email or messaging } \\
\text { system }\end{array}$ & 0 & 0 & 0 & 0 & 0 & 5 & 0 & 2 & 3 \\
\hline $\begin{array}{c}\text { Lot management or } \\
\text { maintenance computer } \\
\text { software }\end{array}$ & $0.0 \%$ & $0.0 \%$ & $0.0 \%$ & $0.0 \%$ & $0.0 \%$ & $45.5 \%$ & $0.0 \%$ & $28.6 \%$ & $100.0 \%$ \\
\hline Other & $0.0 \%$ & $0.0 \%$ & $0.0 \%$ & $33.3 \%$ & $33.3 \%$ & $18.2 \%$ & $0.0 \%$ & $14.3 \%$ & $0.0 \%$ \\
\hline Total & 1 & 1 & 7 & 1 & 1 & 1 & 2 & 1 & 0 \\
& $50.0 \%$ & $100.0 \%$ & $87.5 \%$ & $33.3 \%$ & $33.3 \%$ & $9.1 \%$ & $28.6 \%$ & $14.3 \%$ & $0.0 \%$ \\
\hline & $100 \%$ & 1 & 8 & 3 & 3 & 11 & 7 & 7 & 3 \\
& $100 \%$ & $100 \%$ & $100 \%$ & $100 \%$ & $100 \%$ & $700 \%$ & $100 \%$ & $100 \%$ \\
\hline
\end{tabular}

The "other" responses are presented below, unedited:

- Also a paper form which is used daily and delivered by hand.

- Availability sheet

- Stacking list in AM

- They return the buses and leave the keys

- Info sheet

- Verbally

- Hand held radio

- We have to contact maintenance for vehicle availability

- Face to Face communication

- Yard sheet 
- Verbal or written forms

- Either dispatch or maintenance verbally informs on a regular basis

- Hard copy

- Walk in/person to person

- Dispatcher checks yard

Question 18 then probed the topic to determine how frequently communications take place between Maintenance and Dispatch regarding vehicle availability. Table 2-28 below shows that 52 percent indicate information is communicated in real time and 36 percent indicate that vehicle status information is provided inconsistently. Table 2-29 below displays the frequency of maintenance communication by Transit Agency.

Table 2-28

\section{Frequency of Maintenance Communication}

\begin{tabular}{|l|c|c|}
\hline Frequency of Maintenance Communication & Number & Percent \\
\hline In real time or as they become available & 22 & $52.38 \%$ \\
\hline Hourly & 0 & $0.00 \%$ \\
\hline Daily & 5 & $11.90 \%$ \\
\hline $\begin{array}{l}\text { Vehicle status information is provided } \\
\text { inconsistently }\end{array}$ & 15 & $35.71 \%$ \\
\hline Total & 42 & $100.00 \%$ \\
\hline
\end{tabular}

Table 2-29

Frequency of Maintenance Communication by Transit Agency

\begin{tabular}{|c|c|c|c|c|c|c|c|c|c|}
\hline $\begin{array}{l}\text { Frequency of } \\
\text { Maintenance } \\
\text { Communication }\end{array}$ & $\begin{array}{c}\text { Bay Town } \\
\text { Trolley }\end{array}$ & HART & LeeTran & MCAT & MDT & PalmTran & PSTA & RTS & Votran \\
\hline $\begin{array}{c}\text { In real time or as they become } \\
\text { available }\end{array}$ & $\begin{array}{c}1 \\
100.0 \% \\
\end{array}$ & $\begin{array}{c}1 \\
100.0 \% \\
\end{array}$ & $\begin{array}{c}2 \\
22.2 \% \\
\end{array}$ & $\begin{array}{c}1 \\
33.3 \% \\
\end{array}$ & $\begin{array}{c}2 \\
66.7 \% \\
\end{array}$ & $\begin{array}{c}3 \\
37.5 \% \\
\end{array}$ & $\begin{array}{c}7 \\
77.8 \% \\
\end{array}$ & $\begin{array}{c}3 \\
75.0 \% \\
\end{array}$ & $\begin{array}{c}3 \\
100.0 \% \\
\end{array}$ \\
\hline Hourly & $\begin{array}{c}0 \\
0.0 \% \\
\end{array}$ & $\begin{array}{c}0 \\
0.0 \% \\
\end{array}$ & $\begin{array}{c}0 \\
0.0 \% \\
\end{array}$ & $\begin{array}{c}0 \\
0.0 \%\end{array}$ & $\begin{array}{c}0 \\
0.0 \%\end{array}$ & $\begin{array}{c}0 \\
0.0 \% \\
\end{array}$ & $\begin{array}{c}0 \\
0.0 \% \\
\end{array}$ & $\begin{array}{c}0 \\
0.0 \% \\
\end{array}$ & $\begin{array}{c}0 \\
0.0 \% \\
\end{array}$ \\
\hline Daily & $\begin{array}{c}0 \\
0.0 \% \\
\end{array}$ & $\begin{array}{c}0 \\
0.0 \% \\
\end{array}$ & \begin{tabular}{c|}
2 \\
$22.2 \%$ \\
\end{tabular} & $\begin{array}{c}0 \\
0.0 \%\end{array}$ & $\begin{array}{c}0 \\
0.0 \% \\
\end{array}$ & $\begin{array}{c}3 \\
37.5 \% \\
\end{array}$ & $\begin{array}{c}0 \\
0.0 \% \\
\end{array}$ & $\begin{array}{c}0 \\
0.0 \% \\
\end{array}$ & $\begin{array}{c}0 \\
0.0 \% \\
\end{array}$ \\
\hline $\begin{array}{l}\text { Vehicle status information is } \\
\text { provided inconsistently }\end{array}$ & $\begin{array}{c}0 \\
0.0 \% \\
\end{array}$ & $\begin{array}{c}0 \\
0.0 \% \\
\end{array}$ & $\begin{array}{c}5 \\
55.6 \% \\
\end{array}$ & $\begin{array}{c}2 \\
66.7 \% \\
\end{array}$ & $\begin{array}{c}1 \\
33.3 \% \\
\end{array}$ & $\begin{array}{c}2 \\
25.0 \% \\
\end{array}$ & $\begin{array}{c}2 \\
22.2 \% \\
\end{array}$ & $\begin{array}{c}1 \\
25.0 \% \\
\end{array}$ & $\begin{array}{c}0 \\
0.0 \% \\
\end{array}$ \\
\hline Total & $\begin{array}{c}1 \\
100 \%\end{array}$ & $\begin{array}{c}1 \\
100 \%\end{array}$ & $\begin{array}{c}9 \\
100 \%\end{array}$ & $\begin{array}{c}3 \\
100 \%\end{array}$ & $\begin{array}{c}3 \\
100 \%\end{array}$ & $\begin{array}{c}8 \\
100 \%\end{array}$ & $\begin{array}{c}9 \\
100 \%\end{array}$ & $\begin{array}{c}4 \\
100 \%\end{array}$ & $\begin{array}{c}3 \\
100 \%\end{array}$ \\
\hline
\end{tabular}


In retrospect, in order for Question 19 to be effective, there should have been an initial question asking respondents if they have a view of the bus parking lot. However, as probed, the question asked respondents if it would be helpful to have lot visibility. Eighty percent of respondents indicated that lot visibility "would be" helpful, but presumably many of them know that because they already have lot visibility.

Table 2-30

Helpfulness of Lot Visibility

\begin{tabular}{|l|c|c|}
\hline \multicolumn{1}{|c|}{ Helpfulness of Lot Visibility } & Number & Percent \\
\hline Yes & 31 & $79.5 \%$ \\
\hline No & 3 & $7.7 \%$ \\
\hline It isnt necessary & 5 & $12.8 \%$ \\
\hline Total & 39 & $100.0 \%$ \\
\hline
\end{tabular}

Question 20 asked respondents to identify ITS technologies available to them in their dispatch functions. Since respondents could give multiple answers, there is no simple frequency table for this question. The research team compiled all of the ITS technologies at the agency level and Table 2-31 displays the results. For the most part, the state of technological advancement has been very good with the Florida transit agencies that responded. LeeTran, MCAT, PalmTran, PSTA, and VOTRAN reported having most or all of the tools contained in the question. Only Bay Town Trolley, which is a very small system, does not possess most of the tools available.

Table 2-31

ITS Technologies Available to Dispatchers

\begin{tabular}{|c|c|c|c|c|c|c|c|c|c|}
\hline $\begin{array}{l}\text { ITS available } \\
\text { to Dispatchers }\end{array}$ & $\begin{array}{c}\text { Bay Town } \\
\text { Trolley }\end{array}$ & HART & LeeTran & MCAT & MDT & PalmTran & PSTA & RTS & Votran \\
\hline $\begin{array}{c}\text { Radio or phone } \\
\text { communication }\end{array}$ & $\checkmark$ & $\checkmark$ & $\checkmark$ & $\checkmark$ & $\checkmark$ & $\checkmark$ & $\checkmark$ & $\checkmark$ & $\checkmark$ \\
\hline Lot Management & & & $\checkmark$ & $\checkmark$ & $\checkmark$ & $\checkmark$ & $\checkmark$ & & \\
\hline Scheduling Systems & & $\checkmark$ & $\checkmark$ & $\checkmark$ & $\checkmark$ & $\checkmark$ & $\checkmark$ & $\checkmark$ & $\checkmark$ \\
\hline $\begin{array}{c}\text { Automatic Vehicle } \\
\text { Location }\end{array}$ & & $\checkmark$ & $\checkmark$ & $\checkmark$ & $\checkmark$ & $\checkmark$ & $\checkmark$ & $\checkmark$ & $\checkmark$ \\
\hline $\begin{array}{c}\text { Computer Aided } \\
\text { Dispatch }\end{array}$ & & $\checkmark$ & $\checkmark$ & $\checkmark$ & $\checkmark$ & $\checkmark$ & $\checkmark$ & $\checkmark$ & $\checkmark$ \\
\hline Cameras & $\checkmark$ & $\checkmark$ & $\checkmark$ & $\checkmark$ & & $\checkmark$ & $\checkmark$ & $\checkmark$ & $\checkmark$ \\
\hline Real Time Arrivals & & & $\checkmark$ & $\checkmark$ & $\checkmark$ & $\checkmark$ & $\checkmark$ & & $\checkmark$ \\
\hline Trip Planning & & & $\checkmark$ & $\checkmark$ & & $\checkmark$ & $\checkmark$ & & \\
\hline $\begin{array}{c}\text { Covert Emergency } \\
\text { Alarms }\end{array}$ & & $\checkmark$ & $\checkmark$ & $\checkmark$ & & $\checkmark$ & $\checkmark$ & $\checkmark$ & $\checkmark$ \\
\hline Vehicle Alarms & & $\checkmark$ & & $\checkmark$ & & $\checkmark$ & $\checkmark$ & & $\checkmark$ \\
\hline
\end{tabular}


Question 21 asked if transit agencies are using mobile dispatching, defined as supervisor vehicles equipped with CAD/AVL. Seventy percent of respondents responded in the affirmative for mobile dispatching. Table 2-32 displays the results of this question, and Table 2-33 displays mobile dispatching by transit agency. HART, Miami-Dade, PalmTran, PSTA, RTS, and VOTRAN most consistently responded affirmatively that they utilize mobile dispatch.

Table 2-32

Use of Mobile Dispatching (Supervisor vehicles equipped with CAD/AVL)

\begin{tabular}{|l|c|c|}
\hline \multicolumn{1}{|c|}{ Response } & Number & Percent \\
\hline Yes & 23 & $69.7 \%$ \\
\hline No & 10 & $30.3 \%$ \\
\hline Total & 33 & $100.0 \%$ \\
\hline
\end{tabular}

Table 2-33

Use of Mobile Dispatching (Supervisor vehicles equipped with CAD/AVL) by Transit Agency

\begin{tabular}{|c|c|c|c|c|c|c|c|c|c|}
\hline $\begin{array}{c}\text { Mobile } \\
\text { Dispatching }\end{array}$ & $\begin{array}{c}\text { Bay } \\
\text { Town }\end{array}$ & HART & LeeTran & MCAT & MDT & PalmTran & PSTA & RTS & Votran \\
\hline Yes & $\begin{array}{c}0 \\
0.0 \%\end{array}$ & $100 \%$ & $28.6 \%$ & $66.7 \%$ & $100.0 \%$ & $85.7 \%$ & $85.7 \%$ & $\begin{array}{c}75.0 \% \\
100.0 \%\end{array}$ \\
\hline No & 1 & 0 & 5 & 1 & 0 & 1 & 1 & 1 & 0 \\
& $100.0 \%$ & $0.0 \%$ & $71.4 \%$ & $33.3 \%$ & $0.0 \%$ & $14.3 \%$ & $14.3 \%$ & $25.0 \%$ & $0.0 \%$ \\
\hline Total & 1 & 1 & 7 & 3 & 3 & 7 & 7 & 4 & 3 \\
& $100 \%$ & $100 \%$ & $100 \%$ & $100 \%$ & $100 \%$ & $100 \%$ & $100 \%$ & $100.0 \%$ & $100 \%$ \\
\hline
\end{tabular}

Question 22 asked respondents to identify the vendor of their dispatching software and rate the usability based on a 1 to 10 scale, with 10 being the easiest to use. Of the 32 responses to this question, some respondents identified their product with no rating, some providing a rating but no product, and some provided product and rating. The companies and/or products listed by respondents are as follows:

- Transloc

- Centracom Elite Dispatch

- Trapeze

- Route Match

- Orbital

- Motorola 
- Avail

- Hastus

- TOS

- Transched Teledriver

- Clever Device

- Hastus

Only two of the companies/products listed above received a rating of 6 or below. Virtually all of the other listed companies/products received a 7 or above. The average rating for all systems was 7.1.

At the outset of this study, the research team had a very difficult time obtaining standard operating manuals and training materials for dispatchers. Question 23 asked respondents to indicate how they were trained for their present position. Seventy-one percent of respondents indicated they were trained on the job with only 20 percent indicating they received training prior to starting the job. This is consistent with the same notion that was found in the Best Practices in Extraboard Management study, which found that most agencies size their extraboard based on historical practices within operations. Apparently, the same is true with dispatch where the profession continues from one generation to the next through verbal and on-the-job training. Table 2-34 below displays the result for this question and Table 2-35 displays how dispatchers are trained by transit agency.

Table 2-34

How Dispatchers Are Trained

\begin{tabular}{|l|c|c|}
\hline \multicolumn{1}{|c|}{ Response } & Number & Percent \\
\hline On the job & 32 & $71.11 \%$ \\
\hline $\begin{array}{l}\text { Agency provided separate } \\
\text { training before dispatch duties } \\
\text { began. }\end{array}$ & 9 & $20.00 \%$ \\
\hline Other & 4 & $8.89 \%$ \\
\hline Total & 45 & $100.00 \%$ \\
\hline
\end{tabular}


Table 2-35

How Dispatchers Are Trained by Transit Agency

\begin{tabular}{|c|c|c|c|c|c|c|c|c|c|}
\hline How were you trained? & $\begin{array}{c}\text { Bay Town } \\
\text { Trolley }\end{array}$ & HART & LeeTran & MCAT & MDT & PalmTran & PSTA & RTS & Votran \\
\hline On the job & 1 & 1 & 7 & 3 & 3 & 7 & 6 & 2 & 3 \\
& $50.0 \%$ & $100.0 \%$ & $77.8 \%$ & $75.0 \%$ & $75.0 \%$ & $100.0 \%$ & $60.0 \%$ & $50.0 \%$ & $60.0 \%$ \\
\hline $\begin{array}{c}\text { Agency provided separate } \\
\text { training before dispatch } \\
\text { duties began }\end{array}$ & 1 & 0 & 0 & 1 & 1 & 0 & 2 & 2 & 2 \\
\hline Other & $50.0 \%$ & $0.0 \%$ & $0.0 \%$ & $25.0 \%$ & $25.0 \%$ & $0.0 \%$ & $20.0 \%$ & $50.0 \%$ & $40.0 \%$ \\
\hline Total & 0 & 0 & 2 & 0 & 0 & 0 & 2 & 0 & 0 \\
& $0.0 \%$ & $0.0 \%$ & $22.2 \%$ & $0.0 \%$ & $0.0 \%$ & $0.0 \%$ & $20.0 \%$ & $0.0 \%$ & $0.0 \%$ \\
\hline & $100 \%$ & $100 \%$ & $100 \%$ & $100 \%$ & $100 \%$ & $100 \%$ & $100 \%$ & $100 \%$ & $100 \%$ \\
\hline
\end{tabular}

Question 24 asked respondents to indicate whether dispatchers are trained in the same way and if no, how are they different? With few exceptions, most respondents just provided a "Yes" or "No" response. Of the 36 responses, 30 were "Yes," dispatchers are trained in the same way and 6 responded, "No," they are not.

Question 25 asked respondents to provide the length of their shifts and Question 26 asked respondents to react to the length of those trips in terms of satisfaction. A total of 39 percent of respondents indicated their shift is 8 hours, with 32 percent reporting 8 to 10 hours and 23 percent reporting 10 hour shifts. Ninety-one percent of respondents indicated their shift lengths are just right. Table 2-36 below displays the breakdown in shifts and Table 2-37 displays overall satisfaction with shift lengths.

Table 2-36

Breakdown of Shifts

\begin{tabular}{|c|r|r|}
\hline Hours in Shift & Number & Percent \\
\hline 8 Hours & 12 & $38.7 \%$ \\
\hline 9 Hours & 2 & $6.5 \%$ \\
\hline 8 to 10 Hours & 10 & $32.3 \%$ \\
\hline 10 Hours & 7 & $22.6 \%$ \\
\hline Total & 31 & $100.0 \%$ \\
\hline
\end{tabular}


Table 2-37

\section{Reaction to Length of Shifts}

\begin{tabular}{|l|r|r|}
\hline \multicolumn{1}{|c|}{ Response } & Number & \multicolumn{1}{|c|}{ Percent } \\
\hline Too long & 1 & $2.9 \%$ \\
\hline Too short & 2 & $5.7 \%$ \\
\hline Just right & 32 & $91.4 \%$ \\
\hline Total & 35 & $100.0 \%$ \\
\hline
\end{tabular}

\section{Best Working Practices}

Question 27 asked respondents to list up to three best working practices of their respective agencies dispatch. Below is a list of responses. The research team only deemed one response to be inappropriate for publication.

- Good interaction w/maintenance. Tansloc is a good, too. Access to traffic cams is helpful.

- Sign in procedures, stand-by drivers, extra board assignments.

- Teamwork in dispatch, text to bus communication, promoting from within the organization.

- $\quad \mathrm{VVL}$, Radio, On-time performance.

- Communication, schedule software.

- $A V L$, radio, real time performance.

- Dispatch is primary radio communication to coordinate with other necessary individuals to resolve issues.

- 24-hour Service Customer service (Inner) On Time Performance.

- Being able to multi-function.

- Great training, Scheduling works with unassigned people, Management staff that tries to work with everyone as much as possible.

- Fit for duty inspections of drivers before pull-out, Accident-Incident management, Schedule adherence management.

- None at this time as we have no one assigned to Dispatch.

- The hours.

- Plain English communication. 2) Dispatch is where the drivers report. 3) Knowledge of dispatchers knowing all the routes.

- My shift changes around but it works good for me and they try to make sure we are always covered and they are quick to respond.

- We all have shared responsibilities 2) We all work either on the road or in the office 3) Very good communication between supervisors \& manager.

- Emergency response operator, support bus trade outs.

- Bus assigning, Covering open work with standbys, Payroll entry. 
- Use of stand-by drivers in buses, Flexibility of responsibilities, Flexibility of work schedule.

\section{Areas of Desired Improvement}

Question 28 asked respondents to indicate three things they would like to see improved. Better communication between management and Maintenance are two often cited areas of improvement as well as upgrades to technology. Below are the responses with minimal editing.

- Put radio in its own room, to reduce distractions and background noise. 2 . Rule against calling out operator's names over the radio or calling operators out for mistakes over the radio. 3. Creating a bus list every night with actual bus assignments and scheduled return times, catching changes that went unlogged during busy times of day.

- Control of fare media (all day passes)-returning and reporting is somewhat lax, making purchasing more difficult. 2 . Lack of supervision at window is leading to a lot of disciplinary problems. This is why most other agencies assign a supervisor to do this function. 3. Miscommunications about equipment availability between operations and maintenance have caused any number of headaches. What is needed is a shared fleet management system with excellent uptime. Instead we have a mixture of paper logs, Post-it notes, phone calls, a mishmash of unreliable computer systems without consistent shared access, poor record keeping, and gaps in communication.

- Communication between management, supervisors and dispatchers. When we get an emergency alert from a driver by radio I would like to be able to hear only what is going on that particular bus while I triage the situation.

- Having better communication between management and supervisors. Implementation of new and updated ideas to better manage the everyday operations of dispatch. Holding everyone accountable in order to get the job done right the first time.

- 2 dispatchers on duty, more computer automation for rotation of extra board. communication area of our facility.

- Communication from management about upcoming events, video feeds from all transit centers, consistency in discipline of operators.

- Additional staffing during peak hours on the radio system.

- Keep the driver off of dispatch, less talking on the radios.

- More buses, more drivers, less people calling out.

- Info given better communications between shop and dispatch.

- None I can think of off hand.

- Separate customer service from dispatch. 
- Allow the supervisor to enforce the contract. Receive backup from the manager. Replace the manager and director.

- Procedures in filling work/More Standbys/Better Training.

- Dispatchers need more training equipment.

- Distribution of schedule cards automated phone answering system more user friendly dispatch program.

- The computer software.

- Supervisors only doing dispatch. Road supervisors handle road situations/dispatch handle yard \& office situations. More cross training and every supervisor required to do at least 10 hours per week road duty instead of residing at base all day.

- Communication from maintenance personnel about vehicle availability AVL Closed radio communication system

- Have someone assigned to dispatch. Dispatch located in a different area. Supervisor assigned to dispatch. We use light duty personnel.

- Better computer program. More sound proofing because at shift change it gets noisy.

- More time on the routes. a higher spare ratio get the customer phone calls out of dispatch

- Separate radio room 2) Area to privately talk to drivers instead of talking to driver in parking lot or hallway 3 ) Have more private working area as drivers freely walk through area during shift change.

- Have customer calls go somewhere else instead if dispatch. The ability to use manpower without worrying about to much overtime. More help in dispatch, more dispatchers.

- New radios (hand held).

- Bus visibility in yard attendance tracking other supervisors working in position.

- Communication, Sharing data.

- Better control of office. Better video surveillance. Computer GPS on the buses. 


\section{SECTION THREE \\ CASE STUDIES}

At the conclusion of the survey, CUTR recommended to FDOT conducting case studies at one small transit agency and one medium-size transit agency. The two properties selected were VOTRAN in Daytona Beach, FL and PSTA in Clearwater/St. Petersburg, FL. Below is a description of each case study.

\section{VOTRAN Case Study}

As approved by FDOT, CUTR conducted observations of the VOTRAN dispatch office on January 19, 2011 from 5:15 a.m. to 5:15 p.m. An observation sheet was developed and supplied to VOTRAN in advance. VOTRAN's dispatchers were very welcoming and even asked what they could do to provide the maximum assistance to the project.

\section{Physical Dispatch Environment}

Dispatch is a complex consisting of three offices: the window office, where supervisors interact with operators, the fixed-route dispatch office with two mirror workstations, and the paratransit dispatch office with two mirror workstations. Observations took place in the fixed-route dispatch office.

\section{Functions of Dispatch}

Unlike many other transit systems of its type and size, dispatch does not operate both the window and communications. Window operations are a function of Supervision with the Lead Supervisor and road supervisors under that position. Dispatch is responsible for all radio communications with operators, all telephone communications including the shop, supervisors, the Westside supervisor, and customers (with one exception), and all Mobile Data Terminal (MDT) communications with bus operators. In addition to extraboard operations as discussed below, extraboard operators are used to assist with taking calls from passengers to assist with fixed-route transit information. However, when extraboard operators are not available, dispatchers must take calls from customers and provide route and schedule information.

Dispatch also monitors real-time service using an AVL/GPS and mapping software. The Avail system notifies dispatch, by color, when a bus is running early (red) and running late (gold). Dispatchers can send MDT messages to operators instructing them to watch their time. Dispatch also monitors buses in the vicinity of arriving at the main transfer facility. If a bus is running significantly late, Dispatch can notify the operators at the transfer facility to wait. 


\section{Technology}

The dispatch system program is an integrated platform developed by Avail Technologies for VOTRAN in 2007. Radio, data, and automatic vehicle location (AVL) systems with associated mapping were integrated by Avail. The dispatch radio and monitor is a Zetron console. On board buses are Motorola radios and Mentor Mobile Data Terminals (MDTs).

The Avail monitor contains a database of the coaches and operators and utilizing the AVL/GPS, the monitor signals the dispatcher that the bus is running early (with a red line through the coach entry) or late (with a gold line through the coach entry). If the bus is on time, there is no signal on the monitor. The dispatcher can then zoom into the location where the bus is located using the mapping monitor.

The Avail monitor is also used by operators to "Request to Talk (RTT)." Dispatchers can recognize operators in priority order. In fact, once the RTT is received the dispatcher can immediately collect information on the coach before responding to the call. Finally, the Avail system is used to send and receive Mobile Data Terminal communications. The dispatcher can either send a broadcast data message or a targeted data message. For instance, if an operator reports a hazard in the roadway on a particular corridor, the dispatcher can notify only those operators whose buses will be operating along that corridor of the hazard. Figure 3-1 below displays the Avail Dispatch and Mapping monitors.

\section{Figure 3-1 \\ Avail Dispatch System}

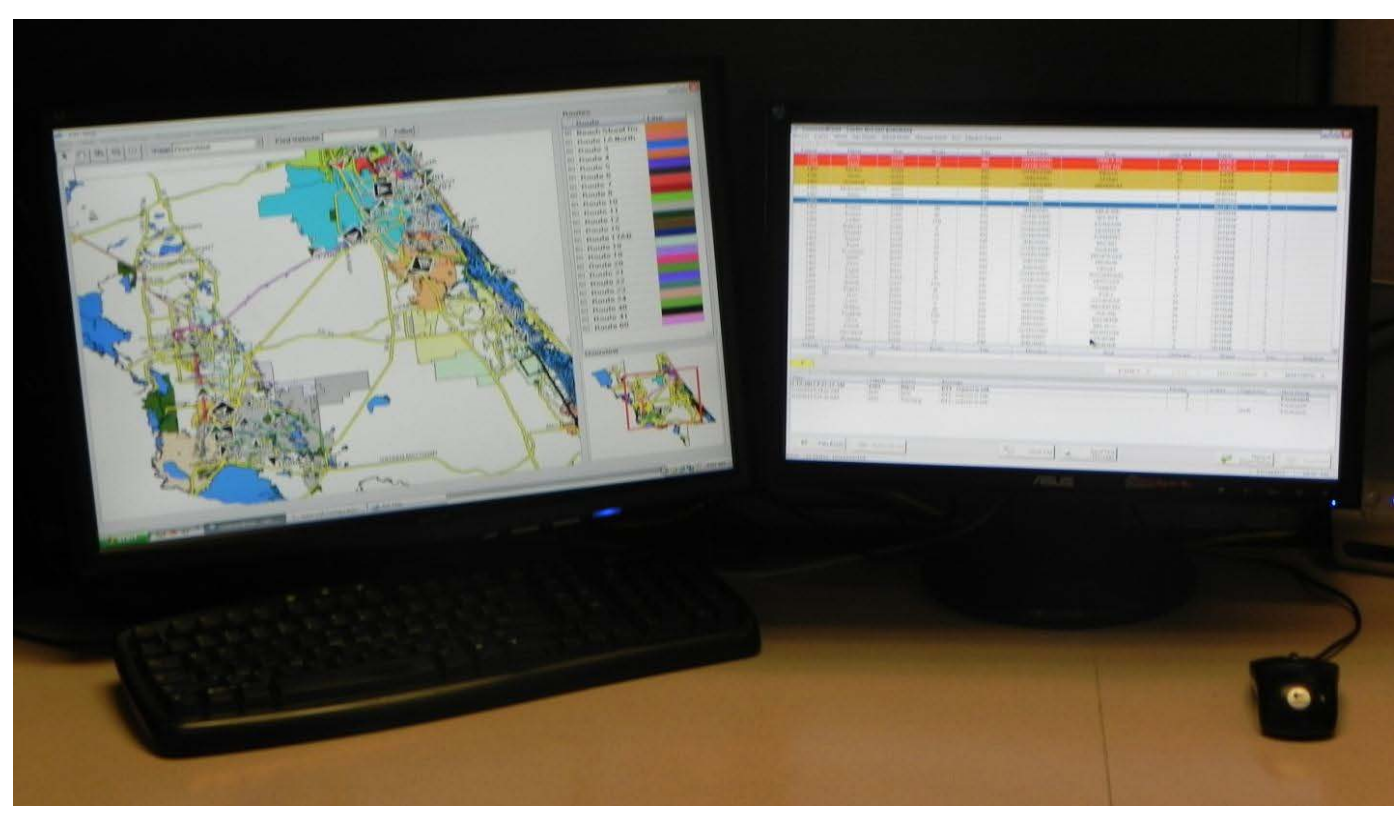




\section{Non-Automated Functions}

Unfortunately, VOTRAN did not consent to provide the research team with its Dispatch Manual which details all of the functions of Dispatch. As a result, it is impossible to chronicle all automated and non-automated functions. Only those that were garnered through observation can be discussed in this section.

Route and schedule information is included in a paper Rolodex console located next to the dispatcher's desk. When customers call for information, dispatchers can flip the console around to the route they need and then provide the time and location information for the passenger. However, a dispatcher will know from the Avail system if a bus is significantly off schedule and can therefore use the real time data to convey accurate information to the customer.

Curiously, although the Avail system does have a means to record wheelchair boardings in real time, currently there is no standard daily report automatically generated from the Avail system. Dispatch manually catalogues and maintains a record of wheelchair boardings for each service day.

Each day, Dispatch prepares an overall daily operations report for the Operations Manager. This is a form that is filled out manually by the dispatchers providing all of the incidents that are detailed in the Observations section below. The Avail system is very good for managing the traffic and volume of communications between operators, supervisors and dispatchers, but the substance of matters Dispatch handles must be recorded manually each day.

\section{Coach Availability}

With each bid, Operations randomly assigns coaches to the runs selected by operators for the entire bid period. From this, a form is made that is used daily and is also hard programmed into the Avail system. Each day, when the lead supervisor comes in, Maintenance provides the standard form with cross-outs for the buses they want to remove from service for that service day. The Lead Supervisor then changes both the operator sign-in sheet at the window and the Dispatch log. Therefore, Dispatchers have an accurate accounting of operator, coach, and run that is updated each morning.

Throughout the service day, Dispatch maintains a consolidated fixed-route defect log sheet. Every equipment problem reported throughout the service day is provided to maintenance at night. The shop then utilizes this report as a foundation for determining the desired coaches to remove from service the next day. This indicates a high degree of functioning between Operations and Maintenance relative to the availability of coaches. 


\section{Extraboard Operations}

VOTRAN maximizes the utilization of extraboard operators by maintaining a hierarchy of duties to be performed. As with most transit agencies, first and foremost the members of the extraboard are utilized to:

- Cover service runs due to absenteeism from vacation or sick operators; and

- Cover service runs or route segments based on equipment issues in the field.

Secondarily, extraboard operators are utilized to replace buses in service and/or in some cases plug service that needs to be operated during service interruptions. VOTRAN maintains a fleet of large cutaway buses that can be used in special circumstances to maintain service if larger coaches must be pulled.

Finally, if extraboard operators are not needed to cover service of any kind, they are placed at a station with a telephone to take calls from customers and provide route and schedule information.

\section{Road Calls}

VOTRAN recently revised its policies regarding road calls. In the past, road supervisors were empowered to request a road call, which entails dispatching a technician in the shop to either deliver a replacement coach to a location or to drive to the location in order to fix the equipment problem. However, the decision to send a technician from the shop has consequences for other functions Maintenance is attempting to accomplish during the service day. Therefore, the current policy is that field supervisors can request a road call, but the lead supervisor makes the final call on whether to dispatch a maintenance technician.

\section{Observations}

Observations were conducted in the VOTRAN Bus Dispatch office on January 19, 2012. A form was developed in MS Excel prior to the observations as a means of recording data. Not all columns in the form were used exactly as titled because events were dynamic and relevant information was placed in the cells. In general, the form included a place to record the following:

- Time frame

- Type of incident (window, radio, mobile data, telephone)

- Action/Activity

- Materials used

- Incident description

- Ten-codes used (VOTRAN does not use Ten-codes)

- Resolution 
A total of 147 separate observations were made between 5:30 a.m. and 5:15 p.m. Some observations were continulations of incidents that had developed earlier in the service day but were ongoing toward resolution. After the observations were completed, the research team divided the incidents into the following seventeen types. Table 3-1 displays the categories.

Table 3-1

Observation Categories

\begin{tabular}{|r|l|}
\hline Number & \multicolumn{1}{|c|}{ Observation Category } \\
\hline 1 & Radio/Communications Check \\
\hline 2 & Passenger call for transit information \\
\hline 3 & Equipment Incident Resolution \\
\hline 4 & Equipment Incident \\
\hline 5 & Service Incident \\
\hline 6 & Equipment Incident Decision/Action \\
\hline 7 & Passenger Incident \\
\hline 8 & Service incident Resolution \\
\hline 9 & Operator Incident Decision/Action \\
\hline 10 & Service Incident Decision/Action \\
\hline 11 & Operator Incident \\
\hline 12 & Operator Incident Resolution \\
\hline 13 & Dispatch letting XB know of next day assignment \\
\hline 14 & Service Coverage Instructions (supervisors to operators) \\
\hline 15 & Passenger Incident Decision/Action \\
\hline 16 & Passenger Incident Resolution \\
\hline 17 & P-N-R lot count \\
\hline
\end{tabular}

\section{Report of Observations}

Of the 147 observations, 32 (22\%) were operators calling into Dispatch for a radio/communications check. The operator and dispatcher confirm that the radio is operating and then the dispatcher provides the exact time to ensure that Mobile Data Terminals are synchronized properly.

A total of $29(20 \%)$ of observations were passengers calling for transit information. This may or may not be a typical number of incidents because on any given day extraboard operators are utilized to answer customer calls when available. Therefore, the total calls taken by dispatchers each day may vary. Table 3-2 below shows the total observations and frequencies based on the seventeen categories established. 
Table 3-2

\section{Observations Totals and Frequencies}

\begin{tabular}{|c|c|c|}
\hline Observation Category & Number & Frequency \\
\hline Radio/Communications Check & 32 & $21.77 \%$ \\
\hline Passenger call for transit information & 29 & $19.73 \%$ \\
\hline Equipment Incident Resolution & 12 & $8.16 \%$ \\
\hline Equipment Incident & 11 & $7.48 \%$ \\
\hline Service Incident & 11 & $7.48 \%$ \\
\hline Equipment Incident Decision/Action & 8 & $5.44 \%$ \\
\hline Passenger Incident & 6 & $4.08 \%$ \\
\hline Service incident Resolution & 6 & $4.08 \%$ \\
\hline Operator Incident Decision/Action & 5 & $3.40 \%$ \\
\hline Service Incident Decision/Action & 5 & $3.40 \%$ \\
\hline Operator Incident & 4 & $2.72 \%$ \\
\hline Operator Incident Resolution & 4 & $2.72 \%$ \\
\hline Dispatch letting XB know of next day assignment & 4 & $2.72 \%$ \\
\hline Service Coverage Instructions (supervisors to operators) & 3 & $2.04 \%$ \\
\hline Passenger Incident Decision/Action & 3 & $2.04 \%$ \\
\hline Passenger Incident Resolution & 3 & $2.04 \%$ \\
\hline P-N-R lot count & 1 & $0.68 \%$ \\
\hline Total & 147 & $100.00 \%$ \\
\hline
\end{tabular}

The remaining primary categories of observations are divided into three types:

- Incident, which entails equipment incidents, service incidents, passenger incidents, and operator incidents;

- Decision/Action, which is usually decided by the Lead Operations Supervisor in conjunction with field supervisors; and

- Resolution, the ultimate conclusion for any of the incident types.

Table 3-3 below displays the aggregated totals for incidents based on the observations.

Table 3-3

Aggregated Totals for Incidents

\begin{tabular}{|l|r|r|}
\hline \multicolumn{1}{|c|}{ Observation Category } & Number & Frequency \\
\hline Radio/Communications Check & 32 & $23.0 \%$ \\
\hline Passenger call for transit information & 29 & $20.9 \%$ \\
\hline Equipment Incident - All (incident, decision/action, resolution) & 31 & $22.3 \%$ \\
\hline Service Incident - All (incident, decision/action, resolution) & 22 & $15.8 \%$ \\
\hline Operator Incident - All (incident, decision/action, resolution) & 13 & $9.4 \%$ \\
\hline Passenger Incident - All (incident, decision/action, resolution) & 12 & $8.6 \%$ \\
\hline & 139 & $100.0 \%$ \\
\hline
\end{tabular}




\section{Pinellas Suncoast Transit Authority (PSTA) Case Study}

As approved by FDOT, CUTR conducted observations of the PSTA dispatch office on March 22, 2011 from 4:20 a.m. to 2:45 p.m. An observation sheet was developed and supplied to PSTA in advance. PSTA's dispatchers were very welcoming and told the research team to move freely between the window and the radio control room.

\section{Physical Dispatch Environment}

Dispatch is a complex consisting of two main offices: the window office, where supervisors interact with operators, and the radio control room, which consists of two mirror workstations with one serving the needs of North County and the other of South County. Observations took place in the window office from 4:20 a.m. to 6:32 a.m. Observations took place in the radio control room from 6:32 a.m. to 2:45 p.m.

\section{Functions of Dispatch}

Unlike VOTRAN, Dispatch only operates the window function with all other communications occurring in the Radio Control room. Dispatch is responsible for two primary functions:

- Operator Check-in and Coach Assignment

- Absentee and Extraboard Management

The radio control center is responsible for all radio communications with operators, all telephone communications including the shop, and supervisors.

Radio controllers have the ability to monitor real-time service using an AVL/GPS and mapping software.

\section{Technology}

The Radio Control room is a platform that includes radio, data, and automatic vehicle location (AVL) systems with associated mapping. The control room console consists of five monitors as pictured in Figure 3-2 below. There are also security cameras covering the PSTA property but the radio controller stated that those are not monitored as closely as the remaining five monitors in the console.

The first monitor to the left is a Google Map screen with real time bus movements provided through the AVL system. The second monitor to the right displays a text version of the mapping screen including, the bus number, the bus operator, route number, speed, and current and next timepoint. The third monitor to the right is the Hastus bus assignment sheet based on the stacking of buses on the lot. The fourth screen to the right displays paddles and headway sheets that radio controllers can pull up when speaking to operators. The fifth and final monitor 
displays radio communications, including the operators that have initiated calls and emergency alarms. Similar to VOTRAN, PSTA has a "Request to Talk" function but it is not operational.

Figure 3-2

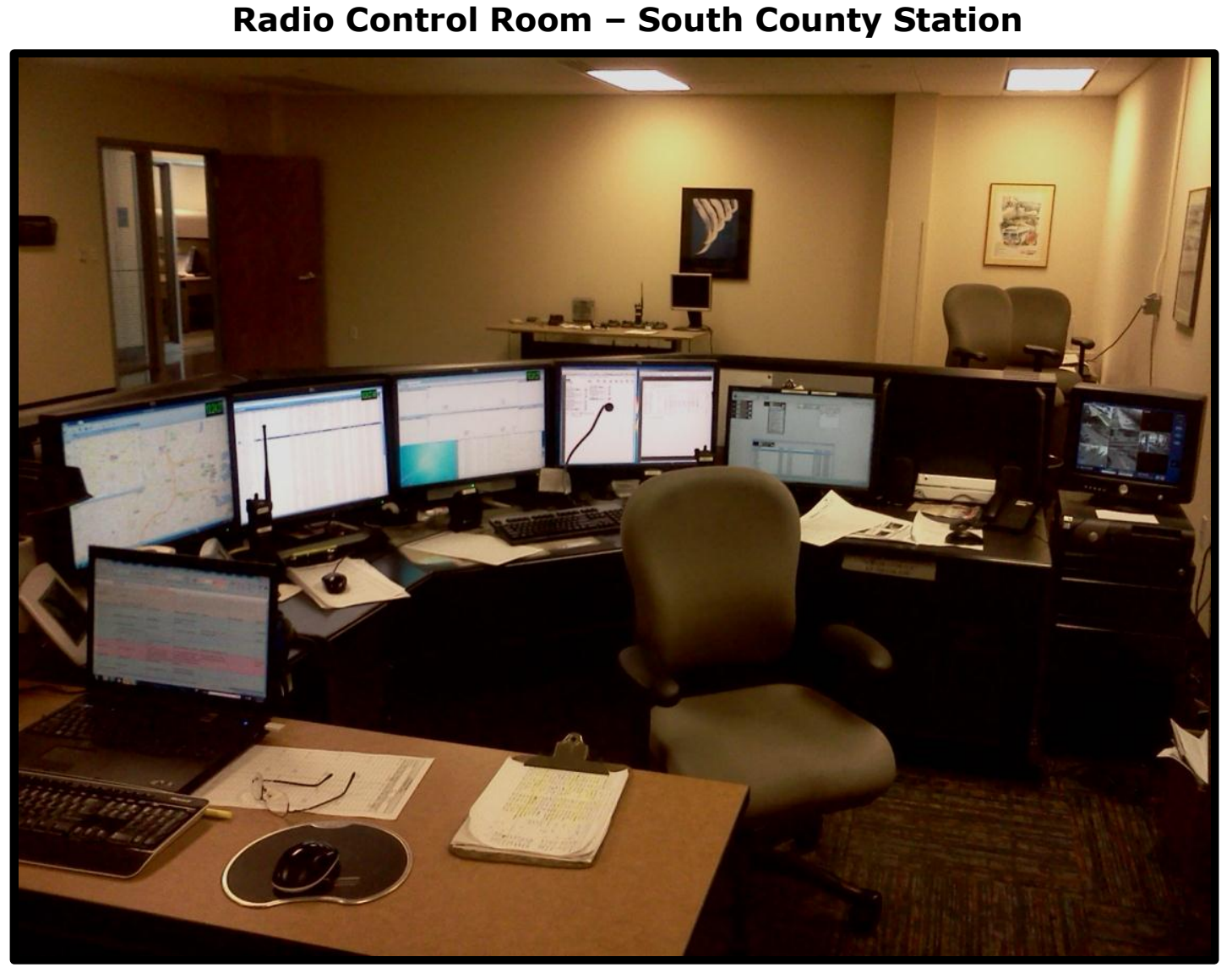

\section{Non-Automated Functions}

The primary observed non-automated function of the radio control room is the maintenance of a paper log to record incidents. The radio controller used the information from her screens to recall the actions for the written log record of the various incidents.

\section{Dispatch: Operator Check-in and Coach Assignment}

As mentioned earlier, the dispatch function consists of two primary functions, operator check-in and coach assignment, and absentee/extraboard management. A few years ago, PSTA decided to change the configuration of their lot from a system of dedicated spaces for coaches based on coach number to a bus stacking system wherein buses are parked front to back in a total of 26 lanes. In an ideal bus stacking system, specific coaches do not have to be assigned to operators; rather, in theory the operator can simply walk to the lot and take the next available, 
unblocked coach in the stack. However, the stacking system became a challenge for PSTA because different routes require different size and type buses. Therefore, during the night Maintenance maps the coach numbers across the 21 lanes that are used and subsequently delivers the map to Dispatch. As operators check in, the dispatcher must assign the most available coach to ensure that buses leave the lot sequentially. Then, at night Lanes one through five are used for pull-in. Figure 3-3 below displays the bus stacking configuration at PSTA. The six lanes to the right that have buses parked are pull-ins; the remaining lanes to the left are buses available for pull-out.

\section{Dispatch: Absentee and Extraboard Management}

The other morning dispatcher maintains a comprehensive list of operators on leave and also takes calls from operators reporting leave. This dispatcher is responsible for managing the extraboard. At PSTA, the extraboard is divided between the designated extraboard and the volunteers who work on their days off. Therefore, as the process of operator check-in and coach assignment is taking place, so is the assignment of extraboard and volunteer operators. These two processes take place until pull-out is complete and throughout the day.

\section{Figure 3-3}

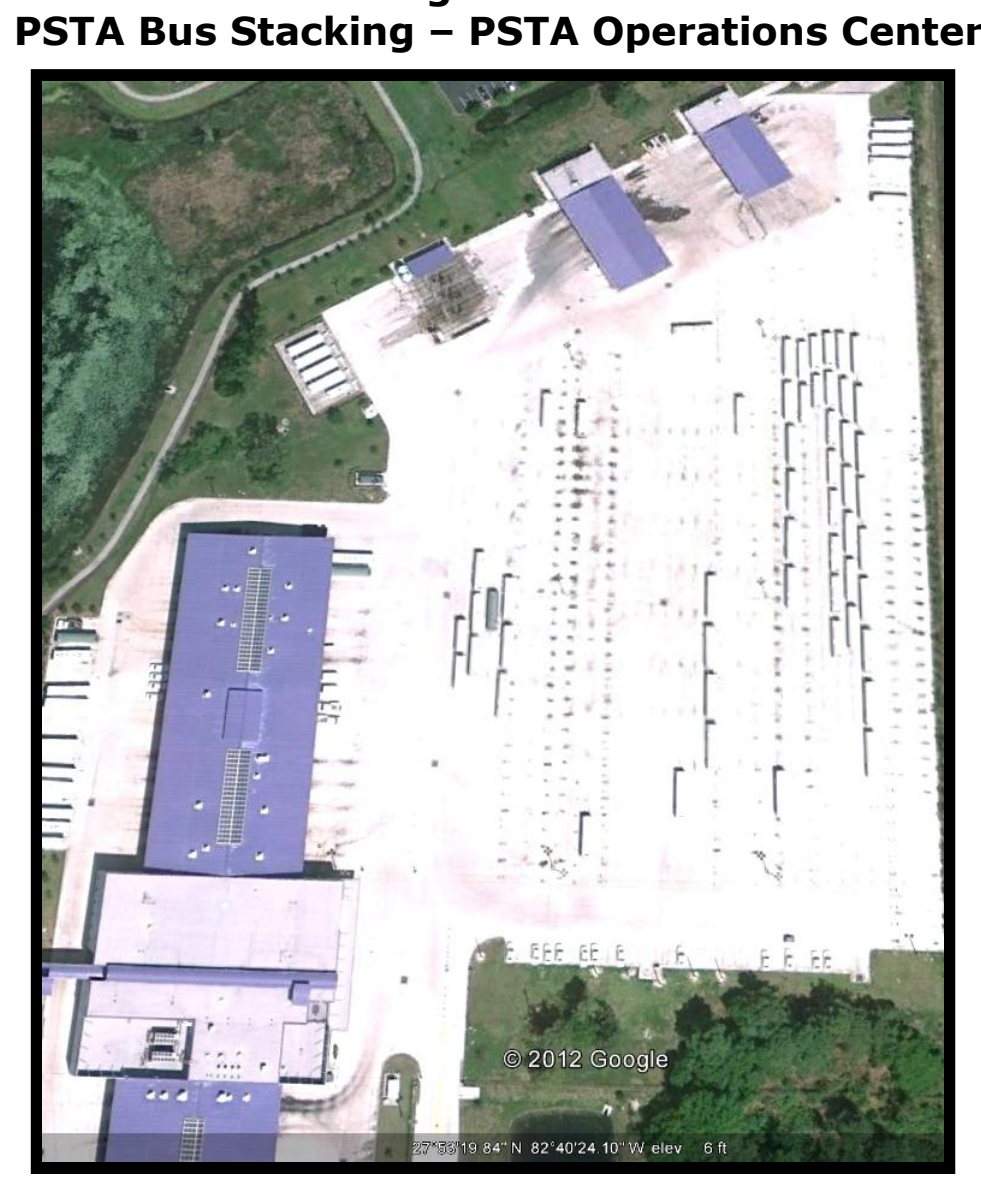




\section{Radio Control Room}

At 6:26 a.m., the observation switched to the Radio Control Room, described above. At that time of day, just the same as the VOTRAN case study, operators are mostly conducting radio checks. The operator identifies coach number and the radio control operator says, "Thanks I can hear you loud and clear. Have a good day out there."

\section{Road Calls}

As will be seen in the observations section below, there are a number of incidents occurring throughout the service days related to equipment problems, including bus not operating properly, destination sign problems, farebox problems and even one accident. In contrast to VOTRAN, the radio control operators at PSTA prioritize the needs in the field and then coordinate with supervisors to respond accordingly. In essence, PSTA dispatchers are more "empowered" in this area than VOTRAN dispatchers, who defer to the Lead Supervisor to make decisions related to road calls.

\section{Observations}

Observations were conducted in the PSTA Bus Dispatch office and Radio Control Room on March 22, 2012. A form was developed in MS Excel prior to the observations as a means of recording data. Not all columns in the form were used exactly as titled because events were dynamic and relevant information was placed in the cells. In general, the form included a place to record the following:

- Time frame

- Type of incident (window, radio, Mobile Data, telephone)

- Action/activity

- Materials used

- Incident description

- Ten-codes used (PSTA uses minimal Ten-codes)

- Resolution

A total of 65 separate observations were made in the Radio Control Room between 6:30 a.m. and 2:45 p.m. Some observations were continuations of incidents that had developed earlier in the service day but were ongoing toward resolution. After the observations were completed, the research team divided the incidents into the following seventeen types. Table 3-4 below displays the categories. 


\section{Table 3-4}

Observation Categories

\begin{tabular}{|r|l|}
\hline $\begin{array}{c}\text { Code } \\
\text { Number }\end{array}$ & \multicolumn{1}{|c|}{ Window Function Only } \\
\hline 1 & Operator Check-in and Coach Assignment \\
\hline 2 & Absentee and Extraboard Management \\
\hline 3 & Radio/Communications Check \\
\hline 4 & Equipment Incident \\
\hline 5 & Service Coverage Instructions (supervisors to operators) \\
\hline 6 & Passenger Incident \\
\hline 7 & Service Incident \\
\hline 8 & Equipment Incident Decision/Action \\
\hline 9 & Service Incident Decision/Action \\
\hline 10 & Equipment Incident Resolution \\
\hline 11 & Paperwork/logging incidents \\
\hline 12 & Yard Parking Incident \\
\hline 13 & Accident/Collision \\
\hline 14 & Miscellaneous \\
\hline
\end{tabular}

\section{Report of Observations}

Of the 65 observations at PSTA, 16 (25\%) were operators calling into the Radio Control Center for a radio/communications check. The operator and Radio control confirm that the radio is operating and then the dispatcher acknowledges radio functioning properly.

Throughout the observation period, there were 14 equipment incidents (21.5\%), 9 service incidents (13.8\%), and 7 passenger incidents (10.8\%). Equipment incidents included bus not gaining speed, reported destination sign malfunctions, and reported farebox malfunctions. Several buses were switched out from both the Shop and by using extraboard operators. Service incidents included operators calling in for instructions on how to circulate in Downtown St. Petersburg with the major race that was taking place that weekend. Passenger incidents mainly centered around cards and passes getting stuck in the farebox. There was one accident during the day when an operator reported being hit by a passenger vehicle which resulted in breaking the sideview mirror on the driver's side. The Radio Control operator sent a supervisor to the scene and called the jurisdiction police to obtain a police report.

It is notable that the number of observations at PSTA was significantly less than VOTRAN. There are two reasons for this: first, VOTRAN dispatchers must take calls from customers for information, which constituted a number of incidents; and second, there are more steps in the decision tree at VOTRAN than at PSTA. As mentioned earlier, the Radio Control operators are much more directly involved in the decision-making process which streamlines the number of recordable incidents. Table 3-5 displays the observations totals and frequencies 
Table 3-5

Observations Totals and Frequencies

\begin{tabular}{|l|r|r|}
\hline \multicolumn{1}{|c|}{ Radio Control Room Only } & Number & Percent \\
\hline Radio/Communications Check & 16 & $24.6 \%$ \\
\hline Equipment Incident & 14 & $21.5 \%$ \\
\hline Service Incident & 9 & $13.8 \%$ \\
\hline Passenger Incident & 7 & $10.8 \%$ \\
\hline Accident/Collision & 6 & $9.2 \%$ \\
\hline Equipment Incident Decision/Action & 3 & $4.6 \%$ \\
\hline Service Incident Decision/Action & 3 & $4.6 \%$ \\
\hline Equipment Incident Resolution & 2 & $3.1 \%$ \\
\hline Yard Parking Incident & 2 & $3.1 \%$ \\
\hline Service Coverage Instructions (supervisors to operators) & 1 & $1.5 \%$ \\
\hline Paperwork/logging incidents & 1 & $1.5 \%$ \\
\hline Miscellaneous & 1 & $1.5 \%$ \\
\hline Total & 65 & $100 \%$ \\
\hline
\end{tabular}




\section{SECTION FOUR \\ SYNTHESIS AND CONCLUSIONS}

The results of the literature review, survey of transit agencies, and the subsequent case studies of VOTRAN and PSTA paint a clear picture of the environment, the role, the functions, and the variations that dispatchers face within and across transit agencies. Below is a synthesis of the findings and implications for future research.

\section{Catalogue the Functions of Dispatch}

First, it must be noted that the definition of dispatch entails a window function, a radio communications function, and in some cases a supervision function when agencies classify supervisors as occupying multiple roles. Clearly, the three primary functions of dispatch as defined for window and radio functions are as follows:

- Incident management

- Labor management

- Equipment management

\section{Incident Management}

When operators in the field experience any kind of difficulty impacting the timely provision of service, radio dispatchers are the primary point of contact. As noted in the case studies, the four types of incidents are equipment malfunctions, service incidents, passenger incidents and accidents (only one occurrence in the observations). The variation in the role dispatchers play is based on the degree of empowerment that operations managers choose to give them when setting up the overall chain of command for the organization. The case studies showed that at VOTRAN, ultimate decisions regarding field responses to any given incident are concentrated with the Lead Supervisor. However, at PSTA, radio control operators are empowered to prioritize incidents and dispatch supervisors to a field response.

\section{Labor Management}

Dispatch management of the extraboard was a component of the Best Practices in Extraboard Management study, which was the primary impetus for this study. However, it is clear that dispatchers play a role in managing the entire operator work force in conjunction with field supervisors. Managing labor includes checking operator uniform appearance, operator absences, assigning coaches to the operators, schedule adherence, and managing overall operator availability to perform scheduled service. All of these functions are performed before the larger function of providing operators assistance with the identified incident types throughout the service day. 


\section{Equipment Management}

The equipment management function has two components: internal and external. Internal equipment management entails the process used by operations and maintenance to ensure the availability of coaches for the service day. At VOTRAN, coach assignment occurs during those times of the year that operators bid on the work they wish to perform. A sheet is made at the conclusion of each bid and is used daily to record any variations such as vehicles pulled for repair or other known change outs. At both VOTRAN and PSTA, there is an overnight report prepared by maintenance and supplied to Dispatch in the morning.

The external component of managing equipment occurs when incidents occur in the field, such as malfunctioning of mirrors, destination signs, fareboxes, and the malfunctioning of the coach itself. This component of equipment management demands more judgment to be used by dispatchers because it entails an assessment of whether there is labor, equipment, and/or shop availability to change out the equipment when necessary.

\section{Interface of Dispatch with Other Organizational Functions}

Clearly, the primary interface for dispatchers aside from communicating with operators occurs with Maintenance and field supervisors. Additionally, when Dispatch does not have primary responsibility for customer service, there is an interface with Customer Service when customers report lost items, etc. At PSTA, customer service representatives can call Dispatch any time they have a real time event to address.

\section{Standard Operating Policies and Procedures}

The only standard operating procedure the research team was able to obtain was the Transit Operations Supervisor (TOS) manual for Miami-Dade County. The survey responses suggest that most dispatchers are trained on the job, and no dispatcher during the observation kept a manual on their desk for reference in completing their daily job duties. The adapted manual for Miami-Dade County is utilized as the basis for the Standard Operating Procedure (SOP) described in the next part of this report.

\section{Best Practices Including Processes and Technology}

Both VOTRAN and PSTA have an electronic map of the service area giving real time bus location, and VOTRAN uses this for the cycling of buses at the main transfer center. A few minutes before scheduled arrivals, the dispatcher identifies the location of the incoming buses to determine if any are late, and then advises other operators to hold buses as necessary. 
Both VOTRAN and PSTA have a function in their radio system for operators to issue a "Request to Talk (RTT)." PSTA has plans to activate the function in the near future. At VOTRAN, the dispatcher uses the RTT to first gather data on what is going on with that operator and then grants the RTT. The RTT function also enables dispatchers to prioritize the order in which operator requests are accepted. At both PSTA and VOTRAN, having an electronic record of calls enables dispatchers to remember all of the incidents and record those incidents later for their daily reports.

At VOTRAN, the use of mobile data terminals enables dispatchers to target communications rather than wasting radio time with broad-based announcements that only impact a segment of operators. For instance, if there is a special event that affects only certain operators in the service area, the dispatcher can send targeted messages via the mobile data terminal. For instance, a VOTRAN operator reported a large hazardous object in the road on a major corridor, resulting in the dispatcher immediately messaging only the impacted operators on that corridor.

\section{Assess Impacts of New Technologies on Dispatch Efficiency and Management}

Clearly the nine systems that responded to this survey are significantly advanced with technology. Eight of the nine agencies have some form of CAD/AVL, eight have cameras on buses, and seven have covert emergency alarms. However, while there are efficiencies gained from using technology, the observations revealed that dispatch functions still rely heavily on face-to-face, pen and paper, telephone, and radio communications. Technology can provide tools, but humans are still required to synthesize, strategize, prioritize, and make decisions to take action.

\section{Pace and Multitasking}

One of the suppositions at the outset of this study was that dispatch can be a fast paced and multifaceted function wherein each day presents new challenges from the previous day. The observations at VOTRAN and PSTA clearly confirm that supposition. In both observations, dispatchers were attempting to manage incidents white new calls were received that reported new incidents. In the case of VOTRAN, the dispatcher kept notes and then used the Avail screen to log incidents well after they were reported. At PSTA, even though the two radio control operators have responsibility for service in either the north or south parts of Pinellas County, the radio control operators routinely helped each other by taking the other's calls during times of intense incident management.

When an accident occurred at PSTA, there was a sequence of tasks the radio control operator had to perform: obtain the pertinent information regarding the accident from the bus operator, instruct the operator on what to do, dispatch a 
supervisor to the location, determine the jurisdiction where the accident took place, call the police dispatcher and supply information, and coordinate the police report. While the pace can be very intense, the research team noted that incident management does come in waves (e.g., after pullout is complete) and then activity dies down for a period.

\section{Extraboard Management}

In the dispatch survey, 53 percent of respondents indicated they do not have enough extraboard operators. The observations at both VOTRAN and PSTA revealed that at some point, there was an occurrence when no operators were available to respond. When this occurs the dispatchers and supervisors must become more creative in managing the incident to ensure that service remains availabile to the public. For instance, at VOTRAN when there was no extraboard operator available, the dispatcher contacted an operator coming off an a.m. peak run and directed the operator to continue his shift to cover the affected service. In the case of VOTRAN and PSTA, the dispatch function had full management responsibilities for managing the extraboard, as did 55 percent of survey respondents.

\section{Customer Service}

Twenty percent of survey respondents said customer calls are routed directly to Dispatch. VOTRAN is one of the transit agencies where customer calls are routed directly to Dispatch. This impacts extraboard management because at VOTRAN unassigned extra board operators help to answer customer phone calls. However, on the day of the observation that only occurred for a very short time before the operator was called to service. The more typical configuration is that customer service is separate from Dispatch, as 52 percent of respondents indicated. At PSTA, customer service has a direct line to dispatch but the only call from customer service was for a lost phone on a bus that the customer was attempting to retrieve in real time.

\section{Generalized Job Duties versus Specialization}

At both VOTRAN and PSTA, there is specialization between the window, radio control, and the field supervision functions. It is very prevalent in the transit industry to not have standard terms with standard definitions. What PSTA calls the dispatch function is responsible only for window management, while the radio control center is what some systems ordinarily refer to as dispatch. However, 59 percent of survey respondents indicated that dispatchers are considered supervisors and can work window, radio and road supervision on a rotating or as needed basis. Two dispatchers advocated for this more comprehensive set of responsibilities as a best practice. One respondent said, "We all have shared responsibilities, we all work either on the road or in the office \{and\} there is very good communication between 
supervisors and manager." Another advocating for this approach said, "Road supervisors handle road situations/dispatch handles yard and office situations. There should be more cross training and every supervisor should be required to do at least 10 hours per week road duty instead of residing at base all day."

\section{Training}

Recently, at the Florida Operations Network meeting, a transit agency requested that a training course be developed for dispatch. As a result, FDOT is funding the development of a curriculum for a dispatch course. The results of this research reveal that more curriculum-based training for dispatchers is needed. A full 71 percent of survey respondents were trained on the job with only 20 percent reporting that the agency provided separate training prior to beginning dispatch duties. In addition, a curriculum-based training would provide the valuable tool of dispatchers from different agencies being able to share different approaches to the job in an environment outside the operations setting. Observations at the two transit systems did not yield insights on training as dispatchers were too busy to talk about peripheral issues.

\section{Implications for Operations Managers}

From Question 27 (identify best practices) and Question 28 (areas of desired improvement), it is clear that most dispatchers are happy with their jobs and like being a dispatcher even though the question was not specifically asked. However, they did have many suggestions for improvement. Dispatchers cited the physical environment as being an issue whether it is ambient noise surrounding them or the need to have areas to communicate more privately and without distractions. There was also discussion about the communication between Operations and Maintenance with one respondent stating, "Miscommunications about equipment availability between operations and maintenance have caused any number of headaches." However, other respondents were very satisfied with their processes of communication between the two.

The most cited item for improvement is improved communications between management, supervisors, and dispatchers. Survey respondents referred to, "implementation of new and updated ideas to better manage the everyday operations of dispatch." Another mentioned, "communication from management about upcoming events \{and\} video feeds from all transit centers." Finally, for those dispatchers who take customer calls, they wish the function would be taken out of dispatch.

Major overhauls to the functions, processes or procedures in dispatch are a challenge for operations managers because the pace is such that the day's events consume the dispatchers' time. However, dispatch environments have had to adapt 
to changes over the past several years as new technology has been installed. Operations managers should consider establishing task forces that would empower dispatchers to take up one issue, one function, or one process or procedure at a time in an effort to make dispatch functions as efficient as possible.

\section{Implications for Future Research}

The research team was unable to identify any effort similar to this one in the course of this study. This report offers insights into the inner-workings of dispatch in order to document how the dispatch function works and how it might be improved. Future research could explore a similar effort with other modes such as rail and paratransit. In the area of training, future research could focus on development of more curriculum-based training and even standardized training for new trainees at the agency level. Also, there is a need to invest in professional development of dispatchers with the possibility of creating certifications similar to maintenance technicians.

With all of the new technologies available to operations environments, future research could focus on mining data from dispatch systems to monitor the performance of dispatch itself (rather than service) and contribute to developing performance standards for dispatch, e.g., average call response times, call lengths, duration of incident management and resolution, etc. 


\section{SECTION FIVE DISPATCH STANDARD OPERATING PROCEDURE}

\section{Introduction}

In 2004, Miami-Dade Transit published a Transit Operations Supervisor Manual (TOSM) that included, among other modules, a full Standard Operating Procedure (SOP) for non-radio dispatch functions. The SOP from the Miami-Dade manual is presented below as an example with explanations of the function of each section (in red italics) to aid in adapting this model to other transit services.

\section{Bus Dispatch - Window Standard Operating Procedure}

To implement a similar procedure, a transit agency should gather all of the functions and duties for their dispatch office. Resources include job descriptions, the collective bargaining contract, training materials, and/or desk audits of dispatchers. Below is a list of duties and functions at Miami-Dade Transit.

\section{Description of Standard Operating Procedures}

- Plan, assign, and review the work of bus operators to assure compliance with departmental rules/regulations, including ADA (Americans with Disabilities Act).

- Assign bus operators according to departmental rules, regulations, and procedures; calculate personnel needs based on level of service required, and availability of equipment and personnel.

- Assure the availability of operators and equipment for posting work assignments.

- Before giving out work, double-check for correct work assignments

- Assign all regular runs and trippers to bus operators on assigned shifts.

- Assemble and distribute schedule cards, transfers, and other related forms.

- Maintain operator attendance records.

- Check operators reporting for duty for uniform regulation compliance.

- Account for bus-to-rail transfers disbursed to bus operators.

- Maintain adequate supply of bus-to-bus transfers.

- Assure adequate supply of all transit operations forms.

- Manage distribution and receipt of toll collection data and apparatus. 
- Inspect charter reports, defect cards, and other forms upon completion of operators' assignments and place material in the proper location.

- Account for all lost-and-found items turned in by bus operators.

- Maintain close coordination with Maintenance for exchange of defective coaches and for vehicle availability.

- Communicate and coordinate with other supervisors and Bus Central Control regarding vehicle and manpower availability and other issues.

- Ensure schedule adherence for operators upon leaving and returning to the garage, on the lot, and in the dispatch office.

In addition to ensuring that current bus service is met, the dispatcher must also deal with service failures, new services/schedules that are added, schedule changes, route alignment (map) changes, bus assignment changes (route, run, or division), changes in operator assignments (such as open run bids and deletions), and prepare for additional service requests such as charters, special services, and emergency variations from scheduled work (such as evacuation/hurricane procedures and bus bridges for Metrorail/Metromover breakdowns). When performing this function, the Supervisor must always be sure to keep all proper records, enforce all County and MDT rules and procedures, and work to prevent favoritism, errors, and misjudgments among Operators, Supervisors, and other employees.

\section{The section below provides guidance to transit agencies to identify hours of operation and shifts and then organize all of the functions and duties for their dispatch office by shift. Resources include general forms, the collective bargaining contract, operator paddles, and/or desk audits of dispatchers. Below is a General Daily Timeline of Responsibilities at Miami-Dade Transit.}

General Daily Timeline of Responsibilities (Duties specific to the shifts are outlined in detail on the following pages.)

3:00 p.m. Create scheduled work for next day's service.

Allocate a.m. extra boards to open work.

Create extra list for the next day (the extra list consists of operators exclusively working overtime to supplement boards).

Complete extra list worksheets.

5:00 p.m. Post boards and extra list for operators (contractual obligation). Print dispatch sheets. 
Midnight Secure available bus list for the next day (from shop supervisor)

Update assigned buses for the next day by 2:00 a.m.

Print sheets again now including assigned buses.

3:30 a.m. Operators begin to report for work and checking in.

4:30 a.m. Take names for the P.M. extra list and next day's A.M. extra list.

7:15 a.m. All report boards should be assigned for A.M. peak service.

Allocate the P.M. extra boards.

Create P.M. extra list.

Transpose boards to P.M. dispatch sheet.

9:00 a.m. Post P.M. boards and extra list for operators (contractual obligation).

\section{Window Duties All Shifts}

4:00 a.m. - 12:00 p.m. - 12:00 p.m. - 8:00 p.m.

- Responsible for all dispatch functions.

- Dispatch regular runs and trippers.

- Check in operators assigned to regular work and assign board operators to open work, using the extra list if necessary

- Maintain attendance log and recap, and an accurate recording on work sheets in TOS.

- Assignment of operators and equipment to special events checking for accurate information and recording of special event slip and time.

- Record board operators and extra list operator pay.

- Coordinate with the tripper window for bus changes and assignment of P.M. pull-outs buses and regular runs.

- Obtain all information on calls for reports from operators involved in accidents or incidents from Bus Central Control. Dispatch needed assistance and following through with Bus Central Control.

- Coordinate with Bus Central Control for information needed regarding buses, operators, and routes, etc.

- Check overtime slips for accuracy, accident/incident forms for legibility, and make sure any witness cards and no-driving slips are attached.

- Receive and record lost-and-found items.

- Relay messages to operators from superintendents.

- Pass out paychecks when needed.

- Coordinate manpower needs with other divisions

- Other duties as required.

Other duties as assigned 4:00 a.m. - 12:00 p.m.

- Generally responsible for dispatching all A.M. work up to 12:00 p.m.

- Check in operators reporting for duty on regular runs, correcting errors in assignments if possible. 
- Keep attendance recap up-to-date, including late and excused information

- Assign and record charters; secure operators and buses for charters.

- Fill out the Daily Service Report.

- Assign and record unscheduled relief for operators who are sick, have court appointments, and physicals, etc.

- Assign operators to open pieces of work.

- List operators that request to be excused or are sick (follow through).

- Coordinate with Lot Supervisor on pull-out buses.

- Check in charters; check for proper information and record time.

- Dispense and receive overtime slips. Check for correct information.

- Dispense and receive accident reports. Have operator sign a non-driving slip, if appropriate.

- Receive and record lost-and-found items.

- Pass out interoffice mail to operators.

- Relay messages from superintendents.

- Pass out operator paychecks.

- Work with Bus Central Control as to information needed on buses, routes, and operators.

- Coordinate with superintendents weekly hold downs to be posted.

- Receive and process or forward operator bid slips for open runs and hold downs.

- Other duties as assigned.

12:00 p.m. $-8: 00$ p.m.

- Generally responsible for all P.M. work reliefs, regular runs, trippers, and control of P.M. Boards, all second reports for A.M. board and extra list.

- Dispatch all P.M. runs, reliefs, and charters, etc.

- Dispatch all P.M. unscheduled reliefs and record properly.

- List operators that request to be excused or are sick.

- Dispense and receive operator overtime slips. Check for correct information.

- Dispense and receive accident reports. Have operator sign a non-driving slip, if appropriate.

- Receive and record lost-and-found items.

- Give reports for the next day (phone calls).

- Pass out operator paychecks.

- Relay messages to operators from superintendents.

- Coordinate flow of buses with the Lot Supervisor and Maintenance Foreman at each division.

- Assign buses to pull-outs and make lot changes.

- Determine the priority of trippers to be cut when necessary because of a shortage of buses or operators, and inform shop of shortage prior to need. 
Supervisors should know the priority routes for each division (same routes should not be missed each day)

- Put away transfer and schedule cards. Keep attendance recap up-to-date.

- Fill out Metrobus Daily Service Report

- Notify Bus Central Control of all late or missed work leaving the garage.

- Process and post Hold Downs on a weekly basis.

- Other duties as assigned.

8:00 p.m. - 4:00 a.m.

- Work window: receive transfers and schedule cards.

- List operators that request to be excused or are sick.

- Clean-up correcting errors if any, of operator assignments in dispatch sheets

- Dispatch late special events or other late services.

- Be certain a full deck of P.M. instruction cards is always available.

- Make any schedule and map changes (detours).

- Handle other services such as stamping up special surveys and football services.

- Place schedule cards, detour maps, and transfers in rack for next day's runs.

- Receive and record late special events

- Receive operators overtime slips. Check for correct information.

- Receive and record any unscheduled relief that have been made.

- Give report times for next day (phone calls).

- Other duties as assigned.

Transit agencies should identify and
document their procedures for
extraboard and overall manpower
management. For instance, transit
agencies with collective bargaining units
may contain clauses regarding the size
of the extraboard, the scheduling of the
extraboard, assigning work based on
seniority, and even clauses to prioritize
call-ins and volunteers to work on days
off. Smaller agencies or agencies with no
bargaining agreement may have greater
flexibility in the management of
manpower. The primary documentation
needed for dispatchers is a complete
listing of all options available to cover
service based on manpower needs
perspective (in contrast to equipment


needs which is another issue). Below is

documentation for Miami-Dade Transit.

\section{Evaluation and Management of Manpower}

Availability of operators is critical for the dispatcher to know at all times. Operator needs should be checked according to a designated buffer that has been developed by management. The buffer will help ensure that missed service is kept at an absolute minimum, with a goal of zero.

Checking in operators and handing them work is the simple part of the dispatch function. The more challenging tasks for the dispatcher involve evaluating manpower, creating the extra list, distributing extra list report times as evenly as possible to avoid high volumes of operators reporting at the same times, and managing the list so that operators are sent home at the appropriate time.

If, despite the best preparations, manpower has been underestimated and a shortage will soon occur, the supervisor can call for volunteers. A fully appropriate use of the PA system is to alert everyone in the room that a manpower shortage is anticipated: "need a volunteer" or "in a couple of hours we'll be running out of Operators" are possible announcements. Those in the room might be able to inform colleagues who are off work that day. Sometimes, operators come in and say, "Do you need anybody today; John Smith wants to work."

When a shortage of operators occurs, the following should be contacted (in order and sent an e-mail):

- Operations manager

- Lead supervisors

- Field supervisors

It is appropriate and absolutely essential for the dispatcher, upon reporting to work at the window, whether in the morning or when relieving another, to evaluate manpower. Manpower must be continually monitored and evaluated throughout the shift and into the next shift.

Transit agencies should identify and document their procedures for extraboard and overall procedures regarding operators and reporting for work. This section deals with operator check-in, operator mail, late operators, miss-outs, runs leaving late, sick or excused, jury duty, transportation to relief points and requests for overtime. 
The primary documentation needed for

dispatchers is a complete listing of all

procedures to follow for operator

management. Below is documentation

for Miami-Dade Transit.

\section{General Information}

\section{Upon Reporting for Duty}

When getting relieved or relieving someone else, the immediate expectation is that all relevant information will be shared, especially relating to manpower, vehicle availability, and requirements.

\section{Operator Check-In (Pull-Outs)}

Operators are required to check in directly with the Window Supervisor and record the check-in electronically with the badge reader. Failure of an operator to run his or her badge or failure of the electronic reader to register a successful check-in must be recorded and reported. This electronic check-in must be done with every report to the window (not just the first report of the day, but every report). It also must be done even when operators report late to the window with a reasonable explanation. It does not matter whether they missed the bus and are late for an extra list assignment, whether they were out on the lot talking with the Superintendent, or whether someone was ahead of them talking at the window, the operator must ALWAYS swipe his or her badge. If the operator did indeed miss his bus, then the supervisor can give that operator a green slip (delay time) and change the report. When the Supervisor had to pass what would have been that operator's report (thus changing the sequence of the assignment of work), then the Supervisor must address that report for the person whose time was passed, change the report, and justify the adjustment.

When the operator reports to the dispatch window for work, the window supervisor should check to see that the operator is dressed in proper uniform according to MDT rules (proper uniform information is contained in the Metrobus Operation Rules and Procedures Manual). The supervisor should distribute to the operator schedule cards, transfers, detour maps, and other related forms, as appropriate for the piece of work. In addition, if a SunPass transponder is required, the operator will sign it out at the window.

\section{Mail Notices for Operators}

The supervisor must determine what to do with the mail that arrives (usually a secretary separates the mail and brings it down-it is normally held in an area near the window). There are different categories of mail or notices that may be sent to 
operators, such as regular mail, personal information, or county-related mail. Specific examples of such mail might include insurance forms, dismissal letters, items requiring a signature, internal and external mail, commendations, etc., or other documents for bus operators. In any case, it is the supervisor's responsibility to distribute whatever mail or notices are delivered for the operators, or to assign someone to distribute the items (if they are batch documents that everyone receives).

\section{Late Operators}

The PA system must be used to call the operator three times before marking him or her as late. An operator is LATE when he or she can no longer check-in at the report time (i.e., if the report time is 6:01:00, the operator has until 6:01:59 to check-in and will be late at 6:02:00). If the Supervisor completes calling for the operator for the third time and the operator has not swiped his or her badge at the window, then the operator is to be marked late.

Regular operators who are late for their reports and report within two (2) hours MUST be placed at the bottom of the report board and shall be required to take work as assigned. These operators can be held until all a.m. or p.m. work is sent out but they cannot be forced to make a second report if they report to the dispatcher after 7:00 a.m. Late operators can catch a split piece or a combination with two reports and may be given a second if they report before 7:00 a.m. but cannot just be given a second report without their acceptance if they report after 7:00 a.m. The same applies to report board operators. Operators making such penalty reports will be paid only for work actually performed; provided, however, that if the supervisor places the operator on stand-by before work is assigned, he or she will be compensated at the applicable rate for all stand-by time.

Even if the supervisor believes there is sufficient manpower and the late operators will not be needed, they cannot be allowed to go home. The contract states that these operators must be placed at the bottom of the report board. The supervisor does not have the discretion to refuse to allow the operator reporting late to go on the clock and begin accruing stand-by time. The operator must stay until he or she catches work or until it is his or her turn to go home-the operator must be used last; any report board or time-slot operator who reports will go in front of the late operator.

Time-slot operators who are late can be required to make two reports. When a time-slot operator is late, he or she becomes a report board operator. 


\section{Miss-Out}

An operator who does not report within two (2) hours of his or her report time is recorded as a miss-out. Check to make sure the operator is not listed as excused or sick, etc. Also, change from late to missed on board list or worksheet for board or regular operators. A miss out does not mean the operator cannot work; use the operator if needed the same as late, if he or she reports in after missed.

\section{Run Leaving Late}

Record relevant data on window log and make appropriate report in the Daily Service Report.

\section{Sick or Excused Request}

An operator requesting to be excused or placed on the sick list must call at least 45 minutes prior to his or her scheduled report time. Failure to call within the required 45 minutes must be reported to the superintendent for disciplinary action.

\section{Excused Operators}

Supervisors shall instruct operators to first make requests to be excused to the superintendent, with proper documentation. In an emergency situation, a supervisor may approve the utilization of one (1) banked holiday. Supervisors may not excuse operators with any other time than a banked holiday. The supervisor may grant such an excuse only after giving consideration to manpower availability issues.

Supervisors may not grant funeral, annual, or administrative leave. Requests to be excused for medical appointments, personal court, house closings, etc., which are normally scheduled in advance, shall not be granted by the supervisor. Such appointments should be made through the Superintendent.

When an operator requests to be excused and the excuse is denied, being sick is not then a secondary option (i.e., if the request to be excused is denied, the operator cannot then be listed as sick). Never allow the operator to ask how they should be absent.

\section{Sick Operators}

\section{Regular Operators:}

If due in to work, check the next day's work to be sure the operator was taken off. Write "sick" by the operator's name on the sheets. 


\section{Board Operators:}

Same as a regular operator, in between the name and badge number on the board list, write "sick." Scratch work assignment and report. When operators call in sick or excused, listen to what they have to say, study the importance of the problem, and then make a decision.

\section{Family Medical Leave Act (FMLA)}

- The supervisor must fill out an FMLA form while the operator is still on the phone, which is to be sent to their superintendent.

- Ask the operator, is it for one day, if yes then enter " $Y$ " or they can leave it open, enter " $\mathrm{N}$ ". If left open operator must call back the day before he wants to return to work before 3:00 p.m.

\section{Relief Sick}

Give a relief operator an unscheduled relief form ("green sheet") to sign. The operator getting relieved must also sign the form and then turn it in. Give the relieved operator a directive to see his Supt. then on open line below the whole number of the operator getting relieved, record the operator name (and badge number) who finished the work and the hours of actual platform time. You must inform the operator that being relieved sick is only for that day. They must report the next day or call back to be placed on the sick list.

\section{Off-Sick List}

The supervisor must check to see the current status of the operator (the reason for being sick) when he or she calls, before giving the approval to return to work. The supervisor may not give the okay and then check; he or she must keep the operator on hold while checking the computer to look and see what the issues are. It is possible that the supervisor may be no longer authorized to remove that individual from the sick list-the operator's status may have changed due to other information, such as changing from sick to OJI (on-the-job injury), and a supervisor cannot clear an operator in that situation.

\section{Jury Duty}

An operator with a P.M. shift may request to be relieved by 10:00 p.m. if he or she is scheduled for jury duty the next day. For additional information related to jury duty, see the Collective Bargaining Agreement.

\section{Transportation to Relief Point}

If an operator calls that transportation (bus) to his or her relief point did not show up, send a roadcall operator with a patrol car ( $\mathrm{P}$-Car) to transport the relief to the 
relief point, or contact the appropriate Field Supervisor. Supervisors shall not allow service to be disrupted.

If an operator misses his relief bus, having him or her relieve the bus late is not an appropriate response to the problem. The supervisor must do everything to ensure that the operator is transported to the relief on time. If the supervisor suspects that the operator did not make every effort to make the relief on time, he or she must be dealt with on a disciplinary level; however, supervisors shall not allow service to be disrupted.

\section{Request for Overtime Slip}

When an operator's daily work is not completed as scheduled, this slip may be requested. Overtime may be granted for a number of issues including: operators having been delayed due to traffic, rain, accidents, train, bridges, or other occurrence beyond their control. In addition to normal delay time, there is additional time created by an operator having done additional work such as making a bus change, having run an extra trip, or having a breakdown.

If overtime is granted, make sure the slip is properly filled out with the operator's name and badge number, date, route/run, bus number, hours, and the supervisor's signature, etc. Give the operator the white copy. The blue copy is for the superintendent and the green copy is for payroll. All of the proper information pertaining to the reason for the overtime must be clearly described. Depending on the situation:

- DT (delayed time) - for those miscellaneous factors that kept the operator from getting back on time.

- ET (extra trip) - when the operator needed to make an extra trip.

- BC (bus change) - when the operator needed to change his or her bus with another operator. Information on the bus being brought back to the garage and the reason must also be recorded. (If an operator comes back to the window after completing work and the supervisor asks him or her to go out again with a good bus to facilitate the exchange of another bus, it is not a "BC" but is a service call ("SC") - see below).

- SC (service call) - when the operator has been placed on service call duty for a short duration of time to perform a number of specific tasks. This action must be approved by the division chief.

- BD (breakdown) - when a bus breaks down. Information on the bus experiencing a breakdown and the reason must also be recorded.

- TRAV (travel) - for issues such as missed buses, unscheduled reliefs, or needing to be transported in a P-car. Comments should include details as to why the travel occurred. 
Especially when an operator is called upon to perform a series of tasks that require overtime, it is essential that the supervisor report all of the information, so that there is an accurate record of the actual events. Such a record is useful for determining if and when operators are taking advantage of situations to obtain additional overtime pay (such as by taking longer to conduct particular tasks than necessary). Operators can, at the discretion of the Supervisor, be questioned if it is suspected that they took too long to return to the garage after performing an assigned task(s).

The section below provides guidance to transit agencies to identify and document their procedures for volunteers willing to work on their days off. This entails procedures for managing the volunteer list and procedures for operators in how to request and then report for work. Below is the documentation for Miami-Dade Transit wherein volunteers are called, "the extra list."

\section{Extra List}

The Extra List is a list of operators and report times scheduled for overtime pay, used to supplement the report boards to achieve the anticipated manpower needs of the day. Operators may volunteer to be placed on the extra list throughout the day; however, every morning at 4:30 a.m., the supervisor takes names of volunteers for the afternoon of that day and the morning of the next day (p.m. and a.m. extra lists). Operators may volunteer until the list, or the period being requested, is completed. Names may NOT be taken earlier than 4:30 a.m.

The process of taking the names of volunteers consists of:

- Taking the first three (3) people in line at the window.

- The next three (3) people from the callers on the phone.

- The supervisor will continue alternating between the next three (3) people in line and the next (3) people on the phone.

Part time operators shall be eligible for extra list work assignments. The principle is first-come first-served, not a seniority basis. Operators receiving work before 4:30 a.m. cannot stay at the window to be added to the extra list.

Care must be taken to start this process only after it is officially $4: 30$ a.m. Operators on the phone may NOT be placed on hold to await the turn of 4:30 a.m.; 
they must be informed as to what the current time is. The phone must continue to be answered in the minutes preceding 4:30 a.m. as it is at any other time of the day. There will be calls about going sick, excused, or for reports to the dispatch office of accidents or other incidents. Many things may be going on in the minutes before 4:30 a.m., and so the phone cannot be ignored during this time.

When the time is officially 4:30 a.m., the Supervisor shall announce the time over the PA system and begin taking the names. An operator may state, "This is John Smith, 830, give me today and tomorrow." It is most effective to only record badge numbers and then at a later time take the list of names from the official form that is set up with a column for the p.m. of that day and a column for the a.m. for the next day.

The supervisor shall continue to take names throughout the day. Even if it is clear that there are plenty of volunteers, the supervisor MUST always take the name if requested by an operator, until the list is created.

The supervisor creates work at 3:00 p.m., evaluates the manpower, and creates the extra list. Once the extra list is created and posted, the supervisor is no longer required to take names for the rest of the day. The supervisor shall post the p.m. extra list by 9:00 a.m. of that day (there is no need to take names for the p.m. after 9:00 a.m., unless there is a manpower shortage, then names should be taken as needed). The extra list for the next day shall be posted by 5:00 p.m. by the supervisor.

\section{Calculation of Extra List}

There is a form that assists with the calculation of the extra list. The need for the extra list is determined by the anticipated use of manpower for open work, start runs, reliefs, and any special service versus the manpower available from the extra boards. When anticipated manpower needs are compared with available manpower on the boards, the supervisor can determine the appropriate size of the extra list. Based upon past experience, the extra list is divided into three periods that accommodate the schedule of work at all divisions:

- A.M. - from start of day until a.m. peak service is in place (approximately 3:45 a.m. to 7:30 a.m.).

- Midday - starts with the first reports after the a.m. peak (approximately 8:00 a.m. to 11:59 a.m.). There is an informal division of the a.m. and midday extra lists; both are posted by 5:00 p.m. for the next day, but the requirements of each need to be calculated separately.

- P.M. - starts after 12:00 p.m. 
The supervisor shall use a calculated buffer to cover what can traditionally be expected to be lost over and above the actual numbers. For example, when a list is made for a particular day, all anticipated needs are counted and all anticipated operators are counted. Even if those numbers match, the supervisor should realize that, between 5:00 p.m. and 7:30 a.m. the next morning, some work will be missed.

\section{Management of the Extra List}

Operators on the extra list will report to work but may not be needed. Those operators whose names are posted on the extra list, and who report, are paid a minimum of two (2) hours (that is a minimum two-hours' pay if they report and work up to one hour and 20 minutes, due to the time-and-a-half rate). Sometimes, operators just need to come in and check to see if they will be needed, and then are sent home. They may accrue one minute of stand-by time, but will still be paid the two-hour minimum.

The Supervisor shall manage the list properly according to the principle of firstcome first-served, which dictates that the first person in line gets the first available piece of work. That piece of work may not be considered "desirable" if, for example, it is only a tripper of a few hours. However, if the operator refuses the piece of work offered, he or she must be placed on the penalty list. Individuals on the penalty list cannot be placed on the extra list for a period of seven (7) days.

It is important to note that, if the operator reports but refuses the piece of work, it is the law that he or she MUST still be paid the two-hour minimum. If an operator goes on the penalty list, but then after seven days comes back on the list and continues to refuse work, then he or she should be written up to the superintendent, but the operator will still be paid. If an operator initially accepts a piece of work, goes out and prepares the bus, but after a few minutes comes back to say that he or she no longer wants the work, then the operator will be written up for disciplinary action, but will still be paid the two-hour minimum.

Note: Part time operators may be part of the extra list within the established guide lines.

The section below provides guidance to a transit agency on how to identify and document its procedures for assigning work to operators. The primary resource for this section is Rule 14.90, Florida Administrative Code (FAC) and the associated System Safety Program Plan 


\section{the agency must maintain. Below is the documentation for Miami-Dade Transit.}

\section{Assignments of Bus Operators}

There are several categories of operators including time-slot operators, report boardo, extra list operators, walk-in operators, and part-time operators.

\section{Time-Slot Operators and Report Board Operators}

Time-slot operators receive priority for pieces of work eight (8) hours or more, and get one report. An assignment that requires a time-slot operator to report to the window more than once is an inappropriate assignment. Time-slot operators may be assigned splits, so long as they do not include a combination of pull-ins and pullouts. In other words, they may be assigned a piece of work that reports at the window, is relieved on the street, and makes another relief on the street-they may NOT be assigned to work wherein they pull-out, get relieved, and return to the window for another piece of work, such as a second pull-out on a second piece of work. A time-slot operator is also exempt from assignments wherein the first pullout of a split is scheduled to return to the garage, and then he or she makes a relief on the street (these types of assignments go to report board operators).

If a time-slot operator has a 12-hour spread, he or she may not be assigned to work more than 12 hours, which begins when the operator first begins on the clock to when he or she leaves the clock (the duration of the working day). For example, if an operator has a 12:00 p.m. report, he or she may not be required to be on duty more than 12 hours from that report time. If the operator reports at 12:00 p.m., stands by and catches a piece of work that gets him relieved at 11:30 pm., but is not due back in the garage until 12:03 a.m., then that is a violation because it keeps the operator on the clock more than 12 hours. The operator MUST be scheduled and into the garage and off the clock within the 12-hour spread.

Note: However, when no other operator is available, operators must not refuse any work. The dispatcher on duty will make arrangements to relive the operator prior to reaching the 12 hour spread time (See Special Notice dated October 12, 2006).

The spread time for report-board operators is 14 hours, and the same considerations are involved, i.e., they must be scheduled in the garage and off the clock before the expiration of the 14-hour spread. The supervisor can, however, assign time-slot operators and report-board operators pieces of work where the work is scheduled past the spread time, as long as the operator is relieved and enough time is allowed for travel back to the garage before the expiration of the spread time. 
An operator can work no more than 10 hours of platform time unless he or she requests otherwise. Stand-by time does not count toward the 10 hours of platform time.

\section{Assignment of Work}

Assignment of work is first-come, first-served, based on the position dictated by the time on the board (time is secondary to position on the board). In the case of report-board operators who are on their second report of the day, the first operator available is the operator who's position on the board is highest, not the operator with the first time. For example, the first operator on the board may have had a piece of work that was finished at 1:30 p.m., and the second report is 2:00 p.m., while the second operator on the board may have caught a short tripper and has a 12:15 p.m. report. If there is a piece of work due out at 2:05 p.m., the supervisor MUST, according to the contract, use the operator with the 2:00 p.m. report before the operator with the $12: 15 \mathrm{p} . \mathrm{m}$. report, even if it means that the operator with the 12:15 p.m. report will not be needed and will have to be paid anyway. A window supervisor is able to change the assignment for that last operator on the board and should work to use the operator where he or she will be needed at an appropriate time.

Because time-slot operators receive priority for pieces of work eight (8) hours or more, if there is no eight-hour piece available to give the time-slot operator priority over the report-board operator, the priority for the next piece of work is determined by the position on the board, if the boards were combined. For example, if there is a 4:30 p.m. time-slot operator and a 5:00 p.m. report-board operator, and the next piece of work is three hours, it cannot be given to the report-board operator just because it's a short piece-it must be given to the operator whose position on the board is highest which, in this example, is the 4:30 p.m. time-slot operator. According to the contract, lacking an eight-hour piece of work, the priority reverts to the position on the board. Supervisors do have the discretion to assign the extra list to pieces of work three (3) hours or less in length, in front of time-slot or report-board operators (the extra list is guaranteed 40 hours per week, but may not work all of it).

The operator who has the highest position on the board dictates that the next piece of work goes to him or her. However, if that piece of work exceeds the time spread, he or she MUST still be offered that piece of work and allowed to, at his or her discretion, waive the protection of the 12- or 14-hour spread time limitation. Some operators will agree to working beyond the spread, but others will not want to work one minute over.

Therefore, the operators must be offered the work if it exceeds their spread time. If they refuse it, then they can be passed and the work given to the next operator. If, 
however, no one accepts it, or no one is available, then the supervisor may, for report-board operators, give them the first portion of the work or a combination, or give it to them and have them scheduled to be relieved. For example, if the supervisor asks the operator, "Do you want the whole piece of work?", and the operator declines, then the supervisor shall try to find someone who is willing to work it. If the supervisor cannot find anyone to work it, then the original operator can be given the work and be scheduled to get relieved. These issues relate to the Transport Workers Union (TWU) contract, not Chapter 14.90 (selections of which are shown on pages 51-52 and in Appendix E). To avoid the possibility of protests, under normal operations, the supervisor should give the work to the report-board operator and have him or her relieved at the appropriate time (instead of offering the work to an extra-list operator). In the case of a report-board operator in the p.m., if there is not an extra list operator available to make the relief, the reportboard operator will be given the work that exceeds the spread and will be required to work it (in the contract). He or she will be paid the additional premium (pay-rate increase) that occurs after the spread time is exceeded.

In assigning work, the supervisor does have some discretion. One of the discretionary issues involves change of assignment. When there are manpower shortages, and after having exhausted the report board, time-slot, and extra list (and called for volunteers or walk-ins with no response), the Supervisor can then use the change of assignment to move scheduled operators up the list.

When spread limits require that an operator be relieved, he or she need not be relieved in the final hour (of the spread). The relief needs to be scheduled for a time when operators will be available to make that relief, meaning that the supervisor must do what is appropriate according to the schedules and available manpower. The Supervisor must not let so much time go by that the operator gets paid longer and then there may not be a relief available. There are many options on how to make the reliefs; however, the interests of the agency should dictate what the options are at a given time, and not the preferences of the operators. The supervisor has this discretion in scheduling the reliefs, and must use good judgment when doing so. The Supervisor must always be aware of changing manpower issues and availability throughout the day.

\section{Part-Time Operators}

Part-time operators shall be eligible for extra list work assignments within the established guide lines. When a particular piece of work is initiated, the Supervisor should not be required to make any modification of it. The supervisor should make a reasonable effort to cover work at straight-time costs. 


\section{Chapter 14.90, Florida Administrative Code}

The assignment of bus operators to pieces of work must be done according to departmental rules, regulations, and procedures. This is accomplished by following Chapter 14.90 of the Florida Administrative Code related to when one can or cannot operate a vehicle. Excerpts from Chapter 14.90 are presented below.

Equipment and Operational Safety Standards Governing Public Sector Bus Transit Systems, Chapter 14.90 of the Florida Administrative Code.

a. "The driver of a bus shall not be permitted or required to drive more than 12 hours in any one 24 hour period..." This pertains to platform (actual behind the wheel) hours. All operators must be checked off before completing 12 platform hours.

b. "...or drive after having been on duty for 16 hours in any one 24 hour period,..." "On duty" includes stand-by time, wait and travel time, bus preparation time, accident report preparation time, time required to see the Superintendent, court and jury duty time, instructional class time, medical examination time, and platform time.

c. "...or drive more than 70 hours in any period of seven consecutive calendar days." Any operator who works his or her statutory limit of 12 driving (platform) hours within the 24-hour period daily will reach his or her 70hour limit on the sixth day, and that operator will need to be limited to a 10hour maximum. This clause forces the seventh day off. There could be several variations of this example.

Note that the wording states, "any period of seven consecutive calendar days." This means that the seven-day period always floats. It can be Sunday through Saturday, Tuesday through Monday, etc.

d. "A driver who has reached the maximum 12 driving hours or 16 hours on duty time shall be required to have a minimum of eight consecutive hours off duty time within any one 24-hour period."

e. "A driver's work period shall begin from the time a driver first reports for duty for his or her employer."

The 24-hour period shall begin with the first report for each operator each operating day. The 24-hour period in most cases will span two calendar days; for example, from 05:55 on Tuesday through 05:54 on Wednesday.

f. "A driver may be permitted to drive for more than the regulated hours if the hours are necessitated by adverse conditions resulting from weather, road 
or traffic conditions, or emergencies resulting from an accident, medical reasons or disaster."

g. "The driver of a bus may be permitted to exceed his or her regulated hours in order to reach a regularly established relief point, provided the additional driving time does not exceed one hour."

\section{Collective Bargaining Agreement}

Always have available the Collective Bargaining Agreement (union contract) for reference to working procedures for bus operators. All working rules not covered herein are contained in the union contract. If unsure of a rule interpretation, contact the lead supervisor.

It should be noted here that interpreting and negotiating the meaning of the contract with operators is NOT an activity that the supervisor should be engaged in while on duty. If an operator protests about his or her work or vehicle assignment at the window, the supervisor will listen, make an instant decision, and enforce that decision. If the supervisor realizes immediately there is a mistake, he or she can correct it. If not, the supervisor will clearly instruct the operator to take the work and the vehicle and run the assignment. The supervisor will tell the operator to take the protest or complaint to the shop steward or superintendent after the work is completed and compensation will be taken care of, if necessary. The window is never the time or place for such a discussion. The work must be run and must leave the garage on time.

The section below provides guidance on identifying and documenting procedures for all special events, including those markets with major football special events requiring operators to sign up in advance to work the games. Included in the section are any procedures regarding rotation of work based on seniority. Below is the documentation for MiamiDade Transit.

\section{Scheduling of Football and Special Events List}

With regard to football park-and-ride events, MDT will post a notice requesting operators to sign up for these services. Each division will then post this list in seniority order, which will apply for the first event. After the first event, the list will rotate on an established basis. The Charter Service for these events will also be 
operated from this list. Lists for high school football, as well as for the Orange Bowl Parade, Marlins games, and Thanksgiving, are separate from the football list.

An attempt shall be made to secure a sufficient number of operators to fill such needs on a voluntary basis; however, back-to-back football park-and-ride events will be treated as a single event and the list rotated after the last event involved. If, within 48 hours of the event, MDT has not secured sufficient operators, MDT has the right to call in operators scheduled to be off-duty on that day in reverse seniority order.

MDT will make a reasonable effort to equitably distribute extra work such as special events park-and-ride, and picked trippers among the bus operators of each operating division.

\section{Special Events}

The assignment of charter work shall be governed by the following procedures (except as indicated above):

- Special Events of a short duration (four hours or less) when determined by the Supervisor shall be tied in with other work so as to coordinate the starting time and location of charters with the availability of operators and buses.

- Special Events work may be assigned to regular operators on their regular work days only when extra board operators are not available. On their days off, Regular and extra board operators will be treated equally as to charter assignments on a first-come first-served basis.

The section below provides guidance on identifying and documenting procedures for dispatchers to follow during the bid process. Bidding usually requires multiple functions to participate, including dispatch. Below is the documentation for Miami-Dade Transit.

\section{Preparing for Schedule Line-Ups}

MDT will provide for at least one (1) general line-up each year. This line-up shall be effective in November. The general line-up shall determine facility locations and vacation schedules as well as work assignments. MDT will provide for at least two (2) more line-ups per year. Unless necessitated by service adjustments and/or other operational requirements, these line-ups will be divisional line-ups. One will be effective in April; the other will be effective in July. Additional line-ups may be 
scheduled as deemed necessary by MDT. For additional information, refer to the Collective Bargaining Agreement (Article VI.2).

It is the supervisor's responsibility to provide operators with bid slips for the lineup, to schedule reliefs for operators requesting reliefs when it is their turn to pick, and to manage manpower to ensure a proper supply of operators to make timely reliefs.

Every request for relief must be logged on the appropriate form, completing all portions of the form. Care must be taken with the logging of the operators requests for relief, as those logs are used by the staff conducting the pick. The pick is stopped when a particular operator's position is reached, and if he or she is not present, then the reason why the operator is not present must be determined. If the operator was unable to be relieved as requested, the pick will wait until he or she arrives. Therefore, this emphasizes the necessity of logging the operator's request for relief properly so that others will know when he or she is supposed to get relieved.

It is the supervisor's responsibility to ensure that the operators receive the appropriate bid slips. Bid slips are available for open runs, hold downs, and lineups. Bid slips for open runs must not be available during a line-up-do not post open runs once the line-up is posted. Any obsolete bid slips must be destroyed (not simply discarded). Every supervisor should be held accountable for determining the operator's need and providing him or her with the appropriate bid slip. Supervisors must also not accept a slip that does not identify the bidding operator-a supervisor must not sign a bid slip (thus accepting it) with no operator name on it.

The supervisor must fax all the bid slips and logs of requested reliefs to the bidding site. by 5:00 p.m. A roadcall operator will deliver the originals. The bidding site has traditionally been at Central Division.

- If the nearest fax machine is not working, another fax machine should be found and used-hand-delivery alone is not an option.

- The fax should be followed with a telephone call to confirm the receipt of the fax.

- If any problems occur with the steps outlined above, the lead supervisor must be contacted.

The supervisor is responsible for ensuring that the line-up is properly posted. He or she should immediately report any problems with the posting of the line-up. The supervisor must be aware of what is posted for the operators at his or her worksite, and be certain that the information is current. The supervisor should go and look at what is posted in the drivers' room and if something is posted that he or she does 
not understand, or something is posted that should not be, he or she needs to see to it that it is corrected.

When new Schedule Cards are made available by the Scheduling Department, supervisors at each division should:

- Make sure the hole number on each Schedule Card matches the corresponding number on the Dispatch Sheet.

- Make sure that each split and combination run has an Instruction Card (second piece of work) attached to it.

- Include all necessary attachments to each Schedule Card (ADA announcements, voice annunciation codes, etc.).

- Replace the old spares (Schedule Cards and Maps) with a new set of Schedule Cards and Maps.

- Replace the old Rotary with the new one.

The section below provides guidance in identifying and documenting equipment hardware and software to be used in dispatch. Beyond the documentation below, this section can also contain procedures to be followed for all CAD/AVL software used by the agency and other automated functions. Below is the documentation for Miami-Dade Transit.

\section{Office/Workstation Equipment for the Window Dispatch Function}

The window supervisor is responsible for the following pieces of equipment. The functioning of the equipment, hardware and software, is the responsibility of the supervisor on duty. The supervisor must report if repairs are needed (on his or her shift) and follow-up to ensure that any problems are fixed.

- Working telephone

- Computer workstation

- Working fax machine

- Working copy machine

- Electronic badge reader

- Hand-held radio

- P.A. system 
The section below addresses the need to identify and document lost and found procedures to include collection, handling and storage of items once in possession of the agency. Below is the documentation for Miami-Dade Transit.

\section{Lost and Found Procedures}

Items lost and mislaid by customers are found at various locations. These items, when found, are the responsibility of MDT and will be handled so as to provide the utmost security for the item(s). The found item(s) will be turned in to the appropriate location. Lost and Found is usually located at the operating base or major transit transfer locations staffed with Customer Service personnel. As a means of maintaining proper control of such items, it is important that when a lost item is received, each receiving office cooperate in establishing control over the item.

The section below addresses the need to identify and document forms that are used in the dispatch function on a daily basis with a description of the form and then the form in an appendix. Below is the documentation for Miami-Dade Transit.

\section{Forms for the Dispatch Function}

The following is a selection of the most important forms used by the supervisor in the window dispatch function. Copies of each form follow the descriptions.

\section{Bus Operator Leave and Attendance Report}

This form (printed on green paper) is used to record leave taken by bus operators. Information on the type of leave is to be included. Categories include breakdown, accident, unscheduled relief, leave usage (vacation, etc.), non-operating time, recap correction, light duty, special duty, and training.

\section{Metrobus Operator's Pre-Trip Inspection}

This card is to be handed out to operators upon checking in at the window. The operators fill out the card at their vehicle before leaving the lot. 


\section{Bus Operations Causeway Toll Cards}

This form logs information on toll passes. The original goes to the lead worker with a copy to the Division.

\section{SunPass Log}

The SunPass log allows the supervisor to keep track of operators signing in and signing out SunPass transponders.

\section{Failure to Run Badge/Report Sick or Excused/Show for Picked Tripper Log}

This form contains space for the supervisor to keep track of and record reasons for occurrences of bus operators failing to swipe their badges, failing to report sick or excused within 45 minutes of their report time, and failing to show for a picked tripper.

\section{No-Show Picked Tripper Memo}

This memo goes to the Superintendent and contains information on an operator noshow for a picked tripper.

\section{Reasonable Suspicion Observation Form}

A bus operator must meet at least two of the different behaviors listed on the form to show reasonable suspicion of using alcohol or controlled substances. If reasonable suspicion exists, the operator shall be taken immediately for a reasonable suspicion drug/alcohol screen in accordance with County procedures.

Criteria on the form include observations on the operator's appearance, body coordination, general attitude, mood, speech, and general behavior. The Supervisor can provide additional comments on the form, as well.

\section{Metrobus Operator's Defective Coach Report}

This form is for the operator to fill out when there is a problem with his or her vehicle.

\section{Lot Change and Roadcall Window Log}

This form records lot change and roadcall information for vehicles at a given division.

\section{Fare Transaction Worksheet}

This form provides a count of all fare types received by an operator of a given route and run. The form must be returned to a Supervisor at the end of the route/shift. 


\section{Farebox Trouble Log}

This form is used to report trouble with fareboxes on buses. Information includes the initial problem, the notification made, and when the service call is completed.

\section{Roadcall Operator}

This form is used to log assignments of a roadcall operator over the course of a day.

\section{P-Car Loaner Form}

The P-Car Loaner lists the date, P-Car number, beginning and ending mileage, driver's name, time out and back in, and the destination. The supervisor's responsibility includes:

- Making sure all operators sign the Key Log.

- Making sure keys are not transferred from operator to operator.

- Having the roadcall operator fuel the P-Cars daily at the end of their shift.

- Being accountable for all keys at the end of the window supervisor's shift.

- Having knowledge of the whereabouts of P-Cars and the return of P-Cars.

- Keeping gas cards with the window supervisor or Lead's Office.

- Making sure that mileage is recorded daily.

- Reporting any damage to P-Car(s) immediately.

- Making sure that P-Cars are used for business purposes only!

\section{Lost and Found Daily Log}

This form is used to record information pertaining to lost and found articles left by customers on transit vehicles or at stops/stations. This form must be completely filled out and signed as appropriate.

\section{Extra List Worksheets}

These sheets assist the supervisor in calculating the extra list for a particular day.

\section{Extra Work Penalty List}

This form lists operators who fail to report for their scheduled extra list duty. operators remain on this list for seven days and during that time are ineligible for the extra list.

\section{Hold Down Bid Slip}

This form is an example of a board operator Hold Down bid slip. 


\section{Yard Duty Bid Assignment Form}

This form is to be signed and a copy attached to the bid slip and the bid receipt for each operator bidding or selecting this assignment.

In 2000, Miami-Dade Transit (MDT) published a Standard Operating Procedure (SOP) entitled, "Bus Traffic Controllers' System Operations Procedures Manual," which is the SOP for all radio functions. Since more systems today have CAD/AVL capability, the language used below is very descriptive of many dispatchers' functions and duties today in 2012. As with the previous SOP, below are techniques to adapt the Miami-Dade language to other transit systems (in red italic). Smaller systems may not require as much formality as larger transit systems in completing an SOP effort.

\section{Bus Dispatch - Radio Standard Operating Procedure}

In this section, the transit agency should
identify and document forms that are
used in the dispatch function on a daily
basis with a description of the form and
then the form in an appendix. Below is
the documentation for Miami-Dade
Transit.

\section{Function of the Bus Traffic Controller}

Keeping buses on schedule is a vital component of providing high quality transit service. In the past, radio supervisors had no idea of the actual location or schedule adherence of buses. They could only react to messages received from bus operators or field supervisors. In essence, they were operating in the dark. The small force of field supervisors, try as they might, could not hope to keep track of the schedule adherence of 500 Bus Operators driving on more than 70 routes.

MDT supervisors now have the ability to "see" and know the status of all buses in terms of schedule and route adherence. AVL systems have revolutionized the supervisory function. The Bus Traffic Controllers, in conjunction with a fully functioning AVL system, is in a position to proactively manage MDT's bus service, rather than waiting for situations to come to their attention over the radio. Therefore, the title of Controller is appropriate. Bus Traffic Controllers have more authority and responsibility than radio dispatch supervisors had in the past. Division dispatchers may be responsible for buses and operators while they are in the yard, but all buses and operators in the field are the responsibility of the Bus Traffic Controllers. MDT envisions the Bus Traffic Controllers as being responsible for the "management" of the system. 
The Controller must have a high level of energy and a strong sense of personal accountability for high quality customer service. MDT expects and requires that Controllers continuously monitor the AVL consoles and take actions to improve bus schedule adherence. This will include identifying buses that are ahead of schedule and directing them to slow down to get back on schedule; identifying buses that are about to bunch into each other and coordinating the actions of the bus operators to restore proper spacing and bus headways; identifying buses running significantly behind schedule and directing field supervisors to the exact location of the bus to determine the cause and take corrective action. These activities can be expected to improve schedule adherence significantly, and make service more reliable for our customers.

The more proactive Bus Traffic Controllers can be in monitoring schedule adherence, the less time field supervisors will need to spend identifying such problems. This will allow field supervisors to spend more time performing other duties where they can be of assistance to passengers and operators. For example, having field supervisors spend more time at transfer centers will allow them to better control bus service leaving these critical locations in the system. Having an MDT representative at the transfer points to provide information, check on the condition of buses and facilities, assist disabled passengers, and give directions to tourists will be another way of "meeting the mobility needs of our customers."

If the Bus Traffic Controllers do their jobs well, MDT's on-time performance and customer focus will improve, helping the agency accomplish its mission of providing "safe, reliable, and courteous transit services."

\section{Team Approach}

Bus Traffic Controllers will work from individual consoles in the Communications Control Center (Bus Central Control), and will be primarily responsible for monitoring buses and handling calls in the order they are received. However, Bus Traffic Controllers are all operating within close proximity of each other, and must regard themselves as part of a team of controllers for the entire bus system. They must operate in a spirit of shared information. They should seek input from other controllers who might have pertinent information regarding any incident. All controllers shall be aware of all major incidents, and be prepared to cover the responsibilities of another if the other controller has to leave the Control Center for any reason. The phrase "not my job" does not apply in the Bus Central Control room.

The Lead Bus Traffic Controller will have the responsibility of establishing priorities within the Control Center, but everyone in the Control Center is ultimately responsible and accountable for all the calls received. A team approach and spirit among Bus Traffic Controllers is required and expected. 
The team approach must also be extended beyond the Control Room. It is important to remember that Bus Traffic Controllers are an integral part of a larger team of all Metrobus employees responsible for the reliable and timely delivery of service for the customers. As such, it is essential that Controllers work well and maintain good rapport with others outside of the Control Room, and with bus operators in particular. For example, Controllers must always exercise courtesy, patience, and tact when speaking with an operator, and controllers should call an operator by name (once verified).

\section{Responsiveness}

In addition to continuously monitoring and enforcing schedule adherence from consoles, a major responsibility of Bus Traffic Controllers is to respond to emergency situations. Silent alarms must be responded to immediately (within seconds), above all other duties. Every Bus Traffic Controller in the Central Control room shall be aware of a silent alarm and be prepared to assist in stabilizing the situation. Similarly, Priority Requests To Talk (PRTT) must be responded to within two minutes. This rapid response is required not only in the interest of protecting the health and safety of passengers and operators, but to increase the level of trust between bus operators and bus operations supervisors. Bus Traffic Controllers must place themselves in the shoes of a bus operator who is expecting assistance in a tense situation. Bus operators will be counseled on when it is appropriate to use PRTT versus RTT.

If Bus Traffic Controllers are already communicating with an operator when another PRTT is received, the Controller should courteously, but firmly advise the operator to whom they are already communicating with, that another high priority call has been received to which they must respond. An acceptable approach would be "Operator (name), I need you to stand by. Another priority call has been received. I will get back to you shortly."

This manual has been prepared to offer guidance in the many decisions that must be made by the Bus Traffic Controller. There are many procedures that have been prepared to assist in working with the consoles' electronic equipment and programs when dealing with specific situations. However, this manual cannot possibly anticipate every situation that a Bus Traffic Controller will encounter. Much of the Bus Traffic Controller's function will be to utilize good judgment and common sense "consistent with prudent business practices." This is another reason why a team approach among Bus Traffic Controllers is important. Good judgment can often be enhanced when sharing information and ideas with others. 


\section{Allocation of Responsibilities in the Control Center}

To facilitate the team approach to the proactive management of the bus system and the responsiveness of the team to problems with buses, each Bus Traffic Controller can be expected to be assigned particular duties on his or her shift. These duties, explained in detail in subsequent sections of this Manual, will be rotated so that each Controller is fully capable of handling all functions in the Bus Central Control room.

First, Bus Traffic Controllers are responsible for responding to silent alarms and other priority service interruptions (such as accidents and other incidents) via radio or telephone communications. Beyond emergencies and other priority interruptions, Controllers must also respond to other roadcalls and work to restore interrupted bus service.

It is extremely important that Controllers answer a ringing telephone immediately. If a Controller is dealing with a radio call when the telephone rings, he or she must put the radio call on hold and answer the phone. If it is determined that the telephone call is not an emergency or priority, then the telephone call can be placed on hold and the radio call resumed.

Second, Controllers are also responsible for monitoring the schedule adherence of buses in the system. The CAD system randomly lists buses that are not adhering to their schedules, while the AVL system allows the Controller to visually spot vehicles that are running either early or late in real time. Controllers should also expect to be assigned a particular route to monitor on a given day (this might be based on data from the CAD system, or perhaps from passenger complaints to MDT regarding a particular route). Finally, Controllers are responsible for reporting all relevant information regarding accidents, incidents, and other roadcalls accurately and in a timely manner.

Of the six consoles in the Control Center, at any given time three or four are assigned to deal with service interruptions first (and schedule adherence second), while another is assigned to deal primarily with schedule adherence. The Controller assigned to console \#5 acts as more of a facilitator among the other consoles, dealing with, among other tasks, communications on the Operations channel, distribution of telephone calls, and dealing with silent alarms (as well as resolving roadcalls and monitoring schedule adherence). 


\section{In this section, the transit agency should identify and document dispatchers' responsibilities in monitoring schedule adherence within the context of the dispatchers' overall job duties. For instance, unless a transit agency can dedicate a dispatcher to monitor schedule adherence, then the role may be limited due to the other types of incidents dispatchers must manage (service, equipment and passenger incidents). Below is the documentation for Miami-Dade Transit.}

\section{Schedule Adherence}

A Bus Traffic Controller's primary responsibility is to keep service in place and on time. The schedule and the passengers are the highest priority of a Bus Traffic Controller. The safety of passengers is MDT's first concern, and there will be times when buses will need to be removed from service. However, Bus Traffic Controllers should use their experience and good judgment to find ways to keep service moving as closely to printed schedules as possible.

An important element of the Bus Traffic Controller's job is to monitor the schedule adherence of MDT's buses on a continuous basis. This means that when there are no calls from operators that require assistance, Controllers shall be actively watching the Automated Vehicle Location ( $A V L$ ) screens on their consoles to determine how the system is performing. In addition, Controllers shall monitor the Schedule Adherence queue of the Fleet-CAD main screen to see a continuously updated list of vehicles that are running either early or late, or have missed their scheduled trip. There are numerous actions Controllers can take to help ensure service is being provided as it should be to promote customer-oriented, high-quality service, in accordance with MDT's mission statement.

\section{Using the CAD/AVL System to Monitor Schedule Adherence}

The Schedule Adherence queue is located in the lower left area of the CAD screen. This queue lists, randomly, vehicles that are ahead or behind schedule, or that have missed their scheduled trip. For each vehicle number in the queue, the time is shown, as well as the operator's badge number, route, run number, status (early, late, missed), and minutes early or late. By pressing the DO key, a schedule processing menu will appear with the following tools:

- Show Schedule - This displays the schedule of a vehicle in the queue and displays an arrow next to the last time point the vehicle passed. 
- Zoom to Veh(icle) - This automatically zooms to the vehicle on the AVL screen within a $1 / 2$-mile radius and level 2 street names.

- Clear and Log - This clears the vehicle information once processing is complete.

- Exit - This closes the Schedule Adherence processing menu.

\section{Buses Running Ahead of Schedule}

Approximately 11 percent of MDT's service has run "hot" (ahead of schedule) in the past. From Central Control consoles, Bus Traffic Controllers should be able to detect buses that are ahead of schedule (shown as pink on the AVL screen). The Controller should contact the bus shown running hot and ask the operator to state the vehicle's location (to confirm the CAD/AVL information). Assuming the bus is running ahead of schedule, the operator should be advised to slow the bus down or pull off to a safe location until it gets back on schedule. This type of monitoring alone, if done continuously and conscientiously by Bus Traffic Controllers, can help MDT achieve the short term goal contained in the Strategic Plan of 80 percent ontime bus performance. Please refer to the Schedule Adherence Procedure for buses running ahead of schedule contained in Appendix C.

\section{Buses Running Behind Schedule}

Similarly, Bus Traffic Controllers should detect and communicate with buses that are running behind schedule (shown as yellow on the AVL screen). Again, the Controller should contact the bus shown running late and ask the operator to state the location of the bus. Assuming the bus is running behind schedule, the operator should be asked to try to get back on schedule, within the parameters of safety. Sometimes just putting the operator on notice that his or her schedule is being monitored is enough to encourage the operator to make every effort to get the bus back on schedule. The operator should also be asked if there are any contributing factors to the bus running behind schedule. If there are conditions such as road work, an accident, adverse weather, flooding, or other conditions beyond the control of the operator, there may be little that can be done to immediately correct the schedule adherence for that bus. However, the Controller will at least know what conditions are affecting schedule adherence on that route and share that information with field supervisors and operators who can possibly make minor adjustments for other buses on that route. Other conditions such as heavy road traffic or heavy passenger loads could be causing the bus to run late. Again, it is beneficial for the Controller to know these conditions and share this information with bus operations managers and schedulers who can take steps of a more permanent nature to address these conditions in a manner that will result in better on-time performance in the future. 
The Bus Traffic Controller should try to consider all factors before resetting a bus that is behind schedule. For instance, a bus might be running late, but its follower might have broken down. In such cases, it might be more appropriate to allow the bus running late to continue running late until a replacement can be found for the bus that has broken down. This will allow more uniform spacing of the buses ahead of and behind the bus that is running late.

Bus Traffic Controllers need to be aware of "bunching" of buses, where buses are not properly spaced in accordance with their schedules. If a bus has fallen behind schedule to the point where its follower is almost behind it, the Controller might advise the operator of the behind-schedule bus to put an "Out of Service" sign on the bus's headsign and go into the mode of only dropping off passengers until it has increased the space between its follower. If the following bus has virtually caught the lead bus, and the following bus has capacity, the lead bus might be instructed to deboard its passengers after issuing emergency transfers, then deadhead to a location that puts the lead bus back on schedule. Bus operators who are deboarding passengers in this fashion should be instructed to announce to their passengers that "Due to operational difficulties, it is necessary for passengers to alight from this bus and board the bus behind us." However, Controllers should have passengers change buses only as a last resort, particularly if weather conditions are adverse. Controllers can authorize a bus to go ahead of its leader if that is the best solution for the passengers, and such action does not prevent the buses from being put back on schedule shortly thereafter. Bus Traffic Controllers should manage service with the principle that it is more important to maintain headways for passengers than it is to maintain bus operators on their own run schedules.

\section{Field Supervisors}

Part of the reason Bus Traffic Controllers are required to continuously monitor the CAD/AVL screens is to allow field supervisors to spend more time at other duties, and less time doing schedule adherence-related work. Schedule adherence checks currently consume about 40 percent of a field supervisor's time. They will still perform this function, but it is MDT's plan for Bus Traffic Controllers to help minimize the time field supervisors spend on this activity. Field supervisors can provide better value for passengers and operators if they are able to spend more time at bus transfer points. From these locations, they can perform a number of functions to improve MDT's service to the public, including, but not limited to:

- helping control schedule adherence by ensuring that buses leave transfer centers on time

- providing information to the public on routes and schedules 
- advising passengers of the real-time status of buses coming into the transfer point (assuming they have access to AVL information)

- assisting disabled passengers who find navigating the bus system challenging (this is particularly important as MDT encourages more and more persons with disabilities to use regular Metrobus service rather than Specialized Transportation Services);

- assisting tourists who need more help than most passengers in terms of directions and information

- providing information to bus operators on route conditions and assist them in other ways, as well as monitor the operators for proper uniforms, transfers, schedules, etc.

- monitoring the activities of personnel who may be hired to clean the transfer centers and the interior of buses as they idle at transfer centers

As stated earlier, these types of activities can add value to MDT's performance, and can only be accomplished if Bus Traffic Controllers monitor their consoles and stay on top of schedule adherence throughout the system.

\section{Common Sense Guidelines for Maintaining Service}

Many different situations will develop that will require Bus Traffic Controllers to make decisions on how to maintain schedule adherence and service. Each situation will be unique, so it is not possible for a manual to prescribe exactly how to deal with each incident. Clearly, Bus Traffic Controllers will benefit from experience in transit, training in the art of dispatching and, above all, common sense. Provided below are factors that a Controller should consider before making a decision to alter bus schedules or take a bus out of service. The general guideline should be:

\section{Maximize Service - Minimize Downtime}

- Safety - A bus operator might be dealing with circumstances involving essential safety factors such as brake lights, brakes, lights, wipers, seat belts, or inoperative doors. In such cases, there is clear liability to the County if the bus is kept in service. The bus operator's judgment will need to be relied upon to determine if the bus can be operated in a safe manner to the nearest layover point. Ordinarily, the best course of action may be to have the bus pull over at the next available safe location. From that point, the Controller must determine if the problem can be fixed in a timely fashion while the bus is on the road. Many of the conditions listed above can be fixed by a service truck mechanic in the field. However, an important consideration must be how long it will take the service truck to arrive at the scene.

- Nature of problem - If there is a problem with the bus that does not present clear danger, but still requires repair (e.g., inoperative wheelchair lift, non- 
registering farebox, low air conditioning), advise the bus to stay in service and arrange for mechanical assistance at the nearest layover point or at the end of the route, depending on when service truck assistance can be obtained. This will allow passengers to make connections and offers a time and place where work can be done with the least disruption to passengers.

- Passenger load - The more passengers there are on a bus, the more important it is to keep the bus in service, if possible. This is especially so for peak morning service heading toward schools, major shopping centers, downtown or other employment centers. This is also important for buses going the opposite direction in the evening peak.

- Frequency of service - It is easier to put a bus out of service on a route with highly frequent service than on a route with infrequent service. For instance, if there is 10 minute service on a route, it is not disastrous to ask passengers to deboard and wait for the next bus which will only be 10 minutes away. Ideally, the bus operator should try to get the bus to the next transfer point to allow passengers to make their connections. It is far more inconvenient to ask passengers who are traveling on a route with 60 minute headways to deboard and wait for the next bus.

- Nature of service - The last bus on a route before service terminates is an extremely important bus for passengers, since they have no other alternative. This bus should be kept in service if at all possible, or replaced to avoid stranding any passengers. The same principle applies to any single-trip service provided by MDT.

- Use your experience - A Bus Traffic Controller's experience will advise that some problems are very difficult to have corrected on the road. If in doubt, call the maintenance shop or check with fellow Bus Traffic Controllers who are available for their opinion on whether a replacement bus should be sent or if the service truck mechanic stands a good chance of fixing the problem. If a service truck is nearby, a decision on whether to trade the bus out can be delayed. However, if the service truck is some time away, it is better to arrange for a replacement bus of the same model, if at all possible. It is better to err and send a bus that might not be needed than to not send a bus when it is ultimately determined to be needed. Again, the schedule and the passengers are the Bus Traffic Controller's highest priorities. The Controller should be mindful that a bus that has been fixed by the service truck is available to be placed back in service prior to returning to the shop, if needed for another situation where a bus has gone down for mechanical reasons.

- Time to get assistance - This factor is extremely important for the Bus Traffic Controller to consider. How far away is the nearest service truck? Are all 
service trucks busy, backed up, or far away from the bus? Is a stand-by bus nearby? Is there a division with a replacement bus nearby? Are there buses going out of service that are relatively close that could be directed to replace the bus? The Controller must have these facts before determining the appropriate action.

- Spares - If all other available buses are in service, and there are no spares, this will certainly be a factor in a Bus Traffic Controller's decision to keep a bus in service.

- Capacity - A Bus Traffic Controller should not "borrow" a bus from a route with high frequency if that bus has a heavy passenger load. This would amount to "robbing Peter to pay Paul."

Bus Traffic Controllers should follow the steps outlined below if it is determined that a bus needs to be removed from service:

1. Look for a stand-by bus if it is the closest resource that can be obtained.

2. Look for a bus going out of service if the stand-by bus is not readily available. This opportunity is more likely during peak hours when there are trippers that pull in and out of service. Keep in mind that bus operators going out of service do not have to honor the request to bring their bus to the operator in need of a replacement. Hence, it is important for bus traffic controllers to maintain a good rapport with all bus operators.

3. Seek a replacement bus from one of the divisions.

4. Take buses from the nearest route that has high frequency that can be spared. If all those buses are running full, this would not be a wise decision. However, if there is a bus carrying a relatively light load of passengers on a high frequency route, it could be diverted to help replace a bus on a route with less service.

5. Notify supervisors and bus operators of any service failures on a route.

As noted in the survey chapter of this report, transit agencies identified a total of 12 companies and products in place for dispatchers in their transit agency. In the section below, the transit agency should identify and document procedures for using the specific CAD/AVL tools used in the transit agency. Below is the documentation for Miami-Dade Transit. 


\section{Logging on and off the CAD/AVL Console}

The following procedure has been developed to provide guidance to Bus Traffic Controllers when logging onto and off the CAD/AVL console each day. Bus Traffic Controllers must complete the logon process as soon as they report to work and should logoff of the CAD/AVL system prior to leaving work at the end of their shift. When logging on, the CAD system will automatically start the AVL system.

Logging into the CAD/AVL Console:

The CAD/AVL workstation will display a logon window whenever you turn on the system, or each time someone has logged off the system at the CAD/AVL console.

To log onto the CAD/AVL system:

1. At the CAD screen, type your assigned User Name at the "LOGON" prompt.

2. Press the ENTER key. If the information is correct, The AR Processing queue, Schedule Adherence queue, and the IR queue will appear and the CAD will automatically start the AVL as access to the system is granted.

- Note: If the CAD screen is not at the "LOGON" prompt, please contact the System Administrator.

Logging off the CAD/AVL Console:

There are two different ways to log off of the CAD system. If a Controller logs off of a console without clearing the queue, pending incidents will reappear when the console is logged on again. This procedure allows a Controller to take a short break, but should not be used when ending a work shift. The "OFFLINE" procedure must be used when ending a work shift.

To log off the CAD/AVL system without clearing the AR queue:

1. Press the $\boldsymbol{F} \mathbf{2 0}$ function key.

2. Scroll down to highlight the "LOGOFF" option and press "RETURN."

3. After a successful LOGOFF, the screen will clear and the "LOGON" prompt will appear.

To log off the CAD/AVL system using the "OFFLINE" procedure:

1. Press the $\boldsymbol{F} \mathbf{2 0}$ function key.

2. Scroll down to highlight the "OFFLINE" option and press "RETURN." 
3. This will stop any new ARS from entering the AR queue. Process and clear all remaining ARS in the queue.

4. Once the AR queue is empty, press the $\boldsymbol{F} \mathbf{2 0}$ function key once more.

5. Scroll down to highlight the "LOGOFF" option and press "RETURN."

6. After a successful LOGOFF, the screen will clear and the "LOGON" prompt will appear.

In this section, the transit agency should identify and document procedures for radio and/or text communications to include etiquette, operator rules/professionalism in using the radio, and procedures for prioritizing call requests. Below is the documentation for Miami-Dade Transit.

\section{Establishing Communications with Bus Operators}

The CAD/AVL system allows you to communicate over the radio network with various buses. Bus Traffic Controllers can communicate with bus operators through voice calls or by sending text messages. The most common communication target is a single bus. However, the CAD/AVL system also makes it possible for Bus Traffic Controllers to make group calls to all of the buses assigned to a specific route or all buses in the MDT fleet.

Voice calls take place using three modes of communication: two-way calls to the driver handset, one-way calls to the driver speaker, and one-way calls to the bus's public address system. Single vehicle calls automatically default to a two-way call to the driver handset. Group calls automatically default to a one-way call to the driver's speaker. While the CAD/AVL system will allow the Bus Traffic Controller to override the default call type, two-way calls to a group of buses are not allowed.

Note: All two-way calls go through the vehicle's cab speaker first. Once the driver handset is lifted, the cab speaker is disengaged and all communications are transmitted through the driver handset.

Text messages can also be sent to one or more drivers when voice communication is not required. As with voice calls, text messages can be sent to a single bus, all of the buses assigned to a specific route, or all buses in the MDT fleet.

The following procedures have been developed to assist Bus Traffic Controllers when making voice calls or sending text messages to a single bus or a group of buses. 


\section{Making a Voice Call to an Individual Vehicle}

To call a single bus:

1. Press the UNIT COMMAND key (F12). This will position the cursor on the "COMMAND" line.

2. Type the vehicle number (vehicle numbers for buses must be preceded by a "0" - e.g., 02120) followed by a slash ("/"). For example, to talk to vehicle 1234, type the following at the "COMMAND" line: 01234/

3. Press the VOICE ON key. The CAD system will attempt to open a voice channel to the bus. An "ACK" message will indicate that the message was received at the vehicle. You may now speak to the bus operator by pressing the red Select $\boldsymbol{T} \boldsymbol{x}$ button on the Maestro keyboard and beginning voice communications.

If the CAD system is unable to communicate with the bus, a "NAK" message, indicating "Negative Acknowledgment," will be displayed, informing the Controller that the "VOICE ON" was unsuccessful.

4. Choose EXIT to close the connection and end the call.

\section{Making a Voice Call to all Vehicles in a Route or Fleet via the Driver Speaker}

To call all buses on a selected route:

1. Press the GROUP COMMAND key (F14). This will position the cursor on the "COMMAND" line.

2. Type an "R" followed by a slash ("/"), then the route number followed by another slash ("/"). For MDT routes that go by letters, such as " $L$ " or "S", please refer to the list on your console that shows the route numbers assigned to these routes. For example, to talk to all buses on Route 119, at the "COMMAND" prompt type: $\mathbf{R / 1 1 9 /}$

3. Press the VOICE ON key to talk to all vehicles on that route. An "ACK" message will indicate that the message was received by the vehicles. You may now speak to the bus operators by pressing the red Select Tx button on the Maestro keyboard and beginning voice communications.

If the CAD system is unable to communicate with the bus, a "NAK" message, indicating "Negative Acknowledgment," will be displayed, informing the Controller that the "VOICE ON" was unsuccessful.

4. Choose EXIT to close the connection and end the call. 
To call all buses in the fleet:

1. Press the GROUP COMMAND key (F14). This will position the cursor on the "COMMAND" line.

2. Type an "A" followed by a slash ("/"). For example, at the "COMMAND" prompt type: A/

3. Press the VOICE ON key to talk to all vehicles in the fleet. An "ACK" message will indicate that the message was received by the vehicles. You may now speak to the bus operators by pressing the red Select Tx button on the Maestro keyboard and begin to voice communications.

If the CAD system is unable to communicate with the bus, a "NAK" message, indicating "Negative Acknowledgment," will be displayed, informing the Controller that the "VOICE ON" was unsuccessful.

4. Choose EXIT to close the connection and end the call.

\section{Making a Voice Call to a Vehicle via the Public Address System}

To call a single bus via the vehicle's public address system:

1. Press the UNIT COMMAND key (F12). This will position the cursor on the "COMMAND" line.

2. Type the vehicle number (vehicle numbers for buses must be preceded by a "0" - e.g., 02120) followed by a slash ("/"). For example, to talk to vehicle 1234, type the following at the "COMMAND" line: 01234/

3. Press the PA ON key. The CAD system will attempt to open a voice channel to the bus. An "ACK" message will indicate that the message was received at the vehicle. You may now speak to the Bus Operator by pressing the red Select Tx button on the Maestro keyboard and begin voice communications.

If the CAD system is unable to communicate with the bus, a "NAK" message, indicating "Negative Acknowledgment," will be displayed, informing the Controller that the "PA ON" was unsuccessful.

4. Choose EXIT to close the connection and end the call.

Making a Voice Call to all Vehicles in a Route or Fleet via the Public Address System

To call all buses on a selected route through the public address system:

1. Press the GROUP COMMAND key (F14). This will position the cursor on the "COMMAND" line. 
2. Type an "R" followed by a slash ("/"), then the route number followed by another slash ("/"). For MDT routes that go by letters, such as " $L$ " or " $S$ ", please refer to the list on your console that shows the route numbers assigned to these routes. For example, to talk to all buses on Route 119, at the "COMMAND" prompt type: $\mathbf{R / 1 1 9 /}$

3. Press the PA ON key. The CAD system will attempt to open a voice channel to the bus. An "ACK" message will indicate that the message was received at the vehicle. You may now speak to the bus operator by pressing the red Select Tx button on the Maestro keyboard and begin voice communications.

If the CAD system is unable to communicate with the bus, a "NAK," message, indicating "Negative Acknowledgment," will be displayed, informing the Controller that the "PA ON" was unsuccessful.

4. Choose EXIT to close the connection and end the call.

To call all buses in a particular fleet through the public address system:

1. Press the GROUP COMMAND key $(\boldsymbol{F 1 4})$. This will position the cursor on the "COMMAND" line.

2. Type an "A" followed by a slash ("/"). For example, at the "COMMAND" prompt type: A/

3. Press the PA ON key. The CAD system will attempt to open a voice channel to the bus. An "ACK" message will indicate that the message was received at the vehicle. You may now speak to the bus operator by pressing the red Select Tx button on the Maestro keyboard and begin voice communications.

If the CAD system is unable to communicate with the bus, a "NAK," message, indicating "Negative Acknowledgment," will be displayed, informing the Controller that the "PA ON" was unsuccessful.

4. Choose EXIT to close the connection and end the call.

\section{Sending a Text Message to a Single Vehicle}

To send a text message to a single vehicle:

1. Press the UNIT COMMAND key (F12). This will position the cursor on the "COMMAND" line.

2. Type the vehicle number (vehicle numbers for buses must be preceded by a "0" - e.g., 02120) followed by a slash ("/"). For example, to talk to vehicle 1234, type the following at the "COMMAND" line: 01234/

3. Type the message you want to send to the operator, or press the "CANNED $\boldsymbol{T E X T}^{\prime \prime}$ key and select the desired pre-defined message using the arrow keys. 
4. Press the "RETURN" key and the message is sent. An "ACK" message will indicate that the message was received by the vehicle. If the CAD system is unable to communicate with the bus, a "NAK" message, indicating "Negative Acknowledgment" will be displayed.

\section{Sending a Text Message to all Vehicles in a Fleet or on a Route}

To send a text message to all buses on a selected route:

1. Press the GROUP COMMAND key (F14). This will position the cursor on the "COMMAND" line.

2. Type an "R" followed by a slash ("/"), then the route number followed by another slash ("/"). For MDT routes that go by letters, such as " $L$ " or " $S$ ", please refer to the list on your console that shows the route numbers assigned to these routes. For example, to talk to all buses on Route 119, at the "COMMAND" prompt type: $\mathbf{R} / \mathbf{1 1 9} /$

3. Type the message you want to send to the operator, or press the "CANNED TEXT" key and select the desired pre-defined message using the arrow keys.

4. Press the "RETURN" key and the message is sent. An "ACK" message will indicate that the message was received by the vehicle. If the CAD system is unable to communicate with the bus, a "NAK" message, indicating "Negative Acknowledgment" will be displayed.

To send a text message to all buses on a selected route:

1. Press the GROUP COMMAND key (F14). This will position the cursor on the "COMMAND" line.

2. Type an "A" followed by a slash ("/"). For example, at the "COMMAND" prompt type: $\mathbf{A} /$

3. Type the message you want to send to the operator, or press the "CANNED TEXT" key and select the desired pre-defined message using the arrow keys.

4. Press the "RETURN" key and the message is sent. An "ACK" message will indicate that the message was received by the vehicle. If the CAD system is unable to communicate with the bus, a "NAK" message, indicating "Negative Acknowledgment" will be displayed. 
In this section, the transit agency should identify and document procedures for addressing not only extensive vehicle delays but other types of incident management to include service incidents, equipment incidents and passenger incidents. All incidents that require some type of response should be addressed with specific procedures. Even Miami-Dade Transit acknowledges to its employees that not every incident can be included in a manual, so in some cases dispatchers must use their judgement and experience. Below is the documentation for Miami-Dade Transit.

\section{EXTENSIVE VEHICLE DELAYS}

The following procedure has been developed to assist Bus Traffic Controllers in the event that extensive delays affecting MDT buses are expected due to major traffic accidents, street hazards, or any other incident affecting vehicle movement.

1. Determine which bus(es) will potentially be affected by the traffic delay.

2. Locate the affected bus(es) using the AVL system.

3. Locate an available Field Supervisor and dispatch that supervisor to the scene. The Field Supervisor should be directed to assess the situation in order to initiate alternate routes for affected buses as an effort to decrease delays.

4. Communications with all Field Supervisors and/or service trucks will be conducted in the following manner:

(a) The initial call to an available Field Supervisor and/or service truck should be made over the Operations "Open" radio channel.

(b) Once contact has been made, the field unit should be instructed to switch the radio to the Bus Traffic Controller console's direct radio channel. (You must provide the field unit with information regarding the appropriate radio channel.) All subsequent communication between you and the field unit should take place over your direct radio channel, rather than over the "Open" Operations radio channel. 
5. Enter preliminary information into CAD Vehicle Incident Report by moving the mouse pointer to the menu window, making the DISPA - Dispatcher Menu active on the CAD monitor. Select INCDT and press the DO key. The Incident Maintenance window will appear.

6. After conferring with the Field Supervisor on the scene about the location of alternate bus route(s), make a group call to all buses on the affected route(s) providing instructions regarding alternate routes implemented to minimize delays.

7. Instruct the bus operator(s) to inform passengers of all delays and alternate routes.

8. Notify division dispatch of actions taken to re-establish bus service outside areas experiencing traffic delays.

9. Notify Customer Services and update Public Information operators periodically as service is adjusted or modified (see Appendix B).

10. You must enter all information pertaining to any temporary alternate routes implemented due to severe traffic delays, including affected route(s) and any lost time in TOS and the CAD Vehicle Incident Report.

11. Notify the appropriate MDT personnel, as outlined in the MDT Emergency Check/Call List included in Appendix A. Provide specific information about the incident and actions taken to stabilize the situation.

In this section, the transit agency should identify and document procedures for not only silent or covert alarms, but any type of emergency situation that requires a potential response of supervisors and local police. Below is the documentation for Miami-Dade Transit.

\section{SILENT ALARM}

All buses in the MDT fleet are equipped with silent alarms. The silent alarm is to be activated by a bus operator only when the operator's life or the lives of passengers are in danger and it is not safe to use regular radio procedures (e.g., hostage situation, a gun is being pointed at the operator, a fire on the bus that requires immediate evacuation, a bomb threat and/or explosion on the bus, etc.)

When an operator activates the on-board silent alarm, the CAD system generates an audible alarm and a red "alert" box with the vehicle's number displayed in the lower left corner of all AVL monitors. In the event that the silent alarm was 
triggered accidentally, MDT bus operators have been instructed to immediately press the PRTT (priority request to talk) button and inform the Bus Traffic Controller that this was an error. It is now appropriate to have voice communications with the bus operator and confirm that the silent alarm was triggered in error.

All Bus Traffic Controllers should PARK (F9) the calls that they are working on, place all other activities on HOLD and be prepared to assist in stabilizing the silent alarm incident. When PARKing calls, be sure to inform the bus operator that communication will be reestablished as soon as the emergency situation has been stabilized.

1. To "Park" an attention request, simply press the PARK (F9) key. The attention request will be placed at the bottom of the attention request queue and may be selected at a later time by pressing the SELECT key (F7) and entering the vehicle number (refer to procedure for making a two-way call to a vehicle).

The following steps should be taken when addressing a silent alarm alert:

1. If more than one silent alarm alert is received at the same time, Bus Traffic Controllers must address each silent alarm alert IMMEDIATELY.

2. Click on the white portion of the red alert box displayed in the lower left corner of the AVL monitor. An "alert vehicle information" window will then be displayed on the AVL screen that contains the vehicle number, vehicle position, vehicle route, the nearest supervisor vehicle and its position, as well as a list of the five (5) nearest vehicles (buses, supervisors, and/or service trucks). The alert vehicle is automatically displayed in the center of the AVL map and will remain in the center of the AVL screen until the silent alarm is acknowledged.

If the vehicle is located in the MDT garage yard:

1. Acknowledge and Clear the silent alarm immediately. Acknowledge the silent alarm by pressing the NEXT key (F6). This action moves the emergency attention request to the selected attention request screen and silences the audible alarm in the control room. The red alert vehicle box will be removed from the AVL screen as soon as the silent alarm is acknowledged.

2. Downgrade the acknowledged Silent Alarm to Alarm Clear by pressing the CLEAR ALARM key. The CAD/AVL system then changes the Code field in the selected attention request screen to Almclr. 
3. Immediately attempt to contact the vehicle via the radio, as described in procedures for making a two-way call to a vehicle, and attempt to determine the nature of the silent alarm.

4. Call Division Dispatch and ask for someone to be sent into the yard to check on the bus and make sure that there is no emergency.

5. If necessary, send a field supervisor or mechanic to the MDT garage yard to assess and/or stabilize the situation.

6. Communications with all field supervisors and/or service trucks will be conducted in the following manner:

(a) The initial call to an available field supervisor and/or service truck should be made over the operations "open" radio channel.

(b) Once contact has been made, the field unit should be instructed to switch the radio to the Bus Traffic Controller console's direct radio channel. (You must provide the field unit with information regarding the appropriate radio channel.) All subsequent communication between you and the field unit should take place over your direct radio channel, rather than over the "open" operations radio channel.

7. If necessary, contact the police immediately, as outlined in the MDT Emergency Check/Call List included in Appendix A. (A list of Emergency phone numbers, including police and fire facilities can be found in Appendix B.). Provide all available information, including the current location and direction of the vehicle under an emergency alert, as well as whether the vehicle is still in motion.

8. Once the silent alarm incident has been stabilized, log and complete the alarm attention request by pressing the LOG key (F10). Important: You should not log any silent alarm attention request until the situation has been fully resolved, as logging the silent alarm breaks communication with the vehicle and clears the attention request.

9. Complete the CAD Vehicle Incident Report by moving the mouse pointer to the menu window, making the DISPA - Dispatcher Menu active on the CAD monitor. Select INCDT and press the DO key. The Incident Maintenance window will appear. Note: An Action Code must be entered in the Vehicle Incident Report to "close" and complete the report.

If rescue services were sent to the scene, the Accident/ Incident/Silent Alarm Memorandum Form must include the rescue vehicle number and alarm number information received from the field supervisor dispatched to the scene. 
If the silent alarm was activated accidentally, this information must be included in the comments portion of the CAD Vehicle Incident Report.

10. Complete Accident/Incident/Silent Alarm Memorandum Form. After final disposition has been achieved for the emergency, the Accident/Incident/Silent Alarm Memorandum Form must be completed by the Bus Traffic Controller who responded to the original Silent Alarm attention request.

If rescue services were sent to the scene, the Accident/ Incident/Silent Alarm Memorandum Form must include the rescue vehicle number and alarm number information received from the field supervisor dispatched to the scene.

If the silent alarm was activated accidentally, this information must be included in the Accident/Incident/Silent Alarm Memorandum Form.

11. Begin notifying the appropriate MDT personnel, as outlined in the MDT Emergency Check/Call List included in Appendix A. Provide specific information about the incident and actions taken to stabilize the situation. If they cannot be reached by telephone, you should contact them by pager. This notification procedure applies seven days a week, 24 hours a day. You must also notify the operator superintendent and division chief.

If the vehicle is NOT located in the MDT garage yard:

1. Acknowledge the silent alarm. Silent alarms supersede all other attention requests and possess the highest priority in the attention request queue.

The Bus Traffic Controller who is handling the silent alarm alert must first acknowledge the silent alarm by pressing the NEXT key (F6). This action moves the emergency attention request to the selected attention request screen and silences the audible alarm in the control room. The red alert vehicle box will be removed from the AVL screen as soon as the silent alarm is acknowledged.

2. Look up the vehicle in TOS (U42) to get information of the vehicle's scheduled route and run. Contact window dispatch to confirm TOS information.

3. Contact the police immediately, as outlined in the MDT Emergency Check/Call List included in Appendix A. (A list of Emergency phone numbers, including police and fire facilities can be found in Appendix B.). Provide all available information, including the current location and 
direction of the vehicle under an emergency alert, as well as whether the vehicle is still in motion.

4. Identify and locate the closest available field supervisor. Advise the closest available field supervisor of the location and direction of the vehicle under an alert condition and dispatch the supervisor to address the emergency situation.

5. Communications with all field supervisors and/or service trucks will be conducted in the following manner:

(a) The initial call to an available field supervisor and/or service truck should be made over the operations "open" radio channel.

(b) Once contact has been made, the field unit should be instructed to switch the radio to the Bus Traffic Controller console's direct radio channel. (You must provide the field unit with information regarding the appropriate radio channel.) All subsequent communication between you and the field unit should take place over your direct radio channel, rather than over the "open" operations radio channel.

6. Continue to monitor the vehicle's location. Update and inform the police and the field supervisor dispatched to the scene regarding the vehicle's status (i.e., vehicle is continuing on scheduled route, vehicle has stopped and is remaining stationary, vehicle is traveling in an erratic pattern, etc.)

7. Begin completing an on-line CAD Vehicle Incident Report by making the DISPA - Dispatcher Menu active on the CAD monitor. Select INCDT and press the DO key. The Incident Maintenance window will appear.

8. If an emergency situation is declared based on field supervisor and/or emergency personnel observations, you must notify all appropriate MDT personnel, as outlined in the MDT Emergency Check/Call List included in Appendix A. You must be prepared to provide specific information about the incident and actions taken to stabilize the situation.

9. Once supervisory personnel and/or emergency representatives have evaluated the situation and determined that the situation has been stabilized, you should downgrade the acknowledged Silent Alarm to Alarm Clear by pressing the CLEAR ALARM key. The CAD/AVL system then changes the Code field in the selected attention request screen to Almclr.

10. If the field supervisor(s) on the scene of the emergency determines that the operator and/or bus must be taken out of service, you must make sure that the following points are considered while working to restore bus service on the scheduled route: 
(a) Every effort should be made to restore service to the route involved by sending a replacement bus and operator to the nearest time point. Notify the field supervisor on the scene of the emergency what action you have taken toward this end when the field supervisor calls back with specifics within 15 minutes of arrival.

(b) If the bus is taken out of service (DEAD), the information must be entered into $\mathrm{U} 62$ and $\mathrm{V} 62$ in TOS.

(c) In the event of Silent Alarm Incidents that result in fatal accidents, injured person(s) who immediately receive medical attention away from the scene; and/or any vehicle involved in the incident is disabled (towed away), the perator must be relieved for a mandatory post-accident drug test. The field supervisor on the scene should transport the Operator to be tested as soon as possible, as FTA test requirements do have a time limit.

You must also notify the operator's division superintendent and division assistant general superintendent. If they cannot be reached by telephone, you should contact them by pager. This notification procedure applies seven days a week, 24 hours a day.

(d) The operator involved may (if not injured), at the field supervisor's discretion, be relieved and returned to the garage so that an immediate report of the emergency situation may be made.

(e) If the bus must be removed from service as a result of the silent alarm incident, you must call the division dispatch and report the bus number, operator name and badge number, route and run number, and the nature of the problem. Division dispatch will check on the status of spare buses in the field and determine if a replacement bus or cut-out is available. $\square$ Note: If there is no replacement bus available, it is permissible, under certain circumstances, to call the bus division that is closest in proximity to the problem bus in order to minimize passenger delay (e.g., if a bus is going out of service for the day).

(f) If a replacement bus or cut-out bus is available, the field supervisor on the scene will confer with you to determine where the bus will go back into service based on the least inconvenience to passengers and on the schedule and current bus spacing, indicated by the AVL system. This information must be added to TOS, the CAD Vehicle Incident Report and the Accident/Incident/Silent Alarm Memorandum Form. 
(g) If no replacement or cut-out bus is available, the bus should be sent to the garage. Once a bus becomes available, you will determine where the bus will go back into service based on the schedule and current bus spacing indicated by the AVL system. This information must be added to TOS, the CAD Vehicle Incident Report, and the Accident/ Incident/Silent Alarm Memorandum Form.

(h) If necessary, locate and dispatch an available service truck to the scene to determine if the bus is able to be driven to the garage. If the service truck mechanic determines that the bus cannot be safely driven, arrange for a tow truck to transport the bus to the garage.

(i) Division dispatch will instruct replacement operators and operators of replacement buses and/or cut-out buses to contact bus traffic control to provide replacement/cut-out bus information and receive information regarding cut-in information.

You must also instruct the operator to log into the CAD system using the transit control head installed in each bus. If a cut-out bus is being used, the operator must first log-out of the system and then log back into the system with the new route and run information you have provided.

11. If the bus is to remain in service, this information must be entered in TOS, the CAD Vehicle Incident Report, and the Accident/Incident/ Silent Alarm Memorandum Form.

12. If the Operator must be replaced:

(a) Call division dispatch and request a replacement operator. Division dispatch will determine the replacement operator. The field supervisor on the scene will confer with you to determine where the bus will go back into service based on the schedule and current bus spacing, established by referring to the AVL system. This information must be added to TOS, the CAD Vehicle Incident Report, and the Accident/Incident/Silent Alarm Memorandum Form.

(b) Division dispatch will instruct replacement operators and operators of replacement buses and/or cut-out buses to contact bus traffic control to provide replacement/cut-out bus information and receive information regarding cut-in information. 
You must also instruct the operator to log into the CAD system using the transit control head installed in each bus. If a cut-out bus is being used, the operator must first log-out of the system and then log back into the system with the new route and run information you have provided.

13. You must enter all information pertaining to replacement operators, replacement buses, cut-out buses, cut-in time and position, and lost time in TOS, the CAD Vehicle Incident Report, and the Accident/ Incident/Silent Alarm Memorandum Form.

(a) Enter all pertinent information pertaining to the silent alarm incident in U42, U62, and V62 in TOS.

(b) Complete Accident/Incident/Silent Alarm Memorandum Form. After final disposition has been achieved for the emergency, the Accident/Incident/Silent Alarm Memorandum Form must be completed by the Bus Traffic Controller who responded to the original Silent Alarm attention request.

If rescue services were sent to the scene, the Accident/Incident/Silent Alarm Memorandum Form must include the rescue vehicle number and alarm number information received from the field supervisor dispatched to the scene.

(c) Complete the CAD Vehicle Incident Report. Be sure to include all information about the field supervisor sent to the scene, specific actions taken to stabilize the situation, and all replacement bus and/or operator information, including cut-in time and position and any lost time. Return to the Incident Maintenance window as described in Step 7. Note: An Action Code must be entered in the Vehicle Incident Report to "close" and complete the report.

If rescue services were sent to the scene, the CAD Vehicle Incident Report must include the rescue vehicle number and alarm number information received from the field supervisor dispatched to the scene.

If the silent alarm was activated accidentally, this information must be included in the comments portion of the CAD Vehicle Incident Report and the Accident/Incident/Silent Alarm Memorandum Form.

$>$ TIP: If you make a mistake and need to back up one screen, press the EXIT key (F20). 
(c1) Type the division in the Division field. ** Hint: Use the PICK LIST key (F14) to display a list of existing divisions.

(c2) If no information has been entered in the Action Code field, this incident is considered Open by the CAD/AVL system and you must press the SCAN/UPDATE OPEN INCIDENTS key (F7). The Scan/Update Incidents window will appear. Note: the CAD/AVL system sorts the Scan/Update Incidents display by incident number.

If information has been entered in the Action Code field, this incident is considered Closed by the CAD/AVL system and you must press the SCAN/UPDATE ALL INCIDENTS key (F8). The Scan/Update Incidents window will appear. Note: The CAD/AVL system sorts the Scan/Update Incidents display by incident number.

(c3) Using the $\square$ or $\square$ keys, select the incident and press the UPDATE INCIDENT key (F7). The Update Incident window will appear.

(c4) Make all of the additions or changes to the incident information. If you need to update the additional comments for the incident, press the EDIT COMMENTS key (F9). The Edit Incident Comments window will appear. Enter additional comments and press the EXIT key (F20).

(c5) When finished updating the incident report, press the EXIT key (F20) to return to the Scan/Update Incidents window. Press the EXIT key (F20) again to return to the Incidents Maintenance window.

14. Continue notifying the appropriate MDT personnel, as outlined in the MDT Emergency Check/Call List included in Appendix A. Provide specific information about the incident and actions taken to stabilize the situation. If they cannot be reached by telephone, you should contact them by pager. This notification procedure applies seven days a week, 24 hours a day. You must also notify the operator superintendent and division chief 


\section{BIBLIOGRAPHY}

Chowdhury, M. S., and Chien, S. I., "Dynamic Vehicle Dispatching at the Intermodal Transfer Station," Transportation Research Record, 1753, Paper No. 013108, 2001.

DeAnnuntis, C.P., and Morris, W. P., Transit Extraboard Management: Optimum Sizing and Strategies (Florida Department of Transportation report BD549-23). University of South Florida, National Center for Transportation Research, Tampa, Fl, 2007.http://www.dot.state.fl.us/research-

center/Completed Proj/Summary PTO/FDOT BD549 23.pdf

Derby, A., and Kijowski, J., "Real-Time Benefits - How One Small Agency Made a Big Impact with ITS and Real-Time Passenger Information," Mass Transit Magazine, 2011.

Dessouky, M., Hall, R., Nowroozi, A., and Mourikas, K., "Bus Dispatching at Timed Transfer Stations Using Bus Tracking Technology," Transportation Research Part C: Emerging Technologies, Vol. 7, No. 4, 1999.

Miami-Dade Transit, Miami-Dade Transit Operations Supervisor Manual, Section 200-Window Operations Supervisor Manual, Miami, Florida, 2004.

Miami-Dade Transit, Miami-Dade Transit Agency Bus Traffic Controllers' System Operations Procedures Manual, Miami, Florida, 2000.

Parker, D. J., "AVL Systems for Bus Transit: Update, TranSystems," TCRP Synthesis 73, Transportation Research Board, 2008.

Stearns, M. D., Sussman, E. D., and Belcher, J., Denver RTD's Computer-Aided Dispatch/Automatic Vehicle Location System: The Human Factors Consequences, U.S. Department of Transportation, John A. Volpe National Transportation Systems Center, Washington, D.C., 1999.

Strathman, J. G., Kimpel, T. J., Dueker, K. J., Gerhart, R. L., Turner, K., Griffin, D., and Callas, S., "Bus Transit Operations Control: Review and an Experiment Involving Tri-Met's Automated Bus Dispatching System," Journal of Public Transportation, Vol. 4, No. 1, 2001. 